\title{
Developing a 2-Phase Screening System to Assess the in vitro and in vivo Stability of Engineered Native Seed Storage Proteins
}

by

\section{Allison F. Jaworski, B.Sc.H}

A thesis submitted to the Faculty of Graduate and Postdoctoral Affairs in partial fulfillment of the requirements for the degree of

Doctor of Philosophy

in

Biology

Department of Biology

Ottawa-Carleton Institute of Biology

Carleton University

Ottawa, Ontario

(C) 2015, Allison F. Jaworski 


\section{Abstract.}

Seed storage proteins are the nitrogen and sulfur reserves for the germinating embryo and comprise the majority of the protein content of a seed (Shewry et al, 1995; Tandang-Silvas et al, 2010). The 11S globulins are the principal seed storage proteins in members of the legume and mustard families. They are targets for protein engineering studies attempting to alter the physicochemical properties (e.g. emulsification and gelling) and nutritional value, with respect to amino acid content, of their seed protein extracts (Muntz et al, 1998; Tandang-Silvas et al, 2011). The factor that has limited the success of these studies to date is insufficient accumulation of the engineered variants in vivo due to their reduced stability, compared to the native protein. To address this issue, this thesis describes the development of a 2-phase screening system that facilitates protein engineering of native 11S globulins by assessing the ability of stable site-directed variants to accumulate in seeds. Phase I employs $E$. coli as an expression system to assess the thermodynamic stability of the engineered seed storage proteins in vitro. Methionine-enriched 11S globulins with stability parameters similar to the wild-type protein are then expressed in $A$. thaliana in phase II, the in vivo component of the screen, to assess the ability of the engineered protein to accumulate in plant seeds. To complement the novel 2-phase screening system, a comprehensive survey of 67-methionine-enriched variants of a model $A$. thaliana 11S globulin was completed, employing fluorescence-monitored guanidine hydrochloride denaturation to identify regions of the protein that are amenable to the introduction of methionine residues. This survey demonstrates that methionine can be introduced into $11 \mathrm{~S}$ globulins but single locations cannot be treated as sinks for the introduction of multiple, sequential methionine residues. The use of HotSpot Wizard in conjunction with available structural data is a successful strategy for short-listing residues as targets for substitution to methionine. 
This thesis developed tools, a 2-phase screen and an information platform identifying regions within the $11 \mathrm{~S}$ globulin structure that are accepting of methionine introduction, to facilitate subsequent protein engineering studies attempting to alter the physicochemical or nutritional properties of seed proteins. 


\section{Statement of Contributions.}

My contributions to the research described in this thesis include:

1. The development of the research questions for each data chapter in addition to the overarching objective of this thesis to create a 2-phase screening system to use in protein engineering studies focusing on improving the physicochemical and nutritivevalues of seed storage proteins in collaboration with Dr. S.M. Aitken

2. The responsibility of developing and establishing the experimental design of each data chapter

3. The collection and analysis of data for each of the three data chapters

4. The writing and preparation of the published manuscript (Chapter 2) in collaboration with Dr. S.M. Aitken.

I formally acknowledge the contributions of the co-author, Dr. S.M. Aitken, of the manuscripts that comprise the research chapters of my thesis. In a collaborative effort, my supervisor, Dr. S.M. Aitken, contributed her expertise to the development of the research questions and experimental design in addition to the preparation of manuscripts for the research chapters of my thesis, and providing insights and guidance throughout the writing of my thesis. 


\section{Acknowledgements.}

I want to express my sincere gratitude to Dr. Susan Aitken for her mentorship, encouragement, guidance and for giving me the opportunity to come into her lab and learn from her and all her talented students. These past six years have not only helped mold my scientific mind but have shaped me into the person I am today. I also want to thank her so much for always encouraging me to strive past any preconceived notions that I (and others) have had pertaining to who I am and what I am capable of in order to surpass those notions and show myself what I really can do - which has surprised me, and made me proud, to say the very least. This has helped shape me into the scientist and person I am now and I am grateful that she has helped me to stretch in her lab to reach for the stars so that I now know I can.

I would also like to thank the numerous members of the Carleton Biology Department that have given me invaluable advice, feedback and support throughout my graduate studies including my committee members Dr. Owen Rowland and Dr. John Vierula, and Dr. Ashkan Golshani, Dr. Amanda MacFarlane, Dr. Andrew Simmons, Dr. Suzanne Patterson and Dr. Alex Wong.

Finally I want to thank my family and friends for supporting me through the ups and downs of grad student life. It could not have been easy - the meanest rollercoaster in the biggest amusement park couldn't compare - but you all helped keep me grounded and encouraged me to strive to be the very best I could be. Thank you so much for always being there. 


\title{
Dedication.
}

\section{To my family}

\author{
Mom, Dad, Paul, Nicole, Val, Gregg and Georgia
}

\section{To my friends}

Alex, Mohsen, Duale, Eddy, Bill, Bahram, Matt, Aimee, Dan, Kristina, Dominique, Katie, Magda, Maryam, Mary and Darlene

\footnotetext{
for always believing I'm superwoman and can do anything I put my mind to.
} 


\section{Table of Contents.}

Abstract. . . . . . . . . . . . . . . . ii

Statement of Contributions. . . . . . . . . . . . . . . . . . . iv

Acknowledgements. . . . . . . . . . . . . . . . . . . . . . . . . v

Dedication.. . . . . . . . . . . . . . . . . . . . vi

Abbreviations. . . . . . . . . . . . . . . . . . . . xiii

List of Tables . . . . . . . . . . . . . . . . . . . . . . . . . . . $\mathrm{x}$

List of Figures. . . . . . . . . . . . . . . . . . . . . . . . . . . xi

Chapter 1: Introduction. . . . . . . . . . . . . . . . . . . . 1

1.1. Methionine in Grain Legumes. . . . . . . . . . . . . . . . . . 1

1.2. Current Approaches for Addressing Amino Acid Deficiencies in Crops. . . . . . . . . . . . . . . . . . . . . . . . . . . . . . 3

1.3. Seed Proteins.. . . . . . . . . . . . . . . . . . . . . . . . . 8

1.3.1. Seed Storage Proteins . . . . . . . . . . . . . . . . . . 10

1.3.1.1. 2 S Albumins. . . . . . . . . . . . . . . . . . . 12

1.3.1.2. Prolamines and Glutelins. . . . . . . . . . . . . . 14

1.3.1.3. Globulins.. . . . . . . . . . . . . . . . . . . . 14

1.3.1.3.1. 7 S Globulins.. . . . . . . . . . . . . . . 18

1.3.1.3.2. 11S Globulins. . . . . . . . . . . . . . . 18

1.4. Developing a Strategy to Sequester more Methionine in the Seed. . 20

1.4.1. Developing a 2-Phase Screening System to Facilitate Future

Protein Engineering Studies on Native Seed Storage Proteins. . . . 21

Chapter 2: Expression and Characterization of the Arabidopsis thaliana 11S globulin family. . . . . . . . . . . . . . . . 23

2.1. Abstract. . . . . . . . . . . . . . . . . . . . . . . . . . . . . 23

2.2. Introduction. . . . . . . . . . . . . . . . . . . . . . . . 23 
2.3. Materials and Methods. . . . . . . . . . . . . . . . . . . . . 27

2.3.1. Reagents. . . . . . . . . . . . . . . . . . . . . . 27

2.3.2. Amplification of A. thaliana Procruciferin Coding Sequences. . 27

2.3.3. Optimization of Expression and Purification Conditions for the Affinity-Tagged Procruciferins. . . . . . . . . . . . . . . . 27

2.3.4. Urea Denaturation of His-proAtCRU Proteins. . . . . . . 29

2.3.5. Differential Scanning Fluorimetry (DSF) of His-proAtCRU Proteins. . . . . . . . . . . . . . . . . . . . . . . . . 30

2.4. Results and Discussion. . . . . . . . . . . . . . . . . . . . 30

2.4.1. Optimization of Expression and Purification Conditions. . . 30

2.4.2. Fluorescence Properties and Relative Stability of the A. thaliana

Procruciferins. . . . . . . . . . . . . . . . . . . . . . . . 37

2.5. Concluding Remarks. . . . . . . . . . . . . . . . . . . . 42

Chapter 3. Developing an in vivo Expression System to Assess Accumulation of Engineered 11S Globulins. . . . . . . . . . . 43

3.1. Abstract. . . . . . . . . . . . . . . . . . . . . . . . . . 43

3.2. Introduction. . . . . . . . . . . . . . . . . . . . . . . . 44

3.3. Methods and Materials . . . . . . . . . . . . . . . . . . 46

3.3.1. Reagents. . . . . . . . . . . . . . . . . . . . . . . 46

3.3.2. Constructing the Plant Vectors. . . . . . . . . . . . . . . 47

3.3.2.1. Promoter-Reporter Constructs. . . . . . . . . . . . 47

3.3.2.2. Cruciferin-HA tag Constructs. . . . . . . . . . . . 47

3.3.3. Transformation of Agrobacterium. . . . . . . . . . 50

3.3.4. Floral dip Transformation of A. thaliana. . . . . . . 50

3.3.5. Selecting Transgenic A. thaliana. . . . . . . . . . . . . 51

3.3.6. GUS Staining of Transgenic A. thaliana Siliques and Seeds.. 52 
3.3.7. Purification of His-proAtCRU3-HA tag from Escherichia coli. . 52

3.3.8. Seed Protein Extraction from A. thaliana. . . . . . . . 53

3.3.9. Immunoblot. . . . . . . . . . . . . . . . 54

3.4. Results and Discussion. . . . . . . . . . . . . . . . . . . . . 54

\section{Chapter 4: Surveying Structural Components of 11S Globulins for} Locations Amenable to the Introduction of Methionine Residues . 61

4.1 Abstract. . . . . . . . . . . . . . . . . . . . . . . . . . . 61

4.2 Introduction. . . . . . . . . . . . . . . . . . . . . . . . 62

4.3 Methods and Materials. . . . . . . . . . . . . . . . . . . . . 67

4.3.1. Reagents. . . . . . . . . . . . . . . . . . . . . . . . 67

4.3.2. Designing and Constructing Methionine-Enriched proAtCRU3 Variants.. . . . . . . . . . . . . . . . . . . . . 67

4.3.3. Expression and Purification of the Methionine-Enriched

His-proAtCRU3 Variants. . . . . . . . . . . . . . . . . . . 68

4.3.4. Guanidine Hydrochloride (GdnHCl) Denaturation

of His-proAtCRU3 Methionine-Enriched Variants. . . . . . . . 69

4.4 Results.. . . . . . . . . . . . . . . . . . . . . . . . . 70

4.4.1. Variants Within the Cupin Domains. . . . . . . . . . . . 83

4.4.2. Variants Within the Hypervariable Regions.. . . . . . . . 89

4.5 Discussion. . . . . . . . . . . . . . . . . . . . . . . . . 96

4.6. Concluding Remarks.. . . . . . . . . . . . . . . . . . . . 102

5. General Conclusions. . . . . . . . . . . . . . . . . . . . . . 104

5.1. Future Directions. . . . . . . . . . . . . . . . . . . . . . 109

Appendix A: List of Publications. . . . . . . . . . . . . . . . . . . 111

References.. . . . . . . . . . . . . . . . . . . . 113 


\section{List of Tables}

Table 3.1: Primers used to construct the promoter-reporter, and cruciferin-HA tag constructs . . . . . . . . . . . . . . . . . . . . . . . . . . 49

Table 4.1: Chemical denaturation parameters for wild-type and site-directed variants of proAtCRU3. . . . . . . . . . . . . . . . . . . . . . . . 75 


\section{List of Figures}

Figure 1.1: The methionine biosynthetic pathway in higher plants . . . . . 2

Figure 1.2: Combining genetic engineering strategies to create a synergistic biotechnological approach to increase the methionine content in plants . . . 7

Figure 1.3: Classification of plant seed proteins $\quad . \quad$. . . . . . . . . . . . . 9

Figure 1.4: The structure of a Berthollectica excelsa 2S albumin (PDB: 2LVF) and schematic depicting the four conserved disulfide bonds typical of $2 \mathrm{~S}$ albumins. . . . . . . . . . . . . . . . . . . . . . . . . . . . . 13

Figure 1.5: Structures of Phaseolus vulgaris 7S globulin (PDB: 2PHL) and Brassica napus 11S proglobulin (PDB: 3KGL). . . . . . . . . . . . . . 16

Figure 2.1: The structure of a Brassica napus procruciferin (PDB: $3 \mathrm{KGL}$ ). . 25

Figure 2.2: SDS-PAGE of batch purifications of His-proAtCRU2 and

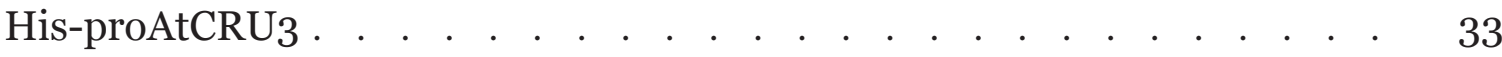

Figure 2.3: SDS-PAGE of $3 \mu \mathrm{g}$ of purified His-proAtCRU1, His-proAtCRU2 and His-proAtCRU3. . . . . . . . . . . . . . . . . . . . . . . . . 36

Figure 2.4: Fluorescence spectra $\left(\lambda_{e x}=295 \mathrm{~nm}\right.$; at $0,1,2,3,4,5$ and $6 \mathrm{M}$ urea) and the effect of urea concentration on the $\lambda_{\max }$ of the tryptophan fluorescence emission maxima of $1 \mu \mathrm{M}$ His-proAtCRU1, His-proAtCRU2 and His-proAtCRU3.. . . . . . . . . . . . . . . . . . . . . . . . . 38

Figure 2.5: Differential scanning fluorimetry $\left(\lambda_{\mathrm{ex}}=470 \mathrm{~nm}\right.$, and $\left.\lambda_{\mathrm{em}}=610 \mathrm{~nm}\right)$ thermal denaturation profiles of His-proAtCRU1, His-proAtCRU2 and His-proAtCRU3.. . . . . . . . . . . . . . . . . . . . . . . . . . 41

Figure 3.1: Whole mounts of Phaseolin::GUS and AtCRU3::GUS transgenic A. thaliana (Col) siliques and seeds stained for GUS activity . . . . . . . . 56

Figure 3.2: Analysis of HA-tagged, AtCRU proteins expressed under the $A t C R U_{3}$ or Phaseolin promoter in the seeds in transgenic $A$. thaliana lines. $\quad 58$

Figure 4.1: The structure of a Brassica napus procruciferin (PDB: 3KGL). 64

Figure 4.2: Schematic representations of the chemical denaturation of protein variants that alter the $C_{m}$ and/or the cooperativity (slope) of the transition from the native to the unfolded state of the wild-type protein. . . . . . . . . . 72 
Figure 4.3: The effect of $\mathrm{GnHCl}$ concentration on the tryptophan fluorescence emission maxima $\left(\lambda_{\max }\right)$ of wild-type proAtCRU 3 and methionine substitution variants located in the cupin domains . . . . . . . . . . . . . . .

Figure 4.4: The effect of $\mathrm{GnHCl}$ concentration on the tryptophan fluorescence emission maxima $\left(\lambda_{\max }\right)$ of wild-type proAtCRU 3 and methionine substitution variants located within the $\beta$-strands of the $\beta$-barrels that comprise the cupin domains . . . . . . . . . . . . . . . . . . . . . . . . . . . . 87

Figure 4.5: The effect of $\mathrm{GnHCl}$ concentration on the tryptophan fluorescence emission maxima $\left(\lambda_{\max }\right)$ of wild-type proAtCRU3 and a sequential series of methionine substitution variants (Q101M, G102M, Q101M:G102M and Q101M:G102M:Q103M:Q104M) located in HVR II . . . . . . . . . . . 91

Figure 4.6: The effect of $\mathrm{GnHCl}$ concentration on the tryptophan fluorescence emission maxima $\left(\lambda_{\max }\right)$ of wild-type proAtCRU 3 and double, quadruple and hextuple methionine insertion variants located in HVR III. . . . . . . .

Figure 4.7: The effect of $\mathrm{GnHCl}$ concentration on the tryptophan fluorescence emission maxima $\left(\lambda_{\max }\right)$ of wild-type proAtCRU3 and the two quadruple methionine substitution variants constructed in HVR II . . . . . . . . . 95 


\section{Abbreviations.}

AtCRU1

AtCRU2

AtCRU3

AtCRU3::AtCRU1-

HA tag

AtCRU3::AtCRU2-

HA tag

AtCRU3::AtCRU3-

HA tag

AtCRU3::GUS

Brassicaceae

Buffer A

Buffer B

Buffer C

Buffer D

Buffer E
Arabidopsis thaliana 11S globulin 1

Arabidopsis thaliana 11S globulin 2

Arabidopsis thaliana 11S globulin 3

$A t C R U_{1}$ with a C-terminal HA tag under the AtCRU3 promoter

AtCRU2 with a C-terminal HA tag under the AtCRU3 promoter

$A t C R U_{3}$ with a C-terminal HA tag under the $A t C R U_{3}$ promoter

GUS reporter gene under the AtCRUS promoter

Mustard plant family

$50 \mathrm{mM}$ potassium phosphate, $\mathrm{pH} 8,10 \mathrm{mM}$ imidazole

$50 \mathrm{mM}$ potassium phosphate, $\mathrm{pH} 8,400 \mathrm{mM} \mathrm{NaCl}$, $10 \mathrm{mM}$ imidazole

$50 \mathrm{mM}$ potassium phosphate, $\mathrm{pH} 8,400 \mathrm{mM} \mathrm{NaCl}$, $50 \mathrm{mM}$ imidazole

$50 \mathrm{mM}$ potassium phosphate, $\mathrm{pH} 8,400 \mathrm{mM} \mathrm{NaCl}, 1$ mM EDTA, 20\% glycerol, 150 mM imidazole

$50 \mathrm{mM}$ potassium phosphate, $\mathrm{pH} 8,400 \mathrm{mM} \mathrm{NaCl}, 1$ mM EDTA, 20\% glycerol 


\begin{tabular}{ll} 
CaMV-35S & Cauliflower Mosaic Virus 35S promoter \\
\hline Cicer arietinum & Chickpea \\
\hline$C_{\mathrm{m}}$ & The chemical denaturation midpoint \\
Cruciferins & $\begin{array}{l}\text { Generic name for 11S globulins in members of the } \\
\text { Brassicaceae family }\end{array}$ \\
\hline CGS & Cystathionine $\gamma$-synthase \\
\hline DSF & Differential scanning fluorimetry \\
\hline DTT & Dithiothreitol
\end{tabular}

EDTA Ethylenediaminetetraacetic acid

ER Endoplasmic reticulum

Fabaceae Legume family

Glycine max Soybean

GnHCl Guanidine hydrochloride

GUS $\quad \beta$-glucuronidase

HA Human influenza hemagglutinin

His-proAtCRU1

$\mathrm{N}$-terminal $\mathrm{His}_{6}$-tagged Arabidopsis thaliana $11 \mathrm{~S}$ proglobulin 1

His-proAtCRU2

$\mathrm{N}$-terminal $\mathrm{His}_{6}$-tagged Arabidopsis thaliana $11 \mathrm{~S}$ proglobulin 2 
His-proAtCRU3

His-proAtCRU3-

HAtag

HRP

HVR

IA

IE

IPTG

$\lambda_{\text {em }}$

$\lambda_{\mathrm{ex}}$

$\lambda_{\max }$

Lens culinaris

LB

Legumins

L-Met

mto

Nicotiana tabacum Tobacco

Ni-NTA

Lentil
$\mathrm{N}$-terminal His ${ }_{6}$-tagged Arabidopsis thaliana $11 \mathrm{~S}$ proglobulin 3

$\mathrm{N}$-terminal $\mathrm{His}_{6}$-tagged Arabidopsis thaliana $11 \mathrm{~S}$

proglobulin 3 with a C-terminal HA tag

Horseradish peroxidase

Hypervariable regions

Intradisulfide bond in $11 \mathrm{~S}$ globulins

Interdisulfide bond in $11 \mathrm{~S}$ globulins

Isopropyl- $\beta$-D-thiogalactopyranoside

Emission wavelength

Excitation wavelength

Tryptophan fluorescence emission maxima

Lysogeny broth

Generic name for $11 \mathrm{~S}$ globulins in members of the

Fabaceae family

Methionine

Methionine overacumulating mutants

Ni-nitrilotriacetic acid resin 
OPHS

PCR

PEM

Phaseolin

Phaseolin::AtCRU1

HA tag

Phaseolin::AtCRU2-

HA tag

Phaseolin::AtCRU3- AtCRU3 with a C-terminal HA tag under the $P$.

HA tag

Phaseolin::GUS

vulgaris 7 S globulin promoter

GUS reporter gene under the $P$. vulgaris $7 \mathrm{~S}$ globulin promoter

Pisum sativum

preproglobulin

proAtCRU1

proAtCRU2

proAtCRU3

proglobulin

proBcCRU

O-phospho-L-homoserine

Polymerase chain reaction

Protein-Energy Malnutrition

${ }_{7}$ S globulin in Phaseolus vulgaris

vulgaris $7 \mathrm{~S}$ globulin promoter

AtCRU2 with a C-terminal HA tag under the $P$. vulgaris $7 \mathrm{~S}$ globulin promoter

promoter

Pea

Initial translation product of $11 \mathrm{~S}$ globulins

(unprocessed form)

Arabidopsis thaliana 11S proglobulin 1

Arabidopsis thaliana 11S proglobulin 2

Arabidopsis thaliana 11S proglobulin 3

11S globulin with the signal peptide removed but not

proteolytical cleaved into its $\alpha$ and $\beta$ chains

Brassica napus 11S proglobulin (PDB: $3 \mathrm{KGL})$ 
PSV

rER

SAM

SAMS

SB

SDS-PAGE

$\boldsymbol{T}_{\mathrm{m}}$

Trp

TS

VPE

Vicilins
Protein storage vacuole

Rough endoplasmic reticulum

$S$-adenosylmethionine

$S$-adenosylmethionine synthetase

Super broth medium

Sodium dodecyl sulphate-polyacrylamide gel

electrophoresis

Thermal denaturation midpoint

L-Tryptophan

Threonine synthase

Vacuolar processing enzyme, the asparaginyl

endopeptidase that cleaves the $11 \mathrm{~S}$ proglobulin

monomers into their $\alpha$ and $\beta$ chains

$7 \mathrm{~S}$ globulins 


\section{Introduction.}

\subsection{Methionine in Grain Legumes.}

Grain legumes, such as chickpea (Cicer arietinum) and lentil (Lens culinaris), are members of the Fabaceae family and provide approximately $10 \%$ of the world's supply of dietary protein and produce approximately $\$ 2$ billion (CDN) in export revenue for Canada, annually (Saskatchewan Pulse Growers, 2009; Pulse Canada, 2010). However, the edible portion of grain legumes, namely their mature dried seeds, is deficient in the two sulfur-containing amino acids methionine and cysteine, from the perspective of human nutrition (Mandal and Mandal, 2000; Galili and Hofgen, 2002). Essential amino acids such as methionine are not synthesized de novo by humans and non-ruminant animals and therefore must be obtained through their diet. Cysteine is considered a semi-essential amino acid since it is synthesized from methionine via the reverse transsulfuration pathway in mammals.

Plants and bacteria, unlike mammals, synthesize methionine de novo. The amino acid backbone, the sulfur atom and the $\varepsilon$-methyl group of methionine are derived from aspartate, via O-phospho-L-homoserine (OPHS), the thiol group of cysteine, via the trans-sulfuration pathway, and the $\beta$-carbon of serine, via methionine synthase, respectively (Figure 1.1) (Ravanel et al, 1998; Shen et al, 2002). Approximately $20 \%$ of cellular methionine is used for protein biosynthesis and to provide soluble methionine reservoirs, while the remaining $80 \%$ is converted to $S$-adenosylmethionine (SAM) by $S$-adenosylmethionine synthetase (SAMS) (Ravanel et al, 1998; Hesse et al, 2004). 


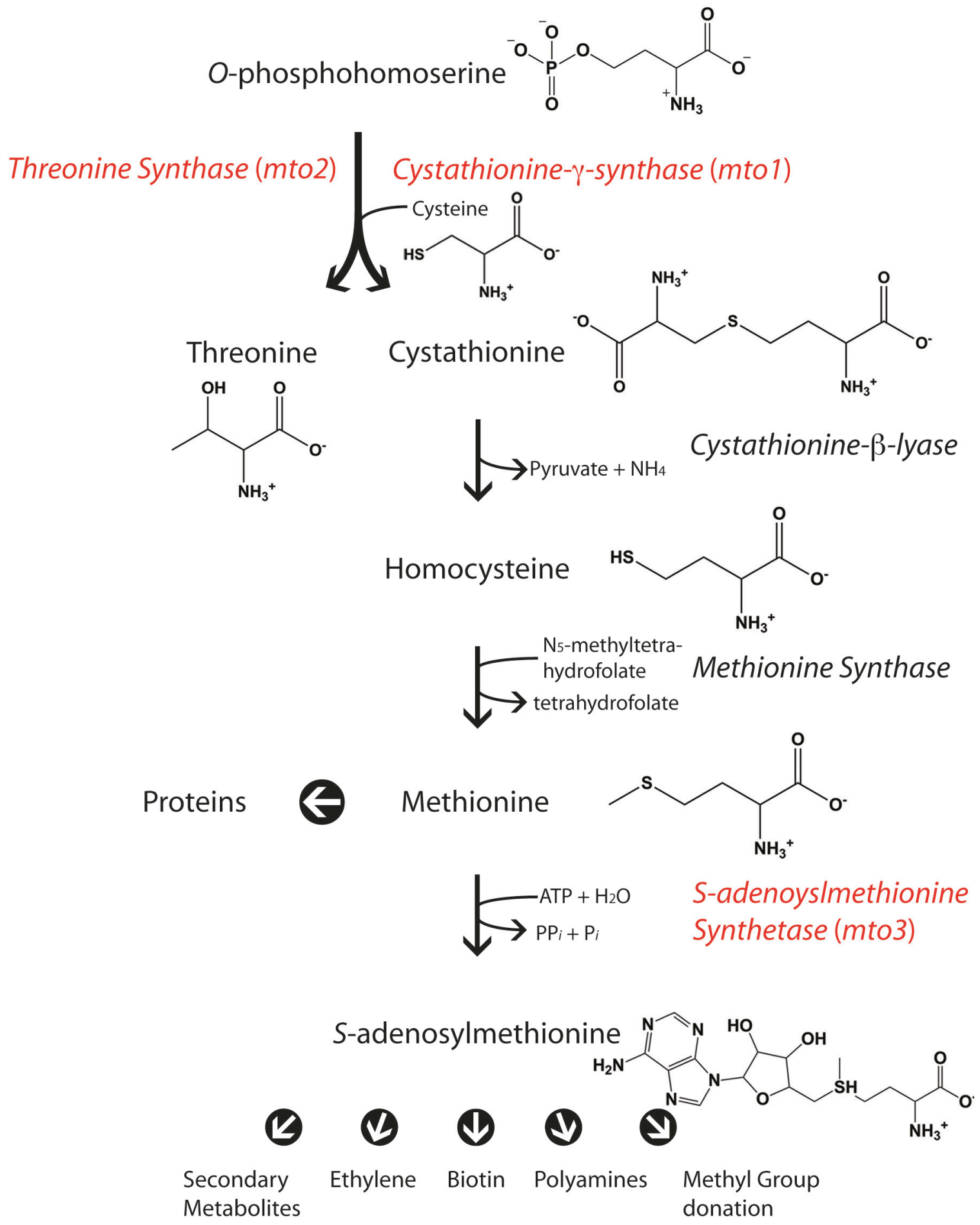

Figure 1.1: The methionine biosynthetic pathway in higher plants. Adapted from: Azevedo et al, 1997; Ravanel et al, 1998; Amir et al, 2002. 
Nutritional deficiency of any of the ten essential proteogenic amino acids, including methionine, in humans may lead to Protein-Energy Malnutrition (PEM), a syndrome with symptoms that include lowered resistance to disease, lowered blood protein levels, and potentially irreversible retardation of both mental and physical development in young children, particularly those under the age of four (Muntz et al, 1998; Amir and Hacham, 2008). An estimated 30\% of the developing world population suffers for PEM and this syndrome is associated with approximately 6 million deaths of children each year (Institute of Medicine, 2005; Galili and Amir, 2013).

\subsection{Current Approaches for Addressing Amino Acid Deficiencies in Crops.}

Attempts to create crops with increased nutritional value, with respect to amino acid content, can be classified as either 'push' or 'pull' strategies, which focus on increasing the production of the deficient amino acid in the source tissue, primarily the leaf, or sequestering more of the deficient amino acid in the sink tissue, namely the seed, respectively.

Push approaches focus on altering the flux of metabolites within the biosynthetic pathway of the deficient amino acid or that of a competing metabolite, thereby yielding an increase in soluble amino acids (Muntz et al, 1998; Hesse et al, 2004). Examples of push strategies include over-expression of branch-point enzymes and expression of feedback-insensitive isoforms of enzymes within the target biosynthetic pathway, and expression of anti-sense constructs of enzymes in competing biosynthetic pathways (Muntz et al, 1998; Mandal and Mandal, 2000; Hesse et al, 2004). For instance, investigations of Arabidopsis thaliana methionine overacumulating (mto) mutants have identified cystathionine $\gamma$-synthase (CGS: mto1) and threonine synthase (TS: mto2), the enzymes that occupy the OPHS 
branch-point (Figure 1.1), and $S$-adenosylmethionine synthase (SAMS: mto3), which produces the regulator of the OPHS branch-point, SAM, as targets for push strategies aiming to increase the pool of soluble methionine (Kusano et al, 2010). Methionine overaccumulation, 10 to 200-fold increase, was reported in young rosette tissue in all the A. thaliana mto mutants (Inaba et al, 1994; Bartlem et al, 2000; Goto et al, 2002; Shen et al, 2002). Although various push approaches have increased the level of soluble methionine, they have generally resulted in plants with detrimental or lethal phenotypes because they have 'pushed' too hard resulting in too large a shift in metabolic flux, disturbing physiological processes (Beauregard and Hefford, 2006). This is exemplified by the mto2 mutant in A. thaliana, which is caused by a point mutation in the coding sequence of TS. Although this mutation resulted in a 20-fold increase in soluble methionine it also yielded dwarfed plants that experienced delayed germination and growth (Bartlem et al, 2000).

Alternative to push strategies are pull strategies, which focus on the amino acid profile of the seed, attempting to increase the demand for specific amino acid(s) therein, resulting in an increase in their content within the seed (Muntz et al, 1998; Hesse et al, 2004). Seed storage proteins are generally the targets for pull strategies since they accumulate to significant levels, accounting for $50-90 \%$ of the protein within a seed (Shewry et al, 1995; Tandang-Silvas et al, 2010). The two main variations on the pull engineering strategy that have been investigated are the introduction of foreign seed storage proteins that are rich in the deficient amino acid, and engineering native seed storage proteins to increase their requirements for the deficient amino acid (Muntz et al, 1998; Mandal and Mandal, 2000; Hesse et al, 2004).

Methionine-rich, 2S seed albumins from Bertholletica excels (Brazil nut) and Helianthus annuus (sunflower) have been introduced into Lupinus angustifolius (lupin), Vicia narbonensis (narbon bean), chickpea and Phaseolus vulgaris 
(bean) in attempts to increase the methionine content within these legume seeds (Saalbach et al, 1995; Molvig et al, 1997; Aragao et al, 1999; Chiaiese et al, 2004). A challenge of this particular pull strategy is the potential adverse reaction of the general population for such a product, as consumers may not be accepting of a food product that contains proteins from other species. This concern is not without scientific merit as the introduction of foreign proteins into crops has resulted in two serious health issues: cross-allergenicity and the creation of new allergens (Muntz et al, 1998). Cross-allergenicity occurs when the non-native protein expressed in the new cultivar causes an allergic response in individuals who were initially allergic to the protein in its native host. For example, while the introduction of a methionine-rich Brazil nut $2 \mathrm{~S}$ albumin into Glycine max (soybean) increased the methionine content of the resulting transgenic soybean, it also produced allergic reactions in individuals allergic to the nut (Nordlee et al, 1996).

Novel methionine residues have been inserted into the methionine-deficient P. vulgaris and G. $\max 7 \mathrm{~S}$ and $11 \mathrm{~S}$ globulins with the goal of creating methionine sinks in the seed but this has led to improperly folded proteins, which degrade once inside the protein storage vacuole and thus not to accumulate in the seed (Hoffman et al, 1988; Utsumi et al, 1993; Muntz, 1998; Utsumi et al, 2002). For example, a 45-nucleotide sequence, derived from a methionine-rich prolamine seed storage protein from Zea mays (corn) was inserted into a native seed storage protein in $P$. vulgaris (Hoffman et al, 1988; Tabe and Higgins, 1998). The engineered protein did not accumulate in the seed, suggesting it was destabilized, and illustrates that the insertion of segments of amino acids into the highly ordered structures of seed storage proteins must take into consideration the necessity of the protein to fold properly in order to accumulate and interact appropriately with other storage molecules. Therefore, more refined engineering strategies are required to increase the methionine content of native seed storage proteins to a nutritionally significant 
level. This includes selecting specific residues for substitution to methionine and/ or targeting regions as insertion points for methionine residues, and determining the effect these mutations have on protein stability. Developing such a strategy to introduce methionine residues into native seed storage proteins, while maintaining wild-type stability of the protein, is the primary objective of this thesis.

The push and pull genetic engineering strategies are complementary to one another. The pull strategy requires an enlarged pool of soluble methionine, since it tends to diminish the soluble methionine pool, diverting methionine from endogenous proteins leading to a reduction in their expression, which has a dampening effect that ultimately limits the change in the overall methionine content in the seed (Galili and Hofgen, 2002; Hesse et al, 2004). An increase in flux through the methionine biosynthetic pathway, created by a push strategy, could alleviate this issue. Similarly, push strategies require sinks for the excess soluble methionine synthesized in order to prevent the disturbances in physiological processes that having an excess of methionine and its downstream metabolites tend to create, which could be provided by the expression of methionine-enriched native seed storage protein(s). Identifying the synergistic relationship of the two strategies, Hesse (2004) suggested the use of a hybrid 'push-pull' approach (Figure 1.2). The application of this hybrid strategy, however, requires 1) a thorough understanding of the methionine biosynthetic pathway and metabolic flux through it in the target species to prevent pushing too hard on the biosynthetic pathway, and 2) the development of a reliable method for engineering seed storage proteins to increase their methionine content while maintaining wild-type stability, permitting its accumulation in vivo. 
PUSH

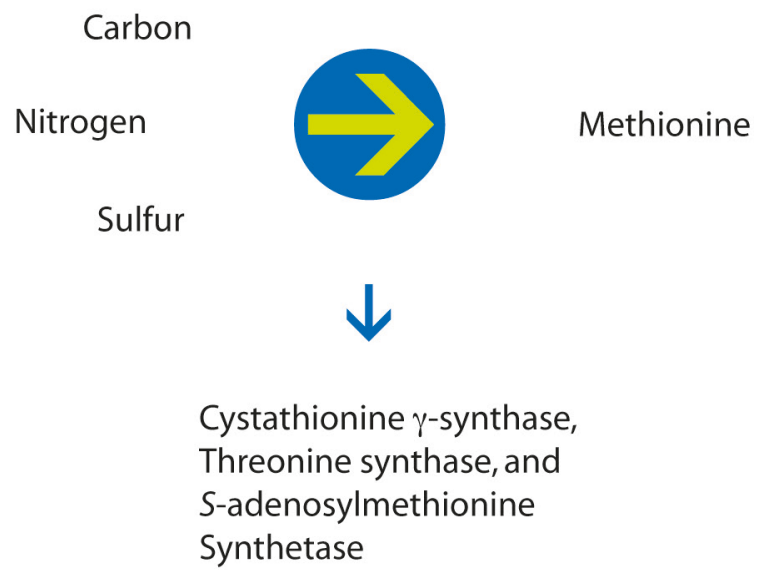

PULL

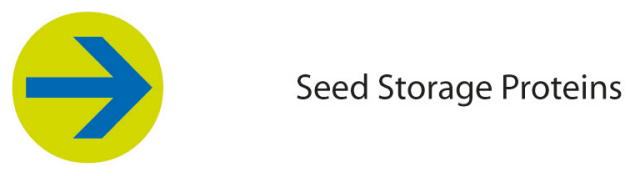

Genetically engineered native seed storage proteins

Figure 1.2: Combining genetic engineering strategies to create a synergistic biotechnological approach to increase the methionine content in plants (Hesse et $a l, 2004)$. 


\subsection{Seed Proteins.}

Protein can account for up to $45 \%$ of the dry weight of a seed (Kadlec et al, 2001). There are three distinct categories of seed proteins, distinguished based on their roles in the seed: structural and metabolic seed proteins, protective seed proteins and seed storage proteins (Figure 1.3) (Mandal and Mandal, 2000; Shewry et al, 2003). The members of the structural and metabolic, and protective seed protein categories are not appropriate targets for enhancing the methionine content of the seed since most do not accumulate sufficiently in the seed to impact it's nutritional properties. In addition, introducing methionine residues into any of these proteins may impair their intended function (e.g. enzymatic or structural), thereby diminishing the viability of the seed. In contrast, seed storage proteins can account for up to $90 \%$ of the protein in a seed and as such the amino acid(s) deficiencies of specific crops coincide with the amino acid profiles of their major seed storage proteins (Shewry et al, 1995; Tandang-Silvas et al, 2010). Therefore, seed storage proteins determine the nutritional quality of the seed, with respect to protein content and quality. As a result, seed storage proteins are regarded as key targets for improving the nutritional value, with respect to amino acid content, of crops (Muntz et al, 1998; Mandal and Mandal, 2000). 


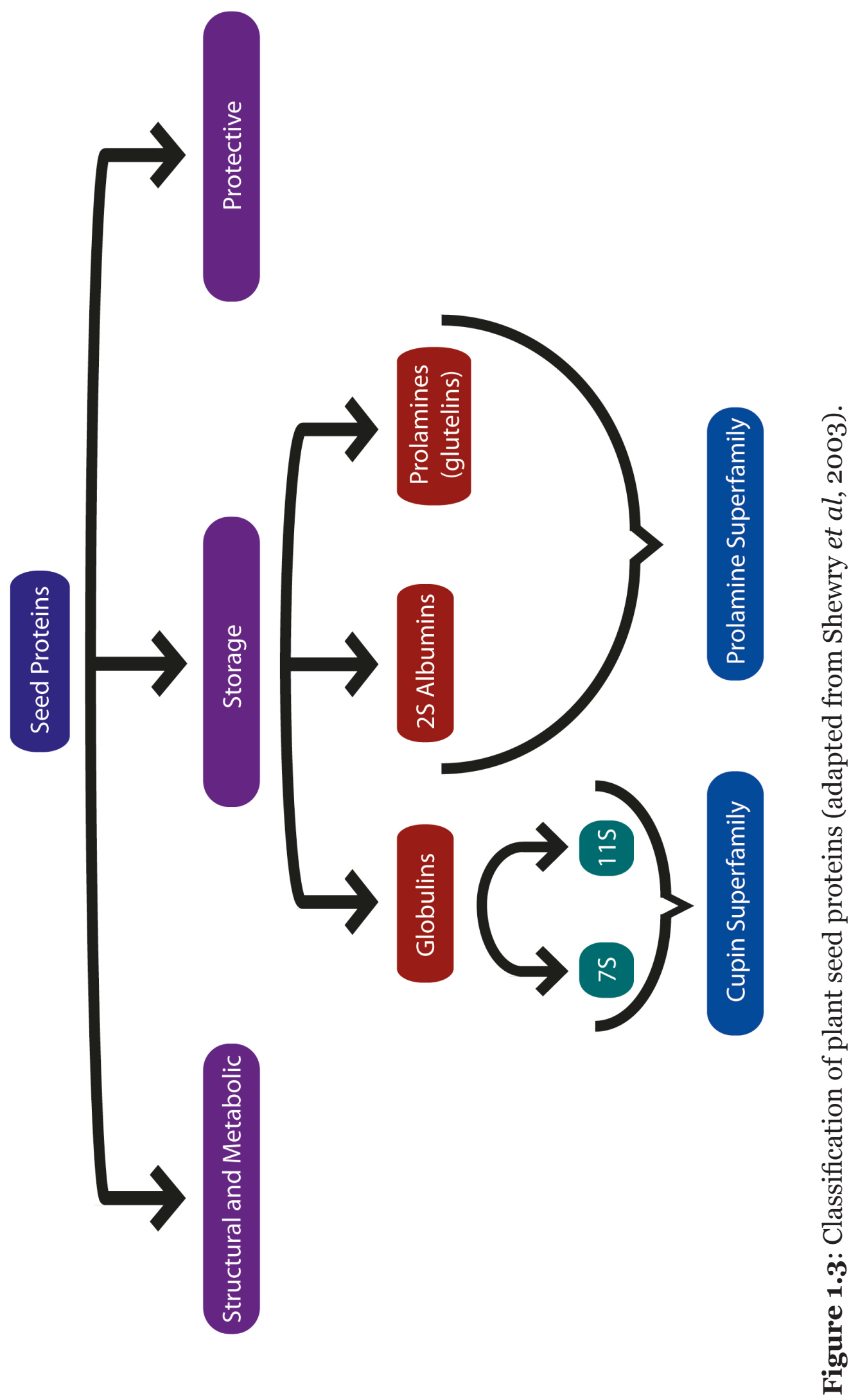




\subsubsection{Seed Storage Proteins.}

Seed storage proteins have evolved to act as long-term amino acid reserves in seeds and are the source of nitrogen and sulfur for the germinating embryo (Muntz, 1998; Herman and Larkins, 1999; Mandal and Mandal, 2000). The amount and type of seed storage protein synthesized in a seed is not only dependent on nutrient availability, but also on the heritage of the seed (Shewry et al, 1995). Seed storage proteins are non-enzymatic, secretory proteins that are deposited in the storage cells during seed maturation, once cell division is complete and further growth of the seed is solely due to cell expansion and accumulation of storage macromolecules in the storage cells, and are degraded during germination (Shewry et al, 1995; Herman and Larkins, 1999; Mandal and Mandal, 2000). The endosperm and cotyledons contain the storage cells for monocots and dicots, respectively. Seed storage proteins are encoded by multigene families and are subject to post-translational modifications, including glycosylation and proteolytic cleavage (Shewry et al, 1995; Mandal and Mandal, 2000). These proteins are deposited in one of two organelles, protein bodies or protein storage vacuoles, in the storage cells of the mature seed, depending on the nature of the protein and the plant species (Shewry et al, 1995; Muntz, 1998; Herman and Larkins, 1999; Mandal and Mandal, 2000). Protein bodies are membrane-bound vesicles that bud off the endoplasmic reticulum (ER) where storage proteins have aggregated. Protein storage vacuoles are differentiated vacuoles that originate from the postGolgi, central vacuoles and hold storage proteins secreted from the ER (Muntz, 1998; Herman and Larkins, 1999).

Seed storage proteins are translated by the ribosomes on the rough ER (rER) and undergo processing therein, such as the removal of the N-terminal signal sequence, glycosylation, disulfide bond formation, and folding aided by molecular chaperones and enzymes. The result is a fully functional storage protein or a stable 
precursor that is further processed by enzymes and/or chaperones in other cellular locations, generally the protein storage vacuole (Shewry et al, 1995; Muntz, 1998; Herman and Larkins, 1999).

A protein may generally be considered a seed storage protein if it comprises $5 \%$ or more of the total protein content of the seed, contains high levels of nitrogen-rich amino acids, and lacks any function other than storage of amino acids for growth of the new seedling (Derbyshire et al, 1976; Herman and Larkins, 1999; Marcone, 1999; Mandal and Mandal, 2000). Seed storage proteins can be classified based on their solubility or evolutionary relationships (Shewry et al, 2003). Historically, seed storage proteins have been classified based on their solubility and in $1924 \mathrm{~T}$. B. Osborne first grouped them into four categories based on the solution with which they were extracted (Figure 1.3). Proteins soluble in water were called albumins, those in saline solution globulins, those in aqueous alcohol solutions prolamines and those in weakly acidic or basic solutions glutelins (Shewry et al, 1995; Mandal and Mandal, 2000). Osborne's classification system still holds true with the notable exception that glutelins have been reclassified as prolamines after structural comparisons, analysis of amino acid composition and more recent solubility tests on reduced glutelins were preformed (Shewry and Tatham, 1990). The increased availability of sequence and structural information has enabled the reclassification of seed storage proteins into the distinct prolamine and cupin protein superfamilies (Figure 1.3) (Shewry et al, 2003; Breitender and Radauer, 2004). These superfamilies contain proteins other than seed storage proteins and are defined on the basis of structural and evolutionary relationships (Shewry et al, 2002). 


\subsubsection{2S Albumins.}

The $2 \mathrm{~S}$ albumins are compact, $14-17 \mathrm{kDa}$, globular proteins that are rich in cysteine, methionine, glutamine and arginine residues, and are widely distributed among both monocot and dicot plant species (Hara-Nishimura et al, 1993; Shewry et al, 1995; Monsalve et al, 2003; Moreno et al, 2004; Moreno and Clemente, 2008). As such, the $2 \mathrm{~S}$ albumins are popular foreign seed storage proteins to introduce into methionine-deficient crops to increase their methionine content, although the allergenic properties of $2 \mathrm{~S}$ albumins diminish their effectiveness (Saalbach et al, 1995; Nordlee et al, 1996; Molvig et al, 1997; Aragao et al, 1999; Chiaiese et al, 2004). The $2 \mathrm{~S}$ albumins are encoded by multigene families and are classified based on structural rather than sequence homology. Their structural homology is based on the arrangement of the eight conserved cysteine residues, referred to as the cysteine skeleton, and the four disulfide bonds, two inter- and two intra-chain, that they form (Figure 1.4) (Muntz, 1998; Moreno et al, 2004; Moreno and Clemente, 2008). 


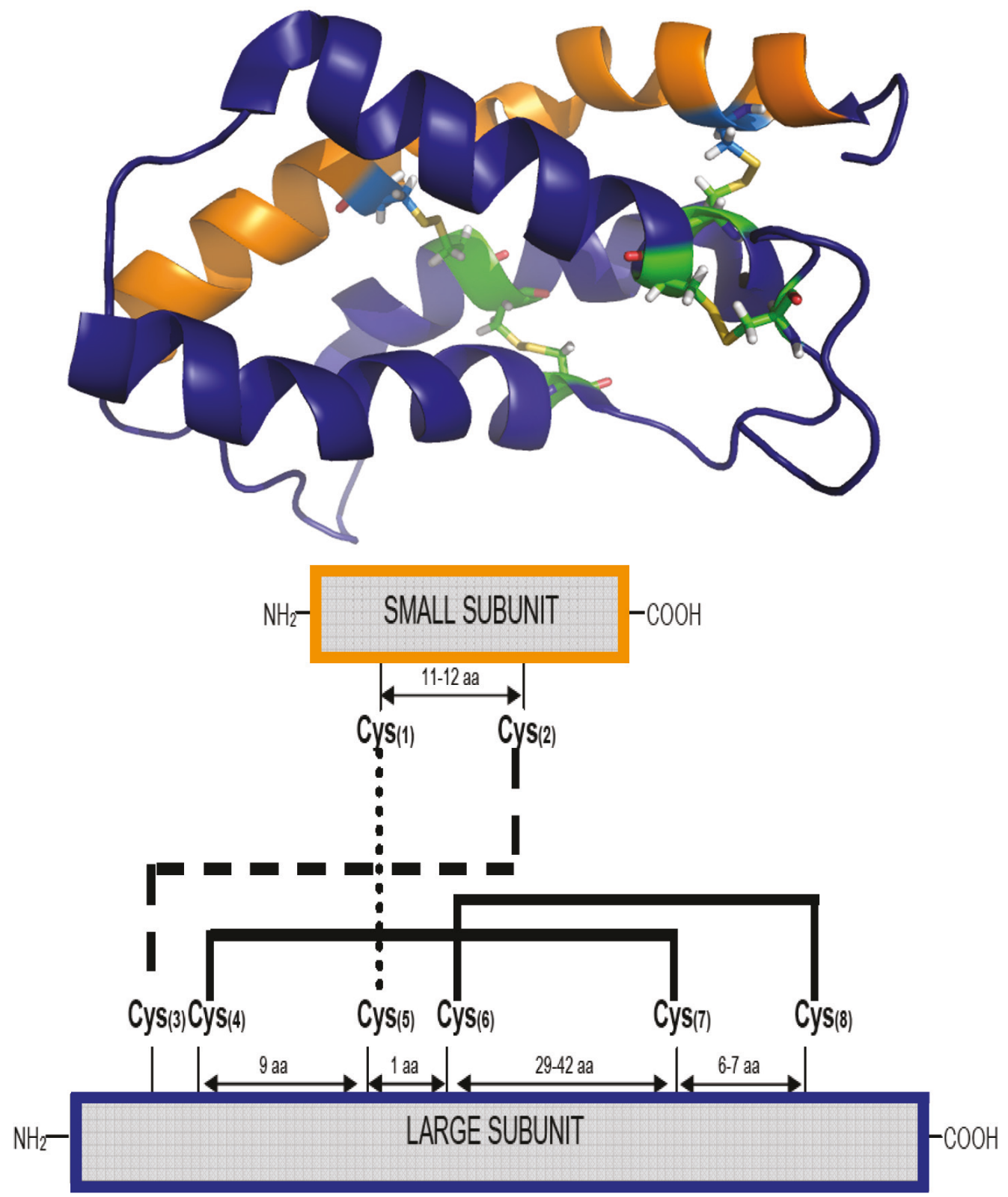

Figure 1.4: The (a) structure of a Berthollectica excelsa 2S albumin (PDB: 2LVF) and (b) schematic depicting the four conserved disulfide bonds typical of $2 \mathrm{~S}$ albumins. (a) The six cysteine residues within the large subunit (blue) are green and the two cysteine residues within the small subunit (orange) are light blue. (b) The two inter-molecular disulfide bonds are depicted by a dotted line and the two intra-molecular disulfide bonds of the large subunit by a solid line (Moreno and Clemente, 2008). 


\subsubsection{Prolamines and Glutelins.}

With the exception of rice and oat, prolamines are the major seed storage proteins in cereal grains, comprising up to $50 \%$ of the total protein content of the seed but they are not present in dicot plants, such as grain legumes (Shewry and Tatham, 1990; Washida et al, 2004). Prolamines are hydrophobic and deficient in the essential amino acids lysine and tryptophan. These seed storage proteins are historically classified based on their high proline and glutamine content, which may account for $30-70 \%$ of the residues in the protein, in addition to their solubility in aqueous alcohol solutions (Shewry and Tatham, 1990; Galili et al, 1993; Shewry et al, 1995; Herman and Larkins, 1999; Washida et al, 2004). Prolamines from the Triticeae (e.g. wheat, barley and rye) and Panicoideae (e.g. maize, sourgum and millet) cereal tribes form distinct sub-groups within this large protein family (Shewry et al, 1995; Herman and Larkins, 1999). The Triticeae prolamines are subdivided into three groups: sulfur-rich, sulfur-poor and high-molecular-weight prolamines, whereas Panicoideae prolamines are subdivided into four groups: $\alpha$, $\beta, \gamma$ and $\delta$-zeins (Shewry and Tatham, 1990; Herman and Larkins, 1999).

The primary objective of this thesis is to develop strategies for engineering thermodynamically stable, methionine-enriched, native seed storage proteins. As such, neither the $2 \mathrm{~S}$ albumins nor the prolamines are the subject of this thesis since they are not the major seed storage proteins in grain legumes, prolamines not even being present dicots, and thus do not effect the quality of the amino acid reservoirs in grain legumins to the extent that storage globulins do.

\subsubsection{Globulins.}

Globulins are saline-soluble, seed storage proteins that are deficient in tryptophan, cysteine and methionine but are rich in glutamic acid and aspartic acid (Jackson et al, 1969; Croy et al, 1979; Mandal and Mandal, 2000; Sales et al, 
2000; Wang et al, 2003; Breitender and Radauer, 2004). These are the most widely distributed group of storage proteins in plants and are found in gymnosperms, such as conifers, and spermatophytes, such as ferns, as well as in the dicot and monocot angiosperms (Lawrence et al, 1994; Shewry et al, 1995; Mills et al, 2002). Globulins, which are further classified as either 11-12S globulins (legumins) or 7-9S globulins (vicilins), are the predominant seed storage proteins of dicot seeds, such as the grain legumes of the Fabaceae family and members of the Brassicaceae family, including A. thaliana (Lawrence et al, 1994; Shewry et al, 1995; Mandal and Mandal, 2000; Autran et al, 2001; Stoger et al, 2001). For example, $7 \mathrm{~S}$ and 11S globulins together account for $70 \%$ of the total seed protein of G. max, a member of the Fabaceae family (Krishnan, 2005).

The $7 \mathrm{~S}$ and $11 \mathrm{~S}$ globulins share common three-dimensional structural features including a pair of cupin domains, a $\beta$-barrel structure of antiparallel $\beta$-strands followed by a group of $\alpha$-helices (Figure 1.5), which demonstrates that they have likely evolved from a common ancestral protein (Lawrence et al, 1994). Possible candidates for the common ancestor, which was likely a single cupin domain protein that underwent a duplication event, are a desiccation-related prokaryotic protein and a prokaryotic germin-like protein (Shutov et al, 1998; Sales et al, 2000; Autran et al, 2001; Mills et al, 2002; Shutov et al, 2003). 
Figure 1.5: Structures of Phaseolus vulgaris $7 \mathrm{~S}$ globulin (PDB: $2 \mathrm{PHL}$ ) (a-c) and Brassica napus 11S proglobulin (PDB: 3KGL) (d-f). The trimer of the mature $7 \mathrm{~S}(\mathrm{a}, \mathrm{b})$ and $11 \mathrm{~S}$ proprotein $(\mathrm{d}, \mathrm{e})$ are presented with their monomers in green, purple and orange, and red, blue and yellow, respectively. The 11S proglobulin trimer is depicted with its interdisulfide (IE) face up (d,e), with the IE and intradisulfide (IA) bonds highlighted in green and purple, respectively. The $7 \mathrm{~S}$ and $11 \mathrm{~S}$ globulin monomers are bicupins with one cupin in the $\mathrm{N}$-terminal region and one in the C-terminal region and as such have structurally equivalent $\mathrm{N}$-terminal and $\mathrm{C}$-terminal domains. These structurally equivalent domains, referred to as N-terminal and C-terminal cupindomains and $\alpha$ and $\beta$ chains in $7 \mathrm{~S}$ (a-c) and ${ }_{11} \mathrm{~S}$ globulins (d-f), respectively, are shown with the $\mathrm{N}$-terminal/ $\alpha$ chains of a darker hue than the $\mathrm{C}$-terminal $/ \beta$ chains. The $11 \mathrm{~S}$ globulin hypervariable regions with available structural data (II, III and V) are highlighted (f: blue, purple, red, respectively). 


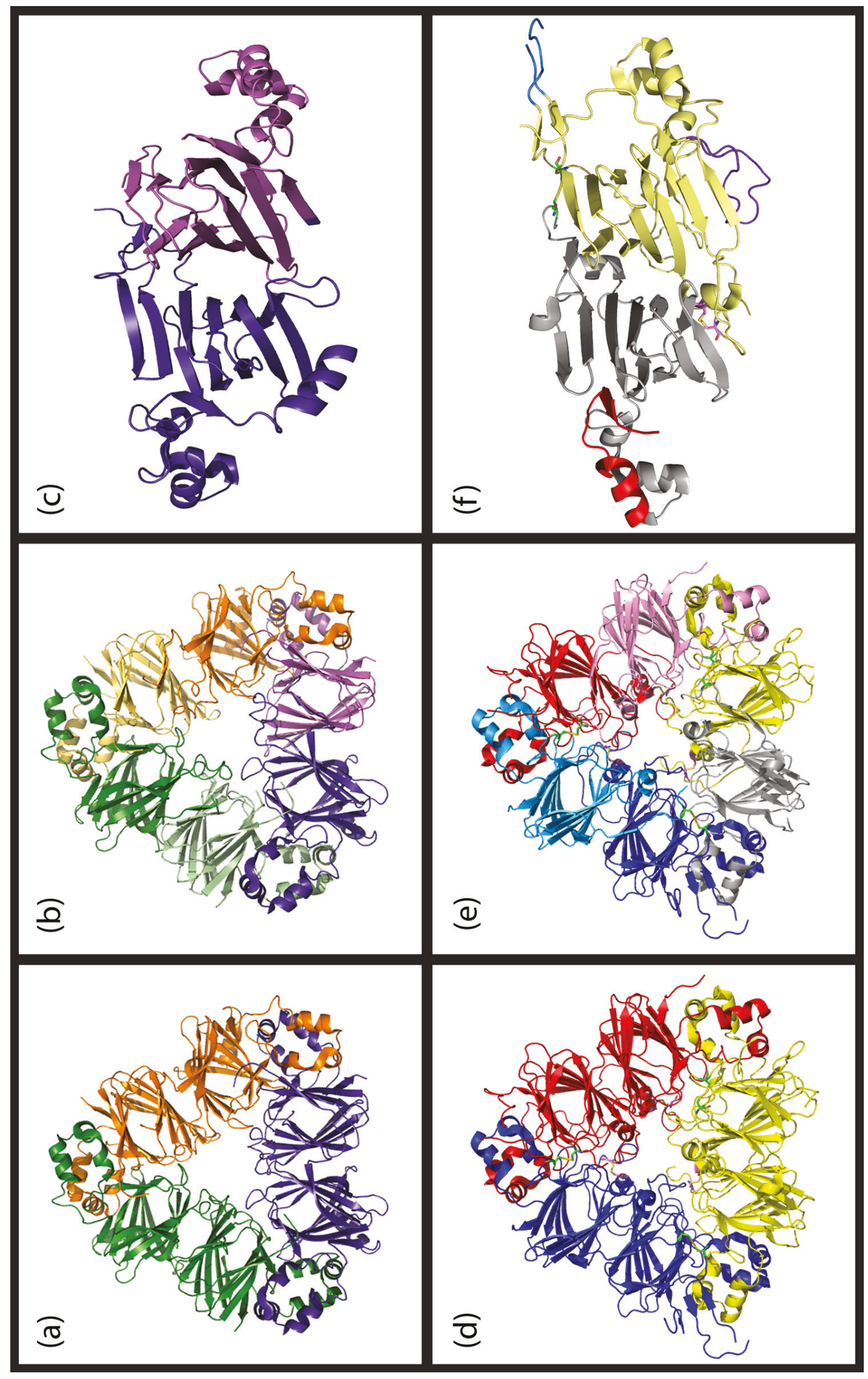




\subsection{S Globulins.}

The $7 \mathrm{~S}$ globulins are composed of three two-domain, 145-240kDa subunits and are generally heterotrimeric but may also be homotrimeric (Gatehouse et al, 1981; Lawrence et al, 1994; Muntz, 1996; Mandal and Mandal, 2000; Stoger et al, 2001; Mills et al, 2002; Shutov et al, 2003). These globulins are characterized on the basis of their sedimentation coefficients, subunit organization and molecular weight (Lawrence et al, 1994). The $7 \mathrm{~S}$ globulin subunits undergo differing degrees of postsecondary modifications including glycosylation and proteolysis by trypsinlike enzymes (Shewry et al, 1995; Muntz, 1996; Shutov et al, 1998; Sales et al, 2000; Autran et al, 2001). Since $7 \mathrm{~S}$ globulins lack cysteine residues, the subunits cannot form intermolecular disulfide bonds within the lumen of the ER, and quaternary association is primarily due to hydrophobic interactions (Lawrence et al, 1994; Shewry et al, 1995; Sales et al, 2000; Shutov et al, 2003). The assembled trimers are transferred, via the Golgi apparatus, to maturing protein storage vacuoles where carbohydrate groups are trimmed and limited proteolysis occurs to ensure efficient packing of the $7 \mathrm{~S}$ globulins with the other storage molecules in the storage cells (Shewry et al, 1995; Muntz, 1996).

\subsection{S Globulins.}

The $11 \mathrm{~S}$ globulins are the major seed storage proteins in members of the Brassicaceae and Fabaceae families, accounting for $40 \%$ of the total seed protein content in soybean (Shewry et al, 1995; Krishnan, 2005). These 300-400kDa seed storage proteins are hexameric proteins, generally existing as heterohexamers, which are encoded by a small gene family, comprising three and five members in $A$. thaliana and G. max, respectively (Muntz, 1996; Jung et al 1997; Jung et al, 1998; Stoger et al, 2001; Adachi et al, 2003). The $\alpha$ and $\beta$ chains of mature $11 \mathrm{~S}$ globulins are structurally equivalent to one another, containing one cupin domain (Figure 
1.5) (Shutov et al, 2012). These proteins also contain five hypervariable regions (HVR), I-V, which are mobile loops on the surfaces of the protein and are generally disordered in crystal structures of $11 \mathrm{~S}$ globulins (Tandang-Silvas et al, 2010).

The signal peptide of the $11 \mathrm{~S}$ globulin preproprotein is co-translationally cleaved from the precursor protein as it enters the lumen of the ER (Muntz, 1996). Once inside, the conserved inter- and intra-domain disulfide bonds in the proprotein are formed between conserved cysteine residues in the $\alpha$ - and $\beta$-domains and within the $\alpha$-domain, respectively. The resulting $50-60 \mathrm{kDa}$ proprotein assembles into trimers primarily through hydrophobic interactions between their $\alpha$-helical regions (Shutov et al, 2003). Once assembled into trimers, which have sedimentation coefficients of approximately 8S, the $11 \mathrm{~S}$ globulin trimers are transferred from the ER lumen to maturing protein storage vacuoles, via electron-dense vesicles called precursor-accumulating vesicles (Hara-Nishimura et al, 1995; Yamada et al, 1999; Adachi et al, 2003). In the protein storage vacuole these $8 \mathrm{~S}$ trimers undergo proteolytic cleavage between a specific asparagine-glycine peptide bond, to produce the separate $\alpha$ and $\beta$ chains, which in the proglobulins are the $\alpha$ and $\beta$ domains, respectively (Hara-Nishimura et al, 1993; Muramatsu and Fukazawa, 1993; Yamada et al, 1999; Adachi et al, 2003). The vacuolar-processing enzyme responsible for this proteolytic cleavage is an asparaginyl endopeptidase (HaraNishimura et al, 1995; Jung et al, 1998; Yamada et al, 1999). The $\beta$ chain created by the cleavage is a $20-25 \mathrm{kDa}$, hydrophobic polypeptide whereas the a chain is slightly more hydrophilic and 30-40 kDa (Muramatsu and Fukazawa, 1993; Muntz, 1996). It is the proper cleavage of the proproteins in the trimer conformation, producing the $\alpha$ and $\beta$ chains of each subunit and the intermolecular disulfide bonds, which elicit and control the conformational changes within each subunit that permits the association of trimer pairs in a face-to-face orientation, through non-covalent interactions, to form the mature hexameric 11S globulin structure (Muntz, 1996; 
Jung et al, 1997; Mills et al, 2002). If the proproteins are misfolded before exiting the ER, they may still assemble into trimers and enter the protein storage vacuole (Muntz, 1996; Jung et al, 1998). However, upon entry into the protein storage vacuole, where the vacuolar-processing enzyme is sequestered, the misfolded proproteins are rapidly degraded before they can associate into hexamers (Muntz, 1996; Jung et al, 1997; Jung et al, 1998).

\subsection{Developing a Strategy to Sequester more Methionine in the Seed.}

Engineering native seed proteins to increase their methionine content has the potential to address the methionine deficiencies found in agriculturally important crops without the adverse side effect of cross-allergenicity that has been reported for the alternative strategy of introducing foreign methionine-rich proteins into the seed (Nordlee et al, 1996; Muntz et al, 1998). The strategy of engineering a native protein is also more likely to be accepted by the general population because the risk of allergenicity is reduced and it does not require the transfer of genes from other species. Since seed storage proteins account for the majority of the protein found within a seed and their amino acid(s) deficiencies coincide with those of the crop, they are regarded as key targets for improving the nutritional value, with respect to amino acid content, of crops (Shewry et al, 1995; Muntz et al, 1998; Mandal and Mandal, 2000; Tandang-Silvas et al, 2010). The amount and type of seed storage protein synthesized in a seed is not only dependent on nutrient availability, but also on the taxonomy of the plant the seed was produced by (Shewry et al, 1995; Hajduch et al, 2006). Neither the $2 \mathrm{~S}$ albumins nor the prolamines are the subject of this study because they do not accumulate significantly in grain legume seeds. Therefore, they are not suitable candidates for engineering studies on native seed storage proteins to increase their methionine content. In contrast, $11 \mathrm{~S}$ globulins, 
which are deficient in methionine according to the human dietary requirements recommended by the World Health Organization, are the predominant seed storage proteins of dicot seeds, such as the grain legumes of the Fabaceae family and members of the Brassicaceae family, including A. thaliana (Shewry et al, 1995; Mandal and Mandal, 2000). It is anticipated that the introduction of multiple methionine residues into $11 \mathrm{~S}$ globulins will be required in order to increase the methionine content to a nutritionally significant level. This emphasizes the need for an efficient method to screen the numerous combinations and permutations of methionine-enriched variants in order to restrict the more resource and time intensive method of in vivo screening to only those variants with wild-type stability.

\subsubsection{Developing a 2-Phase Screening System to Facilitate Future Protein Engineering Studies on Native Seed Storage Proteins.}

Previous protein engineering studies have not assessed the effect of sequence modification (e.g. introduction of methionine residues via substitution or insertion) on the resulting variant's stability prior to transient expression in vivo (Hoffman et al, 1988; Utsumi et al, 1993). As a result, the diminished accumulation of the engineered variants in vivo due to improper folding and/or reduced stability is a key factor that has limited the success of protein engineering studies on native seed storage proteins (Muntz, 1998; Galili and Amir, 2013).

The primary objective of the research reported in this thesis was to develop a 2-phase screening system to identify stable methionine-enriched variants that accumulate appropriately in vivo in the model plant species $A$. thaliana. This novel screening method will overcome the protein mis-folding issues that have plagued other attempts to engineer native seed storage proteins by selecting only variants with the desired properties for testing in the target species (e.g. chickpea). The first phase of the screen employs E. coli as an expression system to allow assessments of 
the in vitro stability of the engineered variants, relative to the wild-type seed storage protein. Stable, methionine-enriched seed storage proteins, identified in phase I, are subsequently expressed in $A$. thaliana in phase II, the in vivo component of the screen, to assess their ability to accumulate in the seeds of a plant.

This 2-phase screening system was established using A. thaliana 11S globulins as model proteins as a proof of concept to demonstrated the feasibility of increasing the methionine content of $11 \mathrm{~S}$ globulins. An attractive feature of this novel screening method is its versatility as it can also be employed to alter the physicochemical properties of seed proteins (e.g. in studies attempting to increase the emulsification of soybean seed protein extracts for downstream food processing) as well as addressing deficiencies of other essential amino acids, such as tryptophan, in $11 \mathrm{~S}$ globulins. With an additional step for optimization of expression conditions, the nutritional properties of other seed storage proteins, such as the lysine deficiency in cereal grain prolamines, could also be modified using this 2-phase screen.

The work described in this thesis is organized into chapters according to the following objectives for the creation of the 2-phase screen:

1. Phase I of the screen required the establishment of an E. coli heterologous expression system for the model $A$. thaliana wild-type $11 \mathrm{~S}$ proglobulins and development of a biochemical method to assess their relative stability in vitro.

2. Phase 2 of the screen necessitated the development of an A. thaliana expression system to assess the in vivo accumulation of the $11 \mathrm{~S}$ globulins introduced into the seeds.

3. A survey of the structural components of $11 \mathrm{~S}$ globulins to identify locations amenable to the introduction of methionine residues was undertaken to demonstrate both the feasibility of constructing methionine-enriched $11 \mathrm{~S}$ globulin variants and the efficiency of the in vitro component of the 2-phase screen. 


\section{Chapter 2: Expression and Characterization of the Arabidopsis thaliana $11 S$ globulin family.}

\subsection{Abstract.}

The 11S globulins are the principal seed storage proteins in a variety of major crop species, including members of the legume and mustard families. They are targets for protein engineering studies attempting to alter the physicochemical properties of seed protein extracts (e.g. soybean) and to improve the nutritional quality of important agricultural crops. A key factor that has limited the success of this approach to date is insufficient accumulation of the engineered protein variants in vivo due to their improper folding and/or reduced stability, compared to the native protein. We have developed the Arabidopsis thaliana 11S proglobulins as a model system to enable studies exploring the factors underlying structural stability in this family of proteins. Yields of $1.5-4 \mathrm{mg} / \mathrm{L}$ were achieved for the three A. thaliana $11 \mathrm{~S}$ proglobulins expressed in the Origami Escherichia coli cell line in Super broth media at $20^{\circ} \mathrm{C}$ for $16 \mathrm{hrs}$ and purified via immobilized-metal affinity chromatography. We also demonstrate that differential scanning fluorimetry is an effective and accessible technique that may facilitate the screening of variants to enable the successful engineering of $11 \mathrm{~S}$ seed storage proteins. The relative in vitro stability of the $A$. thaliana $11 \mathrm{~S}$ proglobulins (proAtCRU1 > proAtCRU3 > proAtCRU2) is consistent between chemical and thermal denaturation studies.

\subsection{Introduction.}

Seed storage proteins have evolved to act as long-term amino acid reserves in seeds and are the source of nitrogen and sulfur for the germinating embryo (Shewry et al, 1995; Herman and Larkin, 1999; Mandal and Mandal, 2000). These 
non-enzymatic, secretory proteins are generally classified, based on their solubility, into one of three categories: albumins (soluble in water), globulins (soluble in saline), or prolamines (soluble in aqueous alcohol) (Osborne, 1924; Shewry et al, 2003). Globulins are further classified into the $11 \mathrm{~S}$ and $7 \mathrm{~S}$ families and the many alternate designations of each indicate the plant groups from which they have been isolated (Lawrence et al, 1994). For example, the 11S proteins of plant species of the Fabaceae (legume: e.g. soybean, chickpea and lentil) and Brassicaceae (mustard: e.g. the model organism Arabidopsis thaliana) families are often referred to as legumins and cruciferins, respectively. The $11 \mathrm{~S}$ globulins are encoded by a small gene family and are the predominant storage proteins in the seeds of dicots, a large group of flowering plants, including many agriculturally important crops, that is distinguished from the grasses primarily by seed, leaf and pollen structure (Shewry et al, 1995; Mandal and Mandal, 2000; Stoger et al, 2003). The A. thaliana genome contains three $11 \mathrm{~S}$ globulin loci (in order of predominance in the seed: AT4G2852O - AtCRU3, AT5G44120 - AtCRU1 and AT1Go3880 - AtCRU2; Wan et al, 2007; Withana-Gamage et al, 2013).

The processed, mature $11 \mathrm{~S}$ globulin is comprised of a pair of cupin domains, a $\beta$-barrel followed by a cluster of $\alpha$-helices (Figure 2.1), which assemble to form heterohexamers in the seed (Adachi et al, 2001; Adachi et al, 2003). The signal peptide of the initial translation product, referred to as the preproglobulin, is removed upon entrance to the endoplasmic reticulum. The assembly of the resulting proglobulins into trimers is primarily mediated by hydrophobic interactions between the $\alpha$-helices (Figures 2.1a and 2.1b) (Shutov et al, 2003). Subsequent proteolytic cleavage, in the protein storage vacuole, at a conserved site between the two cupin domains, generates the disulfide-linked $\alpha$ and $\beta$ chains of the monomer and the resulting conformational shift enables pairs of trimers to associate, producing the mature hexameric 11S globulins (Jung et al, 1997). 


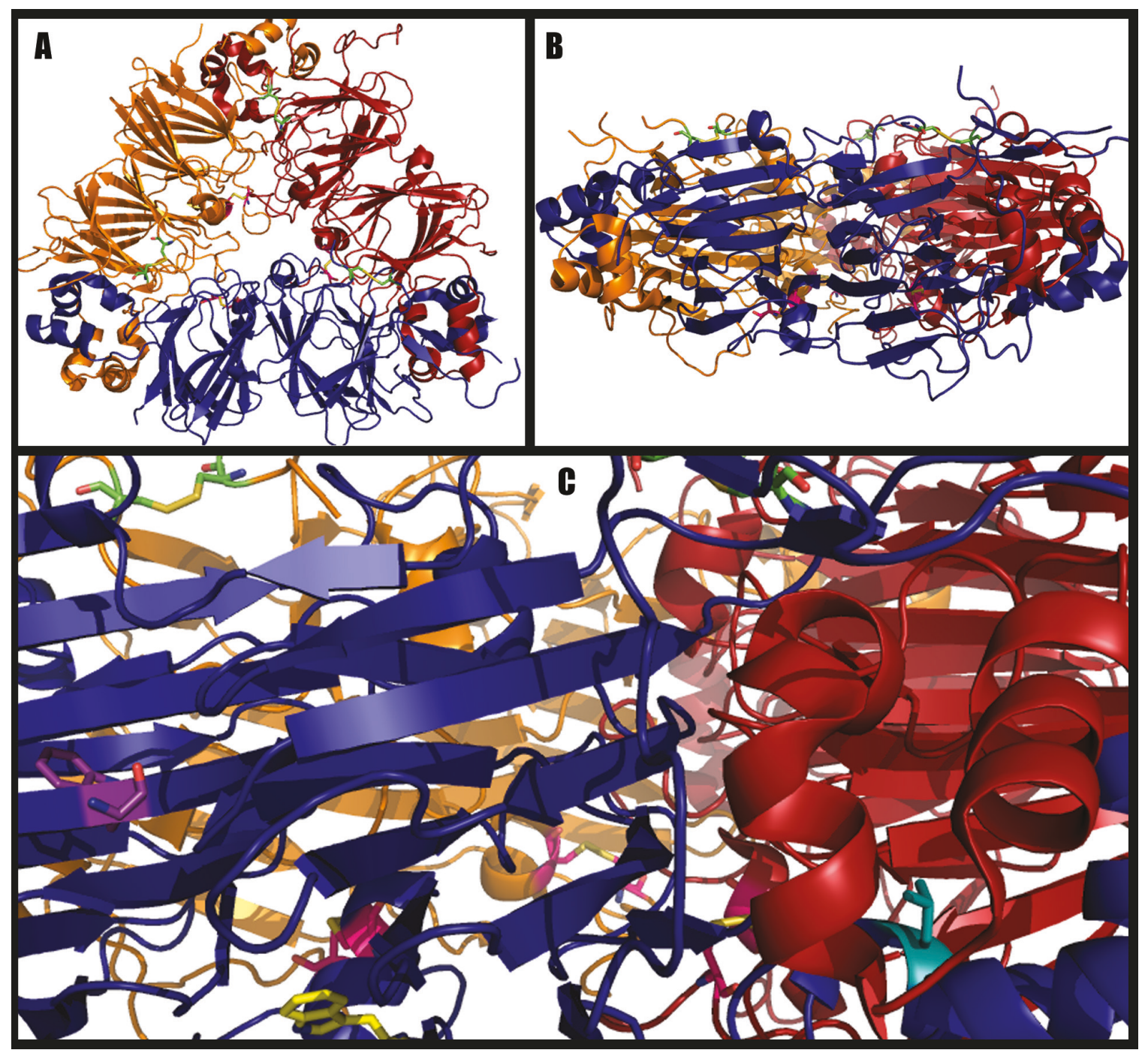

Figure 2.1: The structure of a Brassica napus procruciferin (PDB: $3 \mathrm{KGL}$ ). The three subunits (in orange, red and blue) are shown from the (a) IE face of the trimer and (b) side of the trimer with the IE face on top and the IA face on the bottom. The IA and IE disulfide bonds are pink and green, respectively. (c) The residues corresponding to the candidates for the tryptophan residues that dominate the fluorescence spectrum of the $A$. thatiana procruciferins are shown in stick representation to illustrate their relative positions: W31 (yellow), W397 (purple) and L220 (teal). 
Since $11 \mathrm{~S}$ globulins are the major seed storage proteins in many agriculturally important crops, they are targets for protein engineering studies aimed at modifying their nutritional and functional properties. Factors including nutritional quality, solubility and emulsification influence downstream food applications, as illustrated by the many food products produced from soybean seed extracts (Tandang-Silvas et al, 2011; Galili and Amir, 2013). In their comprehensive 2013 review, Galili and Amir note that a limitation of reported protein engineering studies focusing on seed proteins, including 11S globulins, has been the diminished ability of the resulting variant to appropriately accumulate in vivo (Galili and Amir, 2013). This is likely due to reduced stability or improper folding of the engineered protein as previous studies have generally not assessed the thermodynamic impact of the modifications in a systematic manner. The $11 \mathrm{~S}$ globulins from several plant species including Glycine max, Amaranthus hypochondriacus and Brassica napus have been successfully purified from source as well as, via heterologous expression, from Escherichia coli (Barba de la Rosa et al, 1992a; Barba de la Rosa et al, 1992b; Medina-Godoy et al, 2004; Tandang-Silvas et al, 2004; Prak et al, 2005; CarrazcoPena et al, 2013). Crystal structures of these $11 \mathrm{~S}$ globulins purified from $E$. coli demonstrate that the homotrimers resulting from heterologous expression can be employed to investigate the factors underlying structural stability in this group of proteins (Tandang-Silvas et al, 2004; Tandang-Silvas et al, 2010). The three cruciferins of $A$. thaliana provide a useful system for these studies as the genetics and physiology of this model plant species have been thoroughly characterized. This study reports the first purification and comparative characterization of the $A$. thaliana 11S globulins and provides the basis for development of the tools required to facilitate the engineering of seed storage proteins. 


\subsection{Materials and Methods.}

\subsubsection{Reagents.}

Isopropyl- $\beta$-D-thiogalactopyranoside (IPTG) and ampicillin were purchased from BioShop; tetracycline and lysozyme from Sigma; Ni-nitrilotriacetic acid (NiNTA) resin from Qiagen; protein molecular weight ladder from Invitrogen; and EDTA-free protease inhibitor tablets from Roche. All enzymes and the ER1821 cell line were acquired from New England Biolabs (NEB), oligonucleotide primers were synthesized by Integrated DNA Technologies (IDT) and coding sequences were sequenced by BioBasic. The Origami E. coli strain was obtained from Novagen.

\subsubsection{Amplification of $A$. thaliana Procruciferin Coding Sequences.}

Total RNA was extracted from $A$. thaliana siliques using the RNeasy mini kit (Qiagen), with the DNaseI treatment, and cDNA was synthesized from $1 \mu \mathrm{g}$ of RNA using an oligo $\left(\mathrm{dT}_{18}\right)$ primer and $200 \mathrm{U}$ M-MuLV reverse transcriptase (NEB). The

coding sequences of the three $A$. thaliana procruciferins (proAtCRU1-3) were amplified from cDNA and inserted between the NdeI and BamHI sites of the pTrc-99aAF expression vector (Farsi et al, 2009), which encodes an N-terminal $\mathrm{His}_{6}$-tag. A silent mutation was introduced to remove the internal BamHI site of proAtCRU3 to facilitate insertion into pTrc-99aAF.

\subsubsection{Optimization of Expression and Purification Conditions for the Affinity-Tagged Procruciferins.}

Batch purification of $1 \mathrm{~L}$ cultures, grown in $2.8 \mathrm{~L}$ baffled Fernbach flasks, was employed to determine the optimal expression, growth and purification conditions for the three $\mathrm{N}$-terminally $\mathrm{His}_{6}$-tagged $A$. thaliana procruciferins (His-proAtCRU). The host ER1821 (NEB) or Origami (Novagen) cells containing the pTrc-99aAF/ 
proAtCRU1, pTrc-99aAF/proAtCRU2 or pTrc-99aAF/proAtCRU3 plasmids were cultured at $37{ }^{\circ} \mathrm{C}$ in Lysogeny broth medium (LB: $10 \mathrm{~g} / \mathrm{L}$ tryptone, $5 \mathrm{~g} / \mathrm{L}$ yeast extract) containing either $0.17 \mathrm{M}$ or $0.5 \mathrm{M} \mathrm{NaCl}$, or Super broth medium (SB: $12 \mathrm{~g} / \mathrm{L}$ tryptone, $24 \mathrm{~g} / \mathrm{L}$ yeast extract, $12.5 \mathrm{~g} / \mathrm{L} \mathrm{K}_{2} \mathrm{HPO}_{4}, 3.8 \mathrm{~g} / \mathrm{L} \mathrm{KH}_{2} \mathrm{PO}_{4}, 5.1 \mathrm{~mL} / \mathrm{L}$ glycerol, and Vogel-Bonner salts; Vogel and Bonner, 1956; Jhee et al, 2000). Expression was induced during log phase of growth with $0.15 \mathrm{mM}$ IPTG and growth proceeded for 16 or $60 \mathrm{hrs}$ at 20 or $25^{\circ} \mathrm{C}$. Cells were harvested by centrifugation at $7000 \mathrm{rpm}$ for 10 min at $4{ }^{\circ} \mathrm{C}$, washed with $0.85 \% \mathrm{NaCl}$ and stored at $-80^{\circ} \mathrm{C}$.

All purifications were carried out at $4{ }^{\circ} \mathrm{C}$. Frozen cells were resuspended in $\sim 20 \mathrm{~mL}$ buffer A (50 $\mathrm{mM}$ potassium phosphate, $\mathrm{pH} \mathrm{8,10} \mathrm{mM}$ imidazole) and disrupted by incubation with $1 \mathrm{mg} / \mathrm{mL}$ lysozyme (Sigma) at room temperature for 20 min followed by sonication (10 cycles of $30 \mathrm{~s}$ at $50 \%$ duty) on ice. The lysed cells were centrifuged at $17000 \mathrm{rpm}$ for $60 \mathrm{~min}$ and $50 \mu \mathrm{L} \mathrm{Ni-NTA}$ resin (Qiagen) was incubated with the cleared lysate for $3 \mathrm{hrs}$. The resin was collected via centrifugation at $5000 \mathrm{rpm}$ for $10 \mathrm{~min}$, and washed with $750 \mu \mathrm{L}$ of buffer A followed by a series of $200 \mu \mathrm{L}$ elutions of increasing stringency $(100 \mathrm{mM}, 200 \mathrm{mM}$, $300 \mathrm{mM}$ and $400 \mathrm{mM}$ imidazole in buffer A). Buffer A was supplemented with salt (400 $\mathrm{mM} \mathrm{NaCl}$ or $150 \mathrm{mM}$ potassium phosphate) or surfactants (0.1\% Triton $\mathrm{X}-100$ or Tween-20) to determine the effect of these additives on protein solubility and stability. Aliquots from each purification step were analyzed via SDS-PAGE.

Following optimization of growth and purification conditions, eight litres ( $8 \times 1 \mathrm{~L}$ in $2.8 \mathrm{~L}$ baffled Fernbach flasks) of SB medium, containing $100 \mu \mathrm{g} / \mathrm{mL}$ ampicilin and $10 \mu \mathrm{g} / \mathrm{mL}$ tetracycline, were inoculated (1:10) with an overnight culture of pTrc-99aAF/proAtCRU1, pTrc-99aAF/proAtCRU2 or pTrc-99aAF/ proAtCRU3 in the Origami E. coli strain (Novagen). Growth proceeded for 3 hrs at $37^{\circ} \mathrm{C}$ and then at $20^{\circ} \mathrm{C}$ for $1 \mathrm{hr}$, at which point IPTG was added to a final 
concentration of $0.15 \mathrm{mM}$. Cultures were incubated at $20{ }^{\circ} \mathrm{C}$ for a further $16 \mathrm{hrs}$ and harvested by centrifugation at $7000 \mathrm{rpm}$ for $10 \mathrm{~min}$ at $4{ }^{\circ} \mathrm{C}$. The cell pellets were washed with $0.85 \% \mathrm{NaCl}$.

The harvested cells were resuspended in $\sim 80 \mathrm{~mL}$ of buffer $\mathrm{B}(50 \mathrm{mM}$ potassium phosphate, $\mathrm{pH} 8,400 \mathrm{mM} \mathrm{NaCl}, 10 \mathrm{mM}$ imidazole) containing an EDTAfree protease inhibitor tablet (Roche). The cells were disrupted by incubation with $1 \mathrm{mg} / \mathrm{mL}$ lysozyme (Sigma) at room temperature for $20 \mathrm{~min}$ followed by sonication (10 cycles of $30 \mathrm{~s}$ at $50 \%$ duty) on ice. The lysate was centrifuged at $17000 \mathrm{rpm}$ for $60 \mathrm{~min}$ and the resulting supernatant was incubated with $1 \mathrm{~mL}$ of Ni-NTA resin (Qiagen) for $3 \mathrm{hrs}$ at $4{ }^{\circ} \mathrm{C}$. The Ni-NTA resin/His-proAtCRU slurry was then loaded into a column and washed with $50 \mathrm{~mL}$ of buffer $\mathrm{B}$, followed by $50 \mathrm{~mL}$ of buffer $\mathrm{C}$ (buffer B $+50 \mathrm{mM}$ imidazole). The protein was eluted with a $60 \mathrm{~mL}$ linear gradient of 50-400 mM imidazole. Fractions identified as at least 90\% pure, via SDS-PAGE, were pooled and concentrated. Prior to storage at $-80^{\circ} \mathrm{C}$, the purified cruciferins were dialyzed against $2 \mathrm{~L}$ of buffer $\mathrm{D}$ (50 $\mathrm{mM}$ potassium phosphate, $\mathrm{pH} 8,400 \mathrm{mM} \mathrm{NaCl}$, 1 mM EDTA, 20\% glycerol, $150 \mathrm{mM}$ imidazole) followed by $4 \mathrm{~L}(2 \times 2 \mathrm{~L})$ of buffer E (50 mM potassium phosphate, $\mathrm{pH} \mathrm{8,} 400 \mathrm{mM} \mathrm{NaCl}, 1 \mathrm{mM}$ EDTA, 20\% glycerol). All protein concentrations were measured using the molar extinction coefficients of each procruciferin, determined using the method described by Pace et al (1995).

\subsubsection{Urea Denaturation of His-proAtCRU Proteins.}

Each procruciferin was incubated at $25^{\circ} \mathrm{C}$ with $\mathrm{o}-8 \mathrm{M}$ urea for $18 \mathrm{hrs}$ in $50 \mathrm{mM}$ potassium phosphate buffer, $\mathrm{pH}$ 8. Fluorescence spectra of the $1 \mu \mathrm{M}$ protein samples were recorded on a Varian spectrofluorimeter in a $1 \mathrm{~cm}$ path-length cuvette at $25^{\circ} \mathrm{C}$ with settings of $\lambda_{\mathrm{ex}}=295 \mathrm{~nm}$ and excitation and emission slit widths of $5 \mathrm{~nm}$. 


\subsubsection{Differential Scanning Fluorimetry (DSF) of His-proAtCRU Proteins.}

DSF experiments were recorded on a Rotor-Gene 6000 series, 2-Plex HRM (Corbett) real-time thermocycler $\left(\lambda_{\mathrm{ex}}=470 \mathrm{~nm}\right.$, and $\left.\lambda_{\mathrm{em}}=610 \mathrm{~nm}\right)$ for $25 \mu \mathrm{L}$ volume of $2 \mu \mathrm{M}$ His-proAtCRU and SYPRO orange (Invitrogen: 500o-fold dilution from stock) in $50 \mathrm{mM}$ potassium phosphate, $\mathrm{pH}$. The samples were heated from 25 to $80^{\circ} \mathrm{C}$ and the fluorescence intensity was measured at intervals of $0.1^{\circ} \mathrm{C}$.

\subsection{Results and Discussion.}

Seed storage proteins dominate the protein content of seeds. As such, they are targets for studies attempting to alter the physicochemical and/or nutritional properties of seed protein extracts for downstream food products. A key factor that has limited the success of these studies is diminished accumulation of the engineered variants in the seed due to improper folding and/or reduced stability (Muntz, 1998; Galili and Amir, 2013). An increased understanding of the factors underlying structural stability in this group of proteins will facilitate the engineering of seed storage proteins.

\subsubsection{Optimization of Expression and Purification Conditions.}

Studies describing the heterologous expression of G. max, A. hypochondriacus and $B$. napus $11 \mathrm{~S}$ globulins in $E$. coli have reported that the optimal expression and purification conditions, required to obtain soluble protein, vary between plant species as well as among the $11 \mathrm{~S}$ globulins within a given species (MedinaGodoy et al, 2004; Tandang-Silvas et al, 2004; Prak et al, 2005). Four variables reported to influence the expression of $11 \mathrm{~S}$ globulins were tested in this study to optimize the expression conditions for the three A. thaliana procruciferins: $E$. coli cell line (ER1821 versus Origami), media (LB supplemented with $0.17 \mathrm{M}$ or 
$0.5 \mathrm{M} \mathrm{NaCl}$ versus $\mathrm{SB})$, temperature $\left(20{ }^{\circ} \mathrm{C}\right.$ versus $\left.25^{\circ} \mathrm{C}\right)$ and duration between induction and harvest (16 versus $60 \mathrm{hrs)}$. The addition of salts ( $\mathrm{NaCl}$ or potassium phosphate) or surfactants (Triton X-100 or Tween-20) to the purification buffer was also investigated to optimize the yield of soluble procruciferins and prevent precipitation during purification and storage. In contrast with the distinct expression and purification requirements reported for the five members of the $G$. max 11S proglobulin family, a set of common conditions was established for the $A$. thaliana 11S proglobulins (Prak et al, 2005). Expression in the E. coli Origami cell line (Novagen) in SB media for $16 \mathrm{hrs}$ at $20^{\circ} \mathrm{C}$ and purification, via Ni-NTA affinity chromatography, in the presence of $400 \mathrm{mM} \mathrm{NaCl}$, was effective for the three $A$. thaliana procruciferins.

Cell line and media composition (Figures 2.2a and 2.2b) had primary influences on the production of soluble procruciferin, compared to temperature and duration of growth. The Origami cell line was selected as the host strain for expression since, in contrast with ER1821 cells, it enabled the production of soluble His-AtCRU1-3 proteins (Figure 2.2a). The thioredoxin reductase and glutathionine reductase genes of Origami cells harbor mutations that diminish their respective activities in vivo, thereby creating the oxidizing environment that favors disulfide bond formation (Medina-Godoy et al, 2004; Prak et al, 2005; Carrazco-Pena et al, 2013). Other studies on the heterologous expression of $11 \mathrm{~S}$ globulins have also reported that expression in a cell line with an oxidizing environment enhances the expression of soluble protein (Medina-Godoy et al, 2004; Tandang-Silvas et al, 2004; Prak et al, 2005; Carrazco-Pena et al, 2013). There are two conserved disulfide bonds in $11 \mathrm{~S}$ globulins: an intramolecular (IA) disulfide bond between cysteine residues in the $\alpha$ chain, and an intermolecular (IE) disulfide bond that links the $\alpha$ and $\beta$ chains of the mature 11S globulins (Adachi et al, 2001). The situation of these disulfide bonds has been employed to distinguish the primary surfaces of the trimer (Figure 2.1b) 
and it is the IE surface that interacts with a second trimer to form a hexamer in the mature 11S globulin (Jung et al, 1997; Adachi et al, 2001). The effect of media composition on the production of soluble procruciferins was also investigated and cultures were grown in $\mathrm{LB}$, containing either $0.17 \mathrm{M}$ or $0.5 \mathrm{M} \mathrm{NaCl}$, or an enriched (super broth) media. The effect of salt concentration in the growth media was considered because the globulin class of seed storage proteins is defined by solubility in saline solutions and the presence of $\mathrm{NaCl}$ in culture media was shown to increase the heterologous expression of G. $\max 11 \mathrm{~S}$ proglobulins (Osborne, 1924; Prak et al, 2005). However, supplementation with o.5 M NaCl, compared to the standard 0.17 M in LB, did not improve the A. thaliana procruciferin yield. The SB media, an enriched terrific broth (TB) derivative, supplemented with Vogel and Bonner salts, is most effective for the production of soluble procruciferins as determined by comparison of batch purifications by SDS-PAGE (Figure 2.2b). This is consistent with the findings of Medina-Godoy et al who observed that the yield of an A. hypochondriacus 11S globulin doubled in TB media, compared to that in LB media (Medina-Godoy et al, 2004). 
Figure 2.2: SDS-PAGE of batch purifications of His-proAtCRU2 (a, d) and His-proAtCRU3 (b, c). Lanes are designated as: $\mathrm{P}=$ pellet, $\mathrm{Sn}=$ supernatant, $\mathrm{W}$ = wash with $10 \mathrm{mM}$ imidazole, lanes 1-4 = elution with 100, 200, 300 and 400 mM imidazole, respectively. a) Effect of cell line (ER1821 versus Origami) for expression in $\mathrm{LB}$ media containing $0.17 \mathrm{M} \mathrm{NaCl}$ and purification in buffer $\mathrm{A}$ (50 $\mathrm{mM}$ potassium phosphate, $\mathrm{pH} \mathrm{8,10} \mathrm{mM} \mathrm{imidazole).} \mathrm{b)} \mathrm{Effect} \mathrm{of} \mathrm{media} \mathrm{(0.17} \mathrm{M}$ $\mathrm{NaCl} \mathrm{LB}, 0.5 \mathrm{M} \mathrm{NaCl} \mathrm{LB}$ and SB) for expression in Origami cells and purification in buffer A. c) Effect of supplementation of purification buffer A with an additional $150 \mathrm{mM}$ potassium phosphate or $400 \mathrm{mM} \mathrm{NaCl}$ for expression in Origami cells in SB media. d) Effect of supplementation of purification buffer A with $0.1 \%$ TritonX-100 or 0.1\% Tween-20 for expression in Origami cells in SB media. 


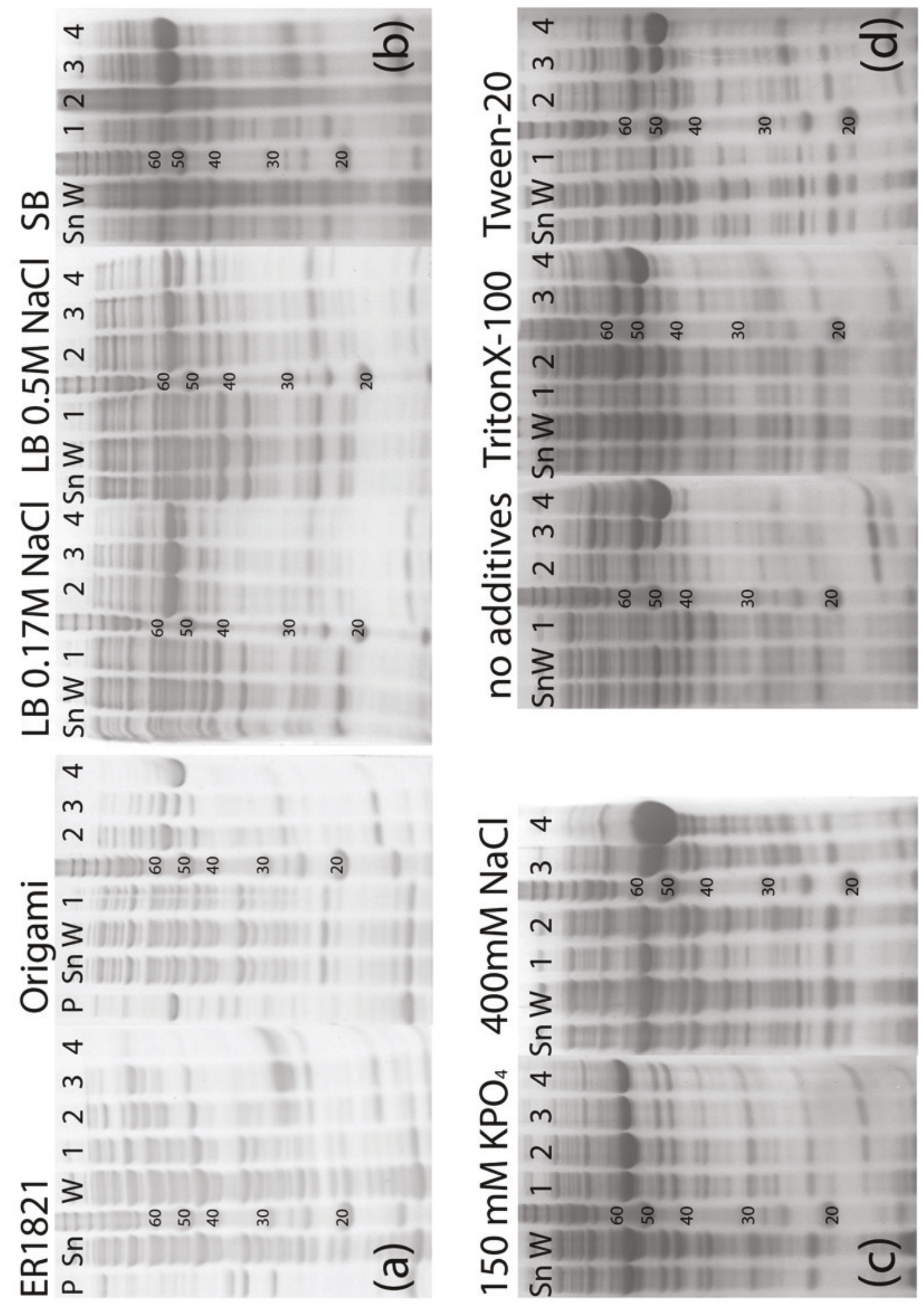


Consistent with the 1924 classification of globulins as saline soluble by T.B. Osborne, the purified A. thaliana procruciferins precipitate in the absence of $\mathrm{NaCl}$ (Osborne, 1924). Although supplementation of the growth media with salt did not impact the yield of soluble procruciferin, the presence of $400 \mathrm{mM} \mathrm{NaCl}$ in the purification and storage buffers is required to prevent precipitation of the purified proteins (Figure 2.2c). In contrast, the addition of the surfactants Triton X-100 or Tween-20 had no observable effect on aggregation (Figure 2.2d). The observed 'salting in' effect, common to many proteins, is the result of both direct interactions of the ions with the polar components of the macromolecular surface and indirect effects mediated by interactions between ions and the water molecules forming the primary hydration shell surrounding the protein (Zhang and Cremer, 2006). The aggregation of His-proAtCRU1 during purification and His-proAtCRU2 following dialysis, in the absence of $\mathrm{NaCl}$, illustrates this effect. The addition of $400 \mathrm{mM} \mathrm{NaCl}$ to the buffers facilitated the purification, dialysis and storage of both procruciferins. The optimized expression, purification and dialysis conditions for the A. thaliana procruciferins enabled yields of $1.5 \mathrm{mg} / \mathrm{L}, 4 \mathrm{mg} / \mathrm{L}$ and $3 \mathrm{mg} / \mathrm{L}$ for His-proAtCRU1, His-proAtCRU2 and His-proAtCRU3, respectively (Figure 2.3). 


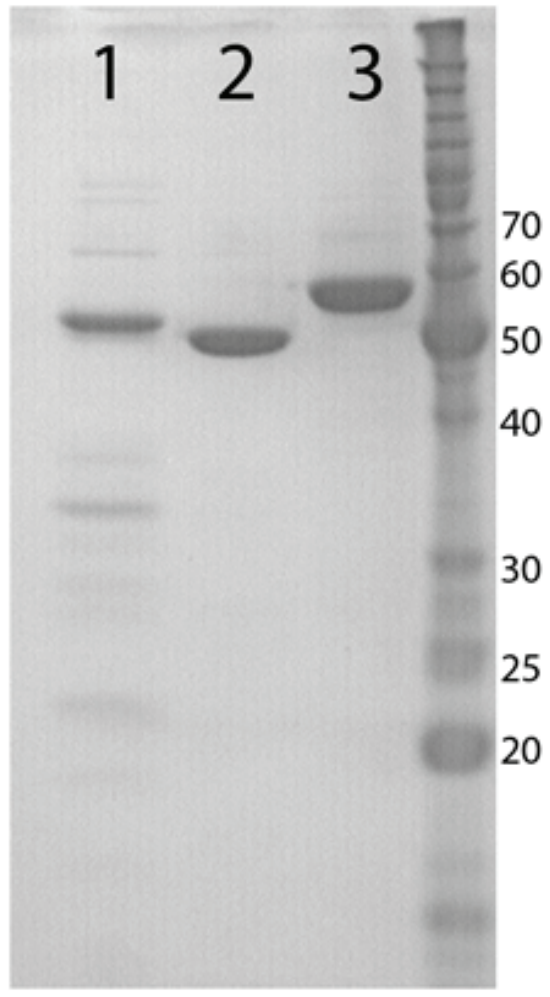

Figure 2.3: SDS-PAGE of $3 \mu \mathrm{g}$ of purified His-proAtCRU1, His-proAtCRU2 and His-proAtCRU3 in lanes $1-3$, respectively. 


\subsubsection{Fluorescence Properties and Relative Stability of the}

\section{A. thaliana Procruciferins.}

The shift of the native tryptophan fluorescence emission maximum, following incubation in 0-8 $\mathrm{M}$ urea, produces distinct denaturation profiles for each $A$. thaliana procruciferin (Figure 2.4). The transition midpoints for this chemical denaturation $\left(C_{m}\right)$ are 1, 2.2 and $4 \mathrm{M}$ urea for His-proAtCRU2, His-proAtCRU 3 and His-proAtCRU1, respectively (Figure 2.4). The observed red-shift in the emission maxima for each $A$. thaliana procruciferin following incubation with urea (Figures 2.4b, 2.4 $\mathrm{d}$ and 2.4f) signifies that the dominant tryptophan residue(s), those primarily responsible for the fluorescence emission spectrum of the protein in the native, folded state, are shielded within the structure and become exposed to the bulk solvent following denaturation. Candidates for the dominant tryptophan residue of each $A$. thaliana procruciferin were identified based on the structure of the related procruciferin from B. napus (PDB: $3 \mathrm{KGL}$; Tandang-Silvas et al, 2004). Residue $\mathrm{W}_{31}$ of the model B. napus procruciferin, conserved in proAtCRU1 (W37) and proAtCRU2 (W31), is situated in a loop that connects a $\beta$-strand and an $\alpha$-helix, and its side chain is buried at the base of the two $\beta$-barrels on the IA face of the procruciferin (Figure 2.1c). The tryptophan at position 397 of the $B$. napus procruciferin is shared by proAtCRU1 (W380), proAtCRU2 (W367) and proAtCRU3 (W431). The indole ring of this residue protrudes into a $\beta$-barrel, forming a polar contact with the side chain of E399 (Figure 2.1c). An alternative candidate for the dominant Trp residue of proAtCRU3 is W246, corresponding to the leucine residue at position 220 of the model B. napus procruciferin, which is buried in the cluster of $\alpha$-helices that is responsible for holding the monomers together in the trimer conformation (Shutov et al, 2003). 

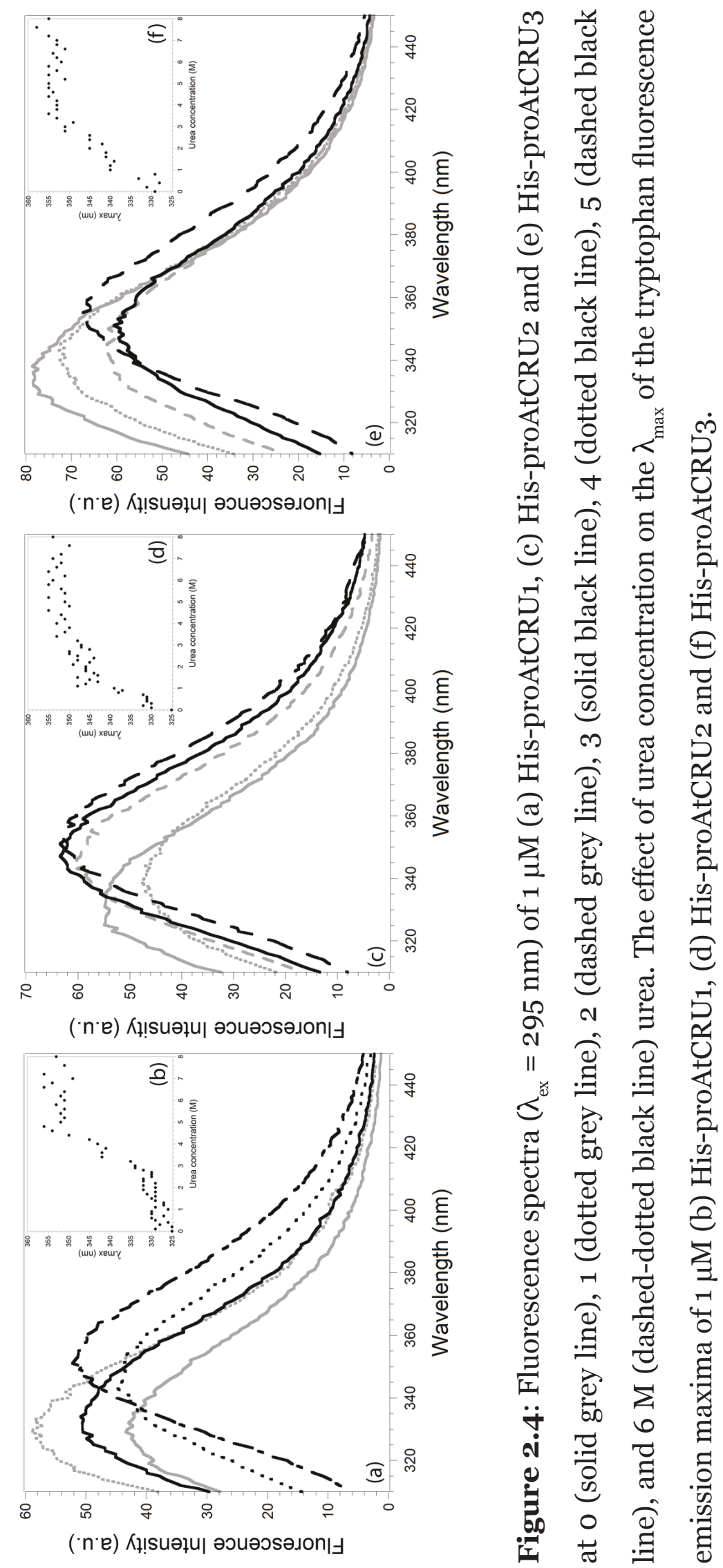
A cooperative transition is observed for the shift in the emission maximum of His-proAtCRU2, from $330-348 \mathrm{~nm}$ between 1 to $2 \mathrm{M}$ urea. In contrast, the transition from 330 to $355 \mathrm{~nm}$ of His-proAtCRU3 occurs between o - $4 \mathrm{M}$ urea, while the $3-5 \mathrm{M}$ transition of His-proAtCRU1 is intermediate. The extended transition in His-proAtCRU3 may be attributed to the fact that it has nine native tryptophan residues. Six of these nine tryptophans are not conserved among the other A. thaliana or B. napus procruciferins, including W246, a candidate for the dominant tryptophan of proAtCRU3. With the exception of W246, these additional, distinctive, intrinsic probes are located in two of the variable regions located on the IA and IE faces of the trimer. The five variable regions in the primary structure of the 11S globulins differ in length and sequence, and are generally disordered in crystal structures (Tandang-Silvas et al, 2010). The five Trp residues located in two of these variable regions in proAtCRU3 may give unique insights into the denaturation of $11 \mathrm{~S}$ proglobulins in urea.

Differential scanning fluorimetry (DSF) is an efficient technique typically used to assess factors that impact the stability of a protein, such as a change in $\mathrm{pH}$ or ligand binding (Niesen et al, 2007). The efficiency of this technique stems from the small volumes and high sample throughput enabled by the use of a fluorescencemonitored thermocycler, commonly employed for real-time PCR. In this study, we have demonstrated that DSF can also be employed to compare the thermal stability of a group of related proteins, specifically the $11 \mathrm{~S}$ seed storage globulins. This novel application of DSF may permit a set of variants to be rapidly screened for relative thermal stability, compared to the wild-type. The thermal stability of each wildtype A. thaliana procruciferin was assessed in this study via DSF (Figure 2.5). The midpoints for thermal denaturation $\left(T_{m}\right)$ are $47.86 \pm 0.07^{\circ} \mathrm{C}, 60.03 \pm 0.03$ ${ }^{\circ} \mathrm{C}$ and $63.43 \pm 0.05{ }^{\circ} \mathrm{C}$ for His-proAtCRU2, His-proAtCRU3 and His-proAtCRU1, respectively. This trend of the relative stabilities is consistent with that observed 
for fluorescence-monitored urea denaturation (Figure 2.4). Investigation of the thermal stability of $11 \mathrm{~S}$ seed storage globulins has identified several structural factors that contribute to stability, including the cavity size at the core of the trimer and the hydrophobic component of the molecular surface (Tandang-Silvas et al, 2010). The thermal denaturation profile of His-proAtCRU2 is unique among the A. thaliana $11 \mathrm{~S}$ globulins in showing aggregation directly following denaturation (Figure 2.5b). This differs from the other two $11 \mathrm{~S}$ globulins, which show a more gradual decline in fluorescence following denaturation (Figures 2.5a and 2.5c), demonstrating aggregation of His-proAtCRU1 and His-proAtCRU3 occurs at higher temperatures. His-proAtCRU2 has the smallest variable region IV segment of the three A. thaliana proteins and it is this mobile variable region that prevents nonspecific interactions between the IE and IA faces of the proglobulin trimers prior to hexamer formation (Adachi et al, 2003). The relatively short length of this variable region in proAtCRU2 may explain both the challenge of in finding appropriate storage conditions for this protein and its relatively low in vitro stability. 


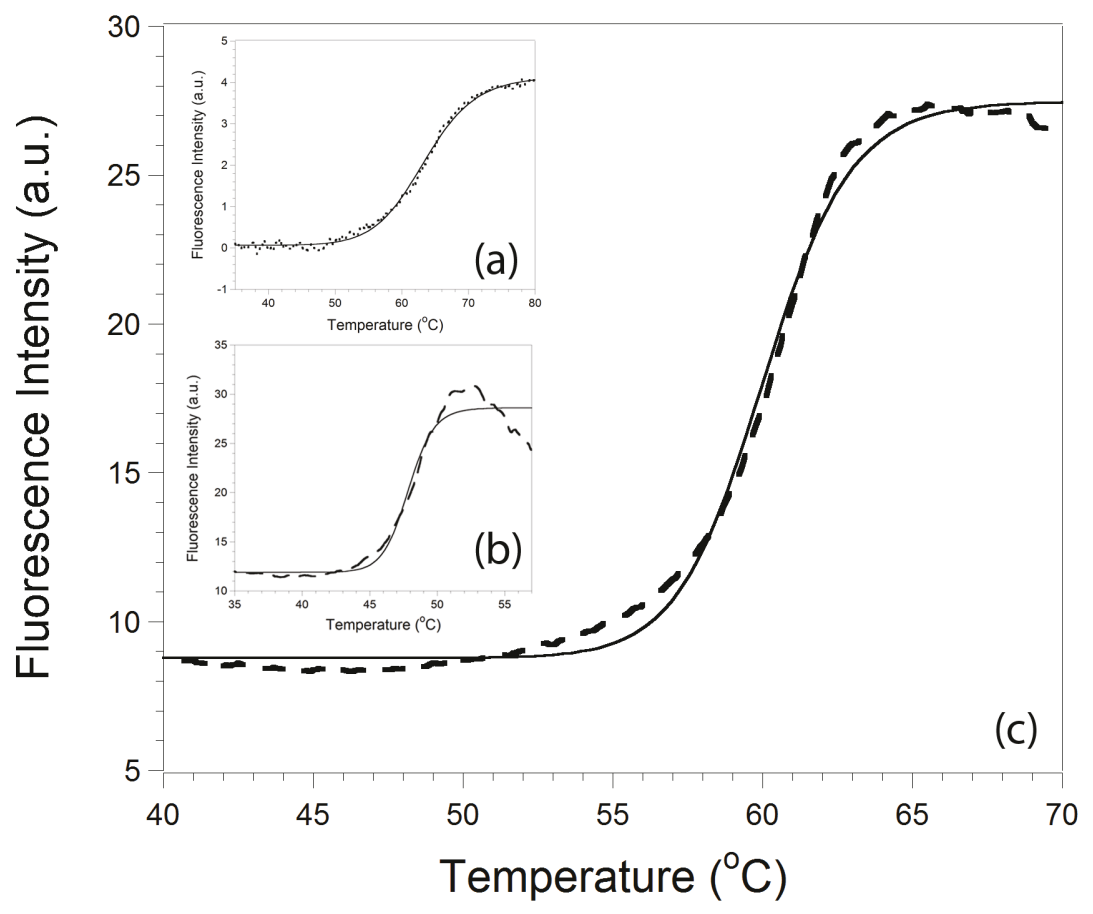

Figure 2.5: Differential scanning fluorimetry $\left(\lambda_{\mathrm{ex}}=470 \mathrm{~nm}\right.$, and $\left.\lambda_{\mathrm{em}}=610 \mathrm{~nm}\right)$ thermal denaturation profiles of (a) His-proAtCRU1, (b) His-proAtCRU2 and (c) His-proAtCRU3. 


\subsection{Concluding remarks.}

The engineering of native seed storage proteins is a promising method to improve their nutritional and physiochemical properties. A factor that has limited the success of these studies is insufficient accumulation in the seed due to improper folding and/or reduced stability of the engineered variants (Muntz, 1998; Galili and Amir, 2013). In order to facilitate future protein engineering studies on $11 \mathrm{~S}$ globulins, a model system to investigate the structural determinants of stability for these important seed storage proteins is required. The results of our study suggest that proAtCRU1 or proAtCRU3 are suited for this purpose. The tendency of proAtCRU2 to aggregate during DSF and its comparatively low prevalence in vivo limit its utility as a model $11 \mathrm{~S}$ proglobulin (Wan et al, 2007). The model system provided by the $A$. thaliana cruciferins and assessments of in vitro stability, including fluorescence-monitored chemical denaturation and the accessible, highthroughput technique of DSF, provide the tools to enable studies exploring the factors underlying structural stability in the $11 \mathrm{~S}$ globulins and to facilitate the engineering of seed storage proteins. 


\section{Chapter 3. Developing an in vivo Expression System to Assess Accumulation of Engineered 11S Globulins.}

\subsection{Abstract.}

The $11 \mathrm{~S}$ globulins are the principal seed storage proteins in major crop species, including Glycine max (soybean) and Cicer arietinum (chickpea). They are targets for protein engineering studies attempting to alter the physicochemical properties of seed protein extracts (e.g. emulsification and gelling) and to improve the nutritional quality of agricultural crops, by providing the proper balance of essential amino acids. A key factor that has limited the success of this approach to date is insufficient accumulation of the engineered protein variants in vivo due to their improper folding and/or reduced stability, compared to the native protein. Here we describe the development of a seed-targeted expression system in the model plant species Arabidopsis thaliana to enable an assessment of the ability of introduced 11S globulins to accumulate appropriately in vivo. This study verifies that the $A$. thaliana cruciferin 3 and phaseolin promoters direct expression of the reporter gene, $\beta$-glucuronidase, to A. thaliana seeds. However, the three native $A$. thaliana cruciferins were detectable in the seed only under control of the phaseolin promoter. An anti-hemagglutinin antibody was employed to selectively detect the affinity-tagged $11 \mathrm{~S}$ globulin proteins as this method is specific for the introduced protein, precluding cross-reaction with native cruciferins. The development of this $A$. thaliana system as a screen for the in vivo stability and accumulation of modified $11 \mathrm{~S}$ globulin variants, described in this study, complements the in vitro stability screen established previously (Jaworski and Aitken, 2014; Chapter 2 of this thesis). 


\subsection{Introduction.}

Seed storage proteins are the nitrogen and sulfur reserves for the germinating embryo and comprise the majority of the protein content of a seed, accounting for 50-90\% of the protein therein (Shewry et al, 1995; Muntz, 1998; Herman and Larkins, 1999; Mandal and Mandal, 2000; Tandang-Silvas et al, 2010). The 11S globulins are the major seed storage proteins in dicot plants belonging to the Fabaceae (legume: e.g. Glycine max (soybean) and Cicer arietinum (chickpea)) and Brassicaceae (mustard: e.g. Brassica napus and the model organism Arabidopsis thaliana) families (Muntz et al, 1998; Mandal and Mandal, 2000; Tandang-Silvas et $a l$, 2011). The $11 \mathrm{~S}$ globulins are salt-soluble, seed storage proteins that are deficient in the essential amino acid methionine (Mandal and Mandal, 2000). They are characterized by a pair of cupin domains, a protein domain comprised of a jelly-roll $\beta$-barrel of antiparallel $\beta$-strands followed by a cluster of three $\alpha$-helices (Adachi et al, 2001; Shutov et al, 2012). After translation, removal of the $\mathrm{N}$-terminal signal peptide and formation of the two conserved disulfide bonds, one intra- and one inter-domain, the $\sim 50-60 \mathrm{kDa} 11 \mathrm{~S}$ proglobulin subunits assemble and accumulate as stable trimers in the lumen of the endoplasmic reticulum (ER) (Muntz, 1996; Jung et al, 1998). Once assembled into trimers, the 11S proglobulins are sorted into the protein storage vacuole where the vacuolar processing enzyme (VPE), an asparaginyl endopeptidase, cleaves the monomers into their $\alpha(\sim 30-40 \mathrm{kDa})$ and $\beta$ chains ( $\sim 20-25 \mathrm{kDa})$, which are held together by the formerly interdomain, now intermolecular, disulfide bond (Chen and Paredes-Lopez, 1997). Cleavage by the VPE allows a conformational change to occur that permits two trimers to assemble to form the mature 11S globulin heterohexamer (Jung et al, 1997; Jung et al, 1998).

The 11S globulins dominate the protein content of dicot seeds and as such dictate the physicochemical properties of their seed protein extracts and their nutritional 
value, with respect to amino acid content. Therefore, the $11 \mathrm{~S}$ globulins are targets for protein engineering studies aimed at improving these qualities in agriculturally important crops, such as soybean. In their comprehensive 2013 review, Galili and Amir indicate that the success of previous protein engineering studies on seed storage proteins, including $11 \mathrm{~S}$ globulins, has been limited by the diminished ability of the resulting variant(s) to accumulate in vivo, due to reduced stability and/or improper folding (Galili and Amir, 2013). Previous protein engineering studies on $11 \mathrm{~S}$ globulins have primarily used transient expression in Nicotiana tabacum (tobacco) under control of the strong, constitutive Cauliflower mosaic virus $35 \mathrm{~S}$ (CaMV-35S) promoter, to test the in vivo expression of the variants in the leaves and/or seeds (Benfey and Chua, 1990; Utsumi et al, 1993; Valdez-Ortiz et al, 2005). Although transient expression in tobacco can be used to test in vivo expression, verifying the in vitro stability first via biophysical techniques enables a larger number of variants to be screened thus eliminating the need for transient expression studies prior to assessment in vivo by stable expression in seeds.

We recently reported the heterologous expression of the A. thaliana $11 \mathrm{~S}$ proglobulin, commonly referred to as procruciferins in Brassicaceae species, family (proAtCRUs) in the Origami Escherichia coli cell line. Biophysical techniques, such as fluorescence-monitored chemical denaturation, were employed to assess the in vitro stability of the $11 \mathrm{~S}$ proglobulins in order to facilitate future protein engineering studies of this protein family (Jaworski and Aitken, 2014; Chapter 2 of this thesis). To complement this work, we report here the development of an A. thaliana expression system to verify the appropriate in vivo accumulation of $11 \mathrm{~S}$ globulin variants using a seed-specific promoter (the Phaseolus vulgaris $7 \mathrm{~S}$ globulin (phaseolin) promoter) and immunoblots of seed protein extracts using an anti-HA (HA: Human influenza hemagglutinin) antibody specific for the affinity tag. An advantage of this method is that, in contrast with anti-globulin antibodies 
that crossreact with native $11 \mathrm{~S}$ globulins, the anti-HA antibody is selective for the introduced protein (Utsumi et al, 1993; Jung et al, 1998; Valdez-Ortiz et al, 2005; Wan et al, 2007). This model plant organism is better suited, as compared to tobacco, for in vivo expression studies focusing on engineering $11 \mathrm{~S}$ globulins as it is a member of the Brassicaceae family and therefore has $11 \mathrm{~S}$ globulins as its major seed storage protein. Additionally, it readily undergoes Agrobacterium-mediated transformation, yielding stable transgenic lines for seed-specific expression, and the genetics and physiology of this model plant species have been thoroughly characterized. This study verifies that the $A t C R U_{3}$ and phaseolin promoters direct the expression of $\beta$-glucuronidase (GUS) to A. thaliana seeds. However, only under the phaseolin promoter were the expressed A. thaliana cruciferins with C-terminal HA tags detected in the seed. Therefore, the phaseolin promoter will be adopted to assess the in vivo expression of $11 \mathrm{~S}$ globulin variants and their ability to accumulate appropriately in seeds. A further advantage of this system is that the anti-HA antibody is specific for the affinity-tagged, introduced protein and does not crossreact with any $A$. thaliana native seed proteins.

\subsection{Methods and Materials.}

\subsubsection{Reagents.}

Spectinomycin, kanamycin, rifampicin and gentamycin sulfate were purchased from BioShop; Silwet L-77 (polyalkyleneoxide modified heptamethyltrisiloxane (84\%) and allyloxypolyethyleneglycol methyl ether (16\%) from Lehle Seeds; AntiHA tag monoclonal antibody (mouse IgG1) from Cedarlane labs; and ImmunStar goat anti-mouse HRP conjugate secondary antibody, Precision Plus Protein Western C standard, Precision Protein StrepTactin-HRP conjugate, and Clarity Western ECL substrate from BioRad. Arabidopsis thaliana (ecotype Columbia) 
and pBI.101.3 were obtained from Dr. Shelley Hepworth and pSBS4006 and pBAR from Dr. Owen Rowland. All enzymes were acquired from New England Biolabs (NEB), oligonucleotide primers were synthesized by Integrated DNA Technologies (IDT) and sequencing was performed by BioBasic prior to vector mobilization into A. thatiana.

\subsubsection{Constructing the Plant Vectors.}

\subsubsection{Promoter-Reporter Constructs.}

Genomic DNA was isolated from young leaf rosette tissue using the DNeasy Plant Kit (Qiagen). Total RNA was extracted from developing A. thaliana siliques and seeds using the RNeasy Mini Kit (Qiagen), with the DNaseI treatment, and cDNA was synthesized from $1 \mu \mathrm{g}$ of RNA using an oligo $\left(\mathrm{dT}_{18}\right)$ primer and 200 $\mathrm{U}$ M-MuLV reverse transcriptase (NEB). The promoter region of AtCRU3 was amplified from gDNA using AtCRU3promXmaI-F and AtCRU3promBamHI-R primers and inserted between the XmaI and BamHI sites in pBI.101.3 to create the AtCRU3::GUS construct (Table 3.1). The $\beta$-glucuronidase (GUS) coding sequence was amplified from the pBI.101.3 plant vector, using the pBI101GUSNcoI-F forward and pBI101GUSHindIII-R reverse primers (Table 3.1), and inserted between the NcoI and HindIII sites of pSBS4006 such that it would be under the internal Phaseolus vulgaris $7 \mathrm{~S}$ globulin (phaseolin) vector promoter, in order to construct the Phaseolin::GUS construct.

\subsubsection{Cruciferin-HA tag Constructs.}

To construct the AtCRU3::AtCRU(1/2/3)-HA tag vectors, the coding sequence of $A t C R U_{3}$ was amplified from cDNA using the primers AtCRU3BamHI-F and AtCRU3-HAtagXbaI-R (which encodes an in-frame HA tag (Human influenza 
hemagglutinin: GYPYDVPDYA), codon optimized for $A$. thatiana expression) (Table 3.1). Following insertion of the promoter (which was excised from the pBI.101.3 promoter-reporter construct (section 3.3.2.1) using XbaI and BamHI) and AtCRU3-HA tag into pBAR, a silent mutation was introduced to remove the internal BamHI site in AtCRU3 and a novel BamHI site was introduce in between $A t C R U_{3}$ and the HA tag, using the rcAtCRU3-BamHI-HAtag-F and rcAtCRU3-BamHI$H A t a g-R$ primers. This was done to facilitate the excision of $A t C R U_{3}$ from the $\mathrm{pBAR}+$ AtCRU3::AtCRU3-HA tag vector using BamHI, in order to insert the two remaining AtCRUs (1 and 2) between the AtCRU3 promoter and the HA tag to create the pBAR + AtCRU3::AtCRU1-HA tag and pBAR + AtCRU3::AtCRU2-HA tag constructs. The coding sequences for AtCRU1 and AtCRU2 were amplified from cDNA using AtCRU1BamHI-F/AtCRU1BamHI-R and AtCRU2BamHI-F/AtCRU2BamHI-R primers (Table 3.1), respectively, and inserted into pBAR AtCRU3::AtCRU3-HA tag using the BamHI site in between the promoter and the tag.

To construct the pSBS4006 + AtCRU(1/2/3)-HA tag vectors, the coding regions wereamplifiedfromtheirrespectivepBARvectorcounterpartsusing AtCRU1BspHI-F/ AtCRU1-HAtagBspHI-R, AtCRU2NcoI-F/AtCRU2/3-HAtagHindIII-R, and AtCRU3BspHI-F/AtCRU2/3-HAtagHindIII-R primers (Table 3.1). The AtCRU1 amplicon was inserted between the NcoI and SwaI sites, and AtCRU2 and AtCRU3 were inserted between the NcoI and HindIII sites of the pSBS4006 plant vector. 
Table 3.1: Primers used to construct the promoter-reporter, and cruciferin-HA tag constructs

\begin{tabular}{|l|l|}
\multicolumn{1}{|c|}{ Primer Name } & \multicolumn{2}{c|}{ Sequence (5' - 3') } \\
\hline AtCRU3promXmaI-F & tcc ccc cgg gct gaa aca atc cca ata cat g \\
\hline AtCRU3promBamHI-R & ttg gat cct gct gag ctt aac cat ttt ct \\
\hline pBI101GUSNcoI-F & $\begin{array}{l}\text { cca tgg ttg caa ggg tta tgt tac gtc ctg tag aaa ccc } \\
\text { caa ccc }\end{array}$ \\
\hline pBI101GUSHindIII-R & aag ctt tca ttg ttt gcc tcc ctg ctg cgg t \\
\hline AtCRU3BamHI-F & gga tcc aaa tgg tta agc tca gca atc \\
\hline AtCRU3-HAtagXbaI-R & $\begin{array}{l}\text { gat cga gga gat tgt cga ggc tgg tta tcc tta tga tgt tcc } \\
\text { tga tta tgc tta atc tag agc }\end{array}$ \\
\hline rcAtCRU3-BamHI-HAtag-F & gga gat tgt cga ggc tgg atc cgg tta tcc tta tga tg \\
\hline rcAtCRU3-BamHI-HAtag-R & cat cat aag gat aac cgg atc cag cct cga caa tct cc \\
\hline AtCRU1BamHI-F & ccg gat cca aat ggc tcg agt ctc ttc tc \\
\hline AtCRU1BamHI-R & cgg gat cca gct gca gcc acc ctt gg \\
\hline AtCRU2BamHI-F & cgg gat cca aat ggg tcg agt ctc at \\
\hline AtCRU2BamHI-R & cgg gat cca gcc cta ggc ctt ccg t \\
\hline AtCRU1BspHI-F & ggt tca tga ttc gag tct ctt ctc ttc \\
\hline AtCRU1-HAtagBspHI-R & ccg att taa att taa gca taa tca gga \\
\hline AtCRU2NcoI-F & cat gcc atg ggt cga gtc tca tct at \\
\hline AtCRU2/3-HAtagHindIII-R & ccc aag ctt tta agc ata atc agg aa \\
\hline AtCRU3BspHI-F & ggt tca tga tta agc tca gca atc tc \\
\hline & \\
\hline
\end{tabular}




\subsubsection{Transformation of Agrobacterium.}

The engineered plant vectors were purified from E. coli and subsequently used to transfect Agrobacterium cells in preparation for floral dip transformation of A. thaliana. Approximately 25-100 ng of each plasmid was added to $40 \mu \mathrm{L}$ of electrocompetent Agrobacteria in a pre-chilled electroporation cuvette with a 0.2cm gap (Biorad). The electroporation conditions were $2.5 \mathrm{kV}, 25 \mu \mathrm{F}$ and $400 \Omega$ for 9 ms. Following the pulse, $1 \mathrm{~mL}$ of LB media was added and the cells were incubated at $200 \mathrm{rpm}$ and $28{ }^{\circ} \mathrm{C}$ for $3 \mathrm{hrs}$. Cells were then plated on LB agar (1.5\% w/v) plates containing $100 \mu \mathrm{g} / \mathrm{mL}$ rifampicin, $40 \mu \mathrm{g} / \mathrm{mL}$ gentamycin sulphate and $50 \mu \mathrm{g} / \mathrm{mL}$ of kanamycin or spectinomycin for pBI.101.3/pBAR and pSBS4006 constructs, respectively. Five independent transformants, verified via colony PCR, per construct were selected for mobilization into A. thaliana via the floral dip method.

\subsubsection{Floral dip Transformation of A. thaliana.}

The A thaliana (ecotype Columbia) seeds were surface sterilized, by soaking in 95\% ethanol for 5 minutes followed by distilled water for an additional 5 minutes, prior to stratification at $4{ }^{\circ} \mathrm{C}$ in the dark for 3 days on $\mathrm{MS}$ plates $\left(2 \mathrm{mM} \mathrm{Ca}\left(\mathrm{NO}_{3}\right)_{2}\right.$, $5 \mathrm{mM} \mathrm{KNO}_{3}, 2.5 \mathrm{mM} \mathrm{KH}_{2} \mathrm{PO}_{4}, 2 \mathrm{mM} \mathrm{MgSO}{ }_{4}, 70 \mu \mathrm{M} \mathrm{H}_{3} \mathrm{BO}_{4}, 14 \mu \mathrm{MnCl}_{2}, 49.5$ $\mu \mathrm{M}$ Fe-EDTA, $0.5 \mu \mathrm{M} \mathrm{CuSO}_{4}, 1 \mu \mathrm{M} \mathrm{ZnSO}_{4}, 0.2 \mu \mathrm{M} \mathrm{NaMoO}_{4}, 10 \mu \mathrm{M} \mathrm{NaCl}$ and $0.01 \mu \mathrm{M} \mathrm{CoCl}_{2}$ ) and $0.7 \%$ agar (Haughn and Somerville, 1981). These plates were subsequently transferred to a growth chamber set to continuous light at $200 \mathrm{~mol} /$ $\mathrm{m} / \mathrm{s}$ and $22^{\circ} \mathrm{C}$, for $7-10$ days. Seedlings were then transplanted to plastic pots, at a density of 5-7 seedlings per pot, containing a commercial soil mixture (BM1 Growing Mix, Berger Horticulture), which had been autoclaved prior to transplanting. The plants were grown for an additional six weeks, with the primary shoots removed during the fifth week to encourage the growth of more secondary shoots in order to increase the number of inflorescences available for transformation. The promoter- 
reporter and cruciferin-HA tag vectors (section 3.3.2) were mobilized into these $A$. thaliana plants using the Agrobacterium-mediated floral dip method described by Zhang and colleagues (Zhang et al, 2006b).

Approximately 24-35 A. thaliana plants were exposed to each construct for transformation. A $500 \mathrm{~mL}$ culture of LB media, containing $100 \mu \mathrm{g} / \mathrm{mL}$ rifampicin, $40 \mu \mathrm{g} / \mathrm{mL}$ gentamycin sulphate and $50 \mu \mathrm{g} / \mathrm{mL}$ of kanamycin or spectinomycin for pBI.101.3/pBAR and pSBS4006 constructs, respectively, was inoculated with $1 \mathrm{~mL}$ from each of the five separate $5 \mathrm{~mL}$ Agrobacterium cultures, started from the five independent colonies selected for each construct (section 3.3.3.) and grown for two days at $28{ }^{\circ} \mathrm{C}$. The $500 \mathrm{~mL}$ culture was incubated at $28^{\circ} \mathrm{C}$ with shaking at $200 \mathrm{rpm}$ for $20 \mathrm{hrs}$. The cells were harvested by centrifuging at $7000 \mathrm{rpm}$ for 10 min and re-suspended in $500 \mathrm{~mL}$ of $5 \%(\mathrm{w} / \mathrm{v})$ sucrose, prior to the addition of Silwet L-77 (Lehle Seeds) to $0.02 \%(\mathrm{v} / \mathrm{v})$. The A. thaliana plants were inverted and dipped into this Agrobacterium suspension for approximately $5 \mathrm{~s}$. The pots were then placed on their sides overnight under a plastic hood to maintain high humidity. The following day, the plastic hood was removed and the plants were returned to the upright position in the growth chamber. Following the completion of flowering, paper bags were placed over the inflorescences to retain all seeds as the siliques dried. The dry seeds were then collected by rubbing the paper bags to break open the siliques and sieved to remove debris.

\subsubsection{Selecting Transgenic A. thaliana.}

The progeny from the $A$. thaliana plants transformed with pBAR and pSBS4006 were seeded at a density of approximately 10 ooo seeds per tray and, following vernalization, sprayed with Basta (active ingredient phosphinothricin (PPT): 250mg/L and 0.01\% v/v Silwet-L77 [Lehle Seeds]) at 2 day intervals to select for transgenic plants. The progeny from $A$. thaliana transformed with pBI.101.3 
were selected on MS plates containing $0.9 \%$ agar and $50 \mu \mathrm{g} / \mathrm{mL}$ kanamycin. Successful transformants, those that survived the treatments, were transplanted into individual pots for growth and the harvesting of independent transgenic lines.

\subsubsection{GUS Staining of Transgenic A. thaliana Siliques and Seeds.}

Developing siliques from Phaseolin::GUS and AtCRU3::GUS T1 plants were harvested, sliced with a razor blade to expose the seeds within, and incubated in heptane for $5 \mathrm{~min}$ on ice. The heptane was removed, the siliques and seeds were subsequently washed with buffer 1 ( $50 \mathrm{mM} \mathrm{NaPO}_{4}, \mathrm{pH} 7,0.5 \mathrm{mM} \mathrm{KFe}(\mathrm{CN})$ and 0.1 \% Triton X-100), and incubated overnight at $37{ }^{\circ} \mathrm{C}$ in buffer 2 (Buffer $\mathrm{A}+0.5 \mathrm{mg}$ / $\mathrm{mL}$ of 5-bromo-4-chloro-3-indoxyl-beta-D-glucuronide (cyclohexylammonium salt: X-GLUC) dissolved in dimethylformylamide). Buffer 2 was removed the following morning and the siliques and seeds were incubated in $70 \%$ ethanol for $24 \mathrm{hrs}$. The following day the tissues were observed using a SteREO Discovery V20 microscope.

\subsubsection{Purification of His-proAtCRU3-HA tag from Escherichia coli.}

The C-terminal HA tag that was added to the 3'-end of the cruciferins in the AtCRU3::AtCRU1/2/3 HAtag and Phaseolin::AtCRU1/2/3 HAtag constructs (section 4.3.2.2.) was also added to the 3 -end of proAtCRU3 and then inserted in between the NdeI and BamHI sites in the E. coli expression vector pTrc-99aAF, which contains an amino-terminal $\mathrm{His}_{6}$-tag and linker that enables Ni-NTA affinity purification (Farsi et al, 2009). The pTrc-99aAF + proAtCRU3 wild-type plasmid constructed in Jaworski and Aitken, 2014 (in Chapter 2 section 2.3.2.of this thesis) was used as the DNA template.

The His-proAtCRU3-HAtag construct was expressed in the Origami (Novagen) E. coli cell line, as described previously (Jaworski and Aitken, 2014 -in Chapter 2 section 2.3.3.of this thesis). The harvested cells were resuspended in $\sim 60 \mathrm{~mL}$ of 
buffer B (50 mM potassium phosphate, $\mathrm{pH} 8,400 \mathrm{mM} \mathrm{NaCl}, 10 \mathrm{mM}$ imidazole). The cells were disrupted by incubation with $1 \mathrm{mg} / \mathrm{mL}$ lysozyme (Sigma) at room temperature for 20 min followed by sonication (10 cycles of $30 \mathrm{~s}$ at $50 \%$ duty) on ice. The lysate was centrifuged at $17000 \mathrm{rpm}$ for $60 \mathrm{~min}$ and the resulting supernatant was incubated with $1 \mathrm{~mL}$ of Ni-NTA resin (Qiagen) for $3 \mathrm{hrs}$ at $4{ }^{\circ} \mathrm{C}$. The Ni-NTA resin/His-proAtCRU slurry was then loaded into a column and washed with $50 \mathrm{~mL}$ of buffer B, followed by $50 \mathrm{~mL}$ of buffer C (buffer $\mathrm{A}+50 \mathrm{mM}$ imidazole). The protein was eluted with a $60 \mathrm{~mL}$ linear gradient of $50-400 \mathrm{mM}$ imidazole. Fractions identified as at least 90\% pure, via SDS-PAGE, were pooled and concentrated. Prior to storage at $-80{ }^{\circ} \mathrm{C}$, the purified proAtCRU3-HAtag protein was dialyzed against $2 \mathrm{~L}$ of buffer $\mathrm{E}$ (50 $\mathrm{mM}$ potassium phosphate, $\mathrm{pH} 8$, $400 \mathrm{mM} \mathrm{NaCl}, 1 \mathrm{mM}$ EDTA, 20\% glycerol).

\subsubsection{Seed Protein Extraction from A. thaliana.}

Total protein extracts were prepared from $150 \mathrm{mg}$ of dried $A$. thaliana seeds, pooled from 15 independent transgenic lines, using the thiourea/urea extraction buffer (7 M urea, 2 M thiourea, 4\% (w/v) CHAPS, 1\% (v/v) Pharmalyte, $\mathrm{pH} 3$ to 10, carrier ampholytes, $18 \mathrm{~mm}$ Tris-HCl, $14 \mathrm{~mm}$ Tris base, a protease inhibitor cocktail “complete Mini” tablet (Roche), 53 units/mL DNase I (Roche), 4.9 Kunitz units/mL RNase A (Sigma), and 0.2\% (v/v) Triton X-100) as described previously (Harder et al, 1999; Gallardo et al, 2002). After $150 \mathrm{mg}$ of $A$. thaliana seeds were ground in liquid nitrogen, $1.2 \mathrm{~mL}$ of extraction buffer was added and, following incubation for $10 \mathrm{~min}$ at $4^{\circ} \mathrm{C}$, dithiothreitol (DTT) was added to a final concentration of $14 \mathrm{mM}$ and the solution incubated at $4^{\circ} \mathrm{C}$ for $20 \mathrm{~min}$. This mixture was subsequently centrifuged at $13500 \mathrm{rpm}$ $10 \mathrm{~min}$. The supernatant was submitted to a second, clarifying centrifugation. 


\subsubsection{Immunoblot.}

Approximately $2 \mu \mathrm{g}$ of the His-proAtCRU3-HAtag control protein, purified from E. coli, $50 \mu \mathrm{g}$ (Figure 3.2 A-B) or $20 \mu \mathrm{g}$ (Figure 3.2 C-D) of the soluble protein extracts from A. thaliana seeds, and $10 \mu \mathrm{l}$ of Precision Plus Protein Western C standard were subjected to SDS-PAGE. Following electrophoresis, proteins were transferred from SDS-PAGE gels to Immuno-Blot PVDF membranes using a Transblot SD semi-dry transfer cell (Bio-Rad). The transfer was carried out in transfer buffer (25 mM Tris, $190 \mathrm{mM}$ glycine and $20 \%(\mathrm{v} / \mathrm{v})$ methanol) at $10 \mathrm{~V}$ for $40 \mathrm{~min}$. The membranes were then blocked with $4 \%$ (w/v) non-fat milk in TBST buffer (20 mM Tris, $14 \mathrm{mM} \mathrm{NaCland} 0.05 \%$ Tween-20, $\mathrm{pH}$ 7.6) for $1 \mathrm{hr}$ at room temperature and then rinsed with TBST buffer six times for $5 \mathrm{~min}$ each. The washed membranes were probed with the primary antibody, mouse anti-HA tag (Cedarlane: diluted to 1:2000 in TBST), for $1 \mathrm{hr}$ at room temperature. The membranes were then washed six times for 5 min with TBST buffer and incubated with the secondary antibody, Immun-Star goat anti-mouse HRP conjugate (BioRad: diluted to 1:20 ooo in TBST) and Precision Protein StrepTactin-HRP conjugate (BioRad: diluted 1: 20

Ooo in TBST), for $1 \mathrm{hr}$ at room temperature. The membranes were subsequently washed six times for 5 min in TBST buffer and developed using the Clarity Western ECL substrate system (BioRad).

\subsection{Results and Discussion.}

One of the main limitations of protein engineering studies on seed storage proteins is the diminished ability of the variant to accumulate in vivo (Galili and Amir, 2013). To facilitate further studies on 11S globulins, the major seed storage protein of plants in the legume and mustard families, an efficient screening system is required to enable selection of only those variants with the desired properties for introduction into the species of interest. To this end, we have recently described the 
heterologous expression of the $A$. thaliana $11 \mathrm{~S}$ proglobulin family in the Origami E. coli cell line to study the in vitro stability via biophysical techniques. This will be used as a model system for determining factors underlying structural stability in this family of proteins in order to facilitate future protein engineering studies on more agriculturally relevant species, such as soybean and chickpea (Jaworski and Aitken, 2014; Chapter 2 of this thesis). To complement this in vitro assessment of stability, via the E. coli expression system, we have developed $A$. thaliana as an expression system that can be used in protein engineering studies to verify that $11 \mathrm{~S}$ variants with in vitro stability comparable to the wild-type protein are able to accumulate in the seeds in vivo.

In order to establish an appropriate $A$. thaliana expression system for $11 \mathrm{~S}$ globulins, a seed-specific promoter that directs expression of $11 \mathrm{~S}$ globulins to the seed and a method to detect the engineered $11 \mathrm{~S}$ globulins specifically are required. To this end, the native $A$. thaliana cruciferin 3 (AtCRU3) promoter and the high expression, $7 \mathrm{~S}$ globulin (phaseolin), seed-specific promoter from P. vulgaris were tested in this study (Chandrasekharan et al, 2002). The promoter-reporter constructs, using GUS as a reporter gene, developed in this study demonstrate that both the AtCRU3 and phaseolin promoters direct expression of GUS to A. thaliana seeds (Figure 3.1). 


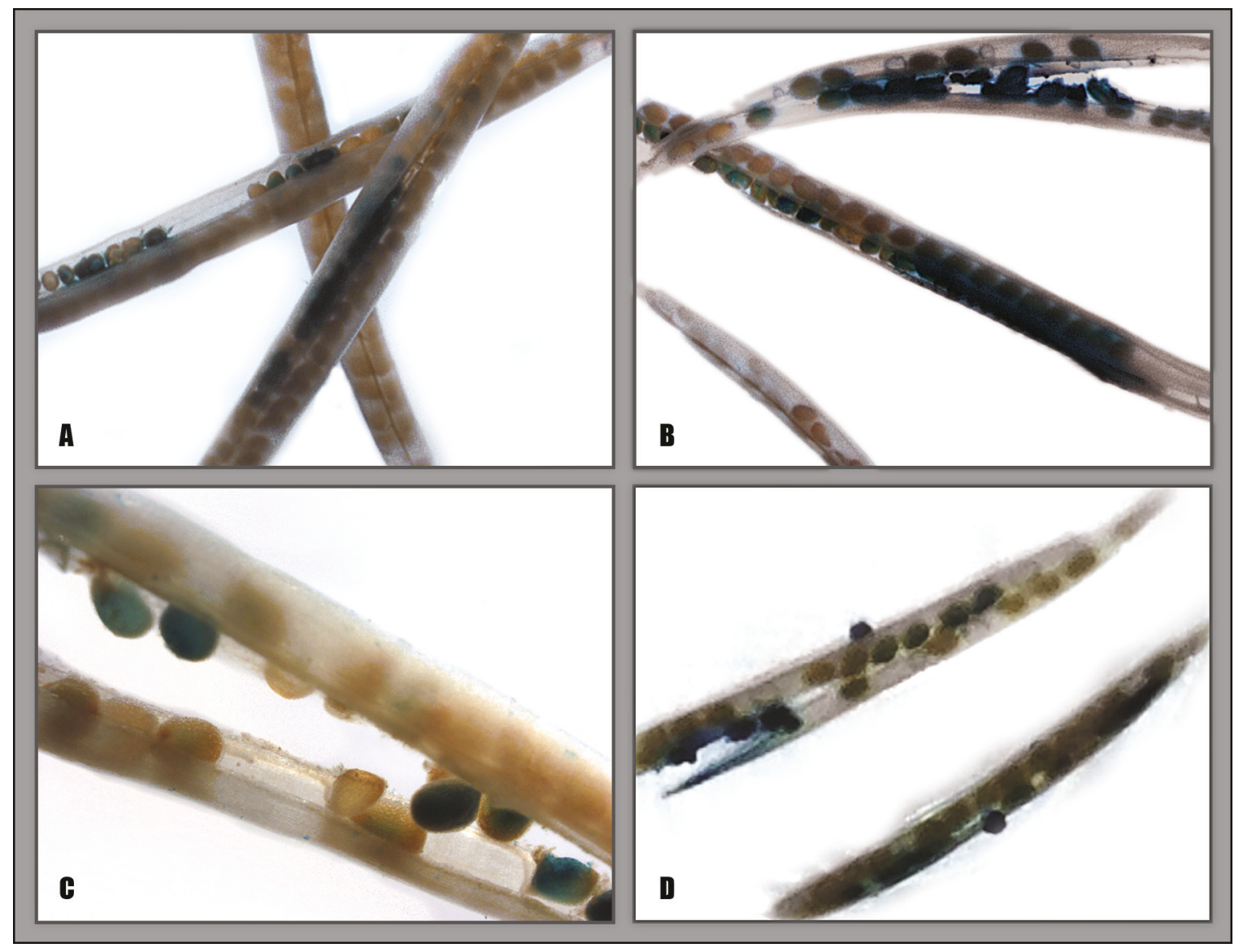

Figure 3.1: Whole mounts of Phaseolin::GUS (A-C) and AtCRU3::GUS (D) transgenic A. thaliana (Col) siliques and seeds stained for GUS activity. Experimental conditions: siliques and seeds were treated with $0.5 \mathrm{mg} / \mathrm{mL} \mathrm{X-Gluc} \mathrm{in} 50 \mathrm{mM} \mathrm{NaPO}_{4}$, $\mathrm{pH}$ 7, $0.5 \mathrm{mM} \mathrm{KFe}(\mathrm{CN})$ and $0.1 \%$ Triton $\mathrm{X}-100$, for $16 \mathrm{hrs}$ at $37^{\circ} \mathrm{C}$. 
Following verification of the ability of the AtCRU3 and phaseolin promoters to direct expression of the GUS reporter gene to A. thaliana seeds, three A. thatiana wild-type $11 \mathrm{~S}$ globulin coding sequences, with the addition of a carboxy-terminal HA tag, were expressed in this model plant species under the AtCRU3 and phaseolin promoters. Immunoblots using anti-HA tag antibodies were performed to determine whether human influenza hemagglutenin tagged $11 \mathrm{~S}$ globulins, expressed under the control of the AtCRU3 and/or phaseolin promoter, accumulate in vivo in A. thaliana seeds. The anti-HA tag antibody does not crossreact with any native protein from wild-type $A$. thaliana soluble seed protein extracts (Figure 3.2 B lane 1, and D lane 5). The $\sim 50-58 \mathrm{kDa}$ proglobulin form of the HA-tagged A. thaliana cruciferins were detected in protein extracts from transgenic lines expressing the introduced coding sequences under the phaseolin promoter but not in those under the AtCRU3 promoter (Figure 3.2). 


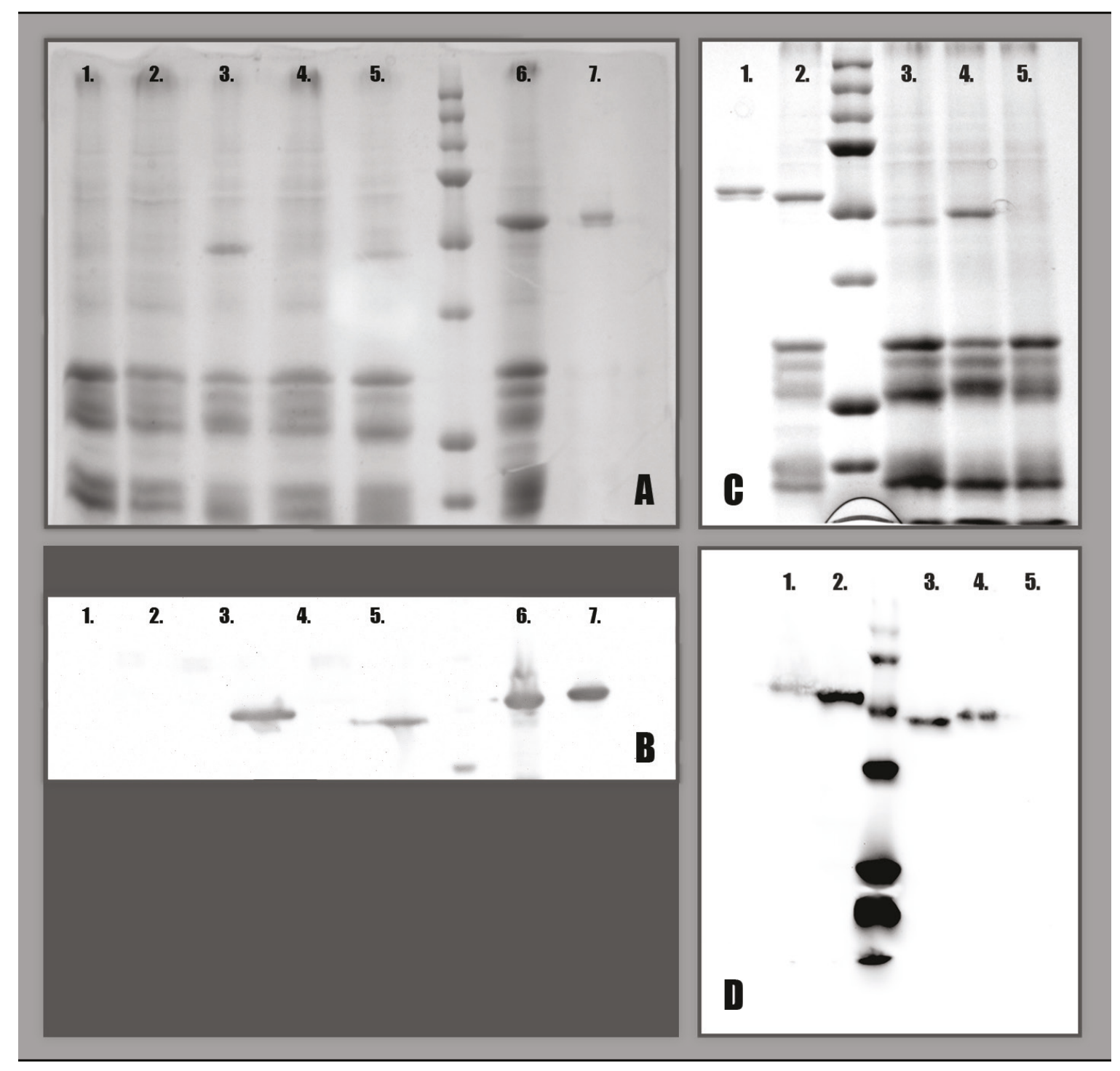

Figure 3.2: Analysis of HA-tagged, AtCRU proteins expressed under the AtCRU3 or Phaseolin promoter in the seeds in transgenic A. thaliana lines. (A and C) SDSPAGE and (B and D) immunoblots of total soluble seed protein extracts from dried A. thaliana seeds from: (A and B lane 1; C and D lane 5) wild-type (Colo); (A and B lane 2) AtCRU3::AtCRU1-HA tag; (A and B lane 3; C and D lane 4) Phaseolin::AtCRU1-HA tag; (A and B lane 4) AtCRU3::AtCRU2-HA tag; (A and B lane 5; C and D lane 3) Phaseolin::AtCRU2-HA tag; (A and B lane 6; C and D lane 2) Phaseolin::AtCRU3-HAtag; and (A and B lane 7; C and D lane 1) HisproAtCRU3-HA tag purified from E. coli. 
The expected protein bands of approximately $20-25 \mathrm{kDa}$ corresponding to the A. thaliana $\beta$ chains, bearing the carboxy-terminal, HA tag, are not observed via the anti-HA tag immunoblot (Figure 3.2). This suggests that the A. thaliana $11 \mathrm{~S}$ globulins with C-terminal HA tags constructed in this study are not fully processed from the stable proglobulin trimers, to produce the $\alpha$ and $\beta$ chains, in mature hexamers. Although previous in vivo studies on $11 \mathrm{~S}$ globulins have detected the mature processed $11 \mathrm{~S}$ globulin, as determined by the presence of $\alpha$ and $\beta$ chains in immunoblots using anti-11S globulin antibodies, the unprocessed proglobulins are also detected (Utsumi et al, 1993; Barba de la Rosa et al, 1996; Jung et al, 1998; Valdez-Ortiz et al, 2005; Wan et al, 2007; Nietzel et al, 2013). The C-terminal HA tag employed in this study may hinder the asparaginyl endopeptidase from accessing the proteolytic site or it may interfere with the vacuolar sorting signal that is present within the C-terminal region of some 11S globulins (Maruyama et al, 2006). The presence of a C-terminal $\mathrm{His}_{6}$-tag on Amaranthus hypochondriacus 11S globulin did not interfere with the processing of the protein to its mature form, which may indicate that it is the sequence or length of HA tag used in this study that impacts processing (Valdez-Ortiz et al, 2005).

Jung and colleagues used an 11S globulin engineered to ensure that it could not be processed into its $\alpha$ and $\beta$ chains to show that stable 11S proglobulins are able to accumulate in vivo without being fully processed into their mature forms (Jung et $a l, 1998)$. The expression system developed in this study verifies the accumulation of $11 \mathrm{~S}$ proglobulins in the seeds of A. thaliana. The work of Jung and colleagues indicates that this expression system will provide the required insights into in vivo stability and accumulation of $11 \mathrm{~S}$ globulins as only stable monomers that can assemble into trimers are able to accumulate in vivo (Jung et al, 1998). 
Chapter 2 describes our work establishing E. coli as a heterologous expression system for 11S globulins and the use of biophysical techniques, such as fluorescencemonitored chemical denaturation, as a means of assessing the in vitro stability of engineered native $11 \mathrm{~S}$ globulins to enable selection of those with the desired properties for expression in vivo. Here we report the development of an in vivo screen for the accumulation of $11 \mathrm{~S}$ globulins in the seeds of the model plant $A$. thaliana. This system drives expression of $11 \mathrm{~S}$ globulin variants in the seed using the seed-specific Phaseolus vulgaris $7 \mathrm{~S}$ globulin (phaseolin) promoter. Immunobloting, using an anti-HA tag antibody that does not crossreact with native seed proteins, enables the specific detection of the expressed $11 \mathrm{~S}$ globulin, which contrasts with previous studies that have used anti-11S globulin antibodies. The two expression systems and selection methods developed in this thesis (Chapter 2 and Chapter 3) are complementary to one another and should be used in concert as a 2-phase screening system to facilitate future protein engineering studies on native seed storage proteins. Such a strategy ensures that only stable variants that accumulate appropriately in vivo will be selected for the resource-intensive step of testing in the target plant species (e.g. soybean or chickpea). 


\section{Chapter 4: Surveying Structural Components of $11 S$ Globulins for Locations Amenable to the Introduction of Methionine Residues.}

\subsection{Abstract.}

11S globulins, the major seed storage proteins in dicot plants, are deficient in the essential amino acid methionine. This study encompassed a comprehensive survey of the cupin domains and hypervariable regions (HVRs) II, III and V of the model $A$. thaliana $11 \mathrm{~S}$ proglobulin, proAtCRU3, to determine locations that are amenable to the introduction of methionine residues, with the goal of building an information platform for subsequent protein engineering studies aiming to alter the amino acid composition of $11 \mathrm{~S}$ globulins. A total of 67 variants with mutations encoding for single, double, triple and quadruple substitutions, and insertions of two or four methionine residues were constructed in this study. The thermodynamic stability of the variants was assessed in vitro via fluorescence-monitored $\mathrm{GnHCl}$ denaturation. The results show that substitution of residues located in the cupin domains of the model proAtCRU3 protein (e.g. V86M, V87M, V86M:V87M, I192M, L268M, V370M, and L268M:V370M) is a viable strategy for adding methionine residue(s) to 11S globulins as these variants retain wild-type stability. Although the HVRs are tolerant of the introduction of methionine residues, via substitution or insertion, single locations in these regions cannot be treated as methionine sinks as the addition of more that two sequential methionine residues results in changes in the stability or unfolding profile of the model 11S globulin. However, the wildtype stability of the quadruple substitution variant Q141M:Q142M:Q160M:Q161M in HVR II demonstrates that the HVRs can accept the addition of more than two methionine residues if they are distributed throughout the region. 
This study demonstrates the efficiency of a 2-phase screening process that selects variants that do not disrupt stability, enabling them to be combined and reassessed in vitro, to identify multiple methionine-enriched variants with wildtype stability prior to testing their ability to accumulate in seeds in vivo. The in vitro component of this 2-phase screen for methionine-enriched variants will therefore enable protein engineering as a viable method of increasing the nutritional value or modifying the physicochemical properties of seeds by reducing the number of variants to test in the more time and resource-intensive in vivo phase of the screen.

\subsection{Introduction.}

The seeds of the legume (Fabaceae) family, which includes Glycine max (soybean), Cicer arietinum (chickpea), Pisum sativum (pea) and Lens culinaris (lentil), have a higher protein content $(\sim 20-40 \%)$ than cereal grains $(\sim 8-15 \%)$ making them an important source of dietary protein (Day, 2013). However, the nutritive value of these important agricultural crops is reduced by their seed amino acid profile. Grain legumes are deficient in methionine, one of the ten essential proteogenic amino acids not synthesized de novo by mammals, according to the requirements for human nutrition since they contain $1.1 \%$ methionine rather than the recommended $3-5 \%$ for daily intake (Tabe and Higgins, 1998; Mandal and Mandal, 2000; Galili and Hofgen, 2002; Hesse et al, 2004). This methionine deficiency stems from the amino acid composition of the major seed storage proteins in these crops, the seed storage globulins (Shewry et al, 1995; TandangSilvas et al, 2010). Seed storage proteins can collectively account for up to $90 \%$ of the protein found within a seed and therefore dictate the amino acid profile therein (Shewry et al, 1995; Tandang-Silvas et al, 2010). 
Mature 11S seed storage globulins, found in the seed protein storage vacuole (PSV), are heterohexamers, which are composed of a pair of trimers (proglobulins) that associate following cleavage of their monomers into the disulfide-linked $\alpha$ and $\beta$ chains (Shutov et al, 2003; Tandang-Silvas et al, 2012). The two conserved disulfide bonds in $11 \mathrm{~S}$ globulins, an intermolecular (IE: between the $\alpha$ and $\beta$ chains) and intramolecular (IA), identify the faces of the trimers and it is the IE face that associate to form the mature hexamer (Adachi et al, 2001; Tandang-Silvas et al, 2012). Prior to proteolytic cleavage in the PSV, by the vacuolar-processing asparaginyl endopeptidase, the $11 \mathrm{~S}$ proglobulins form stable trimers in the lumen of the endoplasmic reticulum (ER), with their monomers associating in a headto-tail orientation through hydrophobic interactions between their cupin domain a-helices (Figure 4.1) (Shutov et al, 2003; Tandang-Silvas et al, 2012). Each 11S globulin monomer is comprised of a pair of cupin domains, a jelly-roll $\beta$-barrel of antiparallel $\beta$-strands followed by a cluster of three $\alpha$-helices, one in each of the $\alpha$ and $\beta$ segments, and contains five hypervariable regions (HVR), I-V, which are present on the molecular surfaces of the 11S proglobulin trimers (Adachi et al, 2001; Utsumi et al, 2002; Shutov et al, 2012) (Figure 4.1). The amino and carboxytermini correspond to HVRs I and V, respectively and regions II-IV are extended loops, of variable length between $11 \mathrm{~S}$ globulins even within the protein family of a given species, that are generally not well defined in available crystal structures. 
Figure 4.1: The structure of a Brassica napus procruciferin (PDB: $3 \mathrm{KGL}$ ). The three subunits (in grey, red and blue) are shown (A) from the IE face of the trimer, (B) in profile with the IE face on top and the IA face on the bottom, and (C) from the IE face of the trimer with the $\alpha$ and $\beta$ chains distinguish such that the $\alpha$ chains are of a darker hue (dark grey, dark blue, and dark red) than the respective $\beta$ chains (light grey, light blue and pink, respectively). The IA and IE disulfide bonds are purple and green, respectively, and are indicated by arrows of the same colour in (A). Hypervariable regions II, III and V are highlighted in green-cyan, yellow and orange, respectively, in monomer A in the context of the trimer (D) and monomer (E). HVR I and IV are disordered in the B. napus crystal structure and therefore not depicted. 


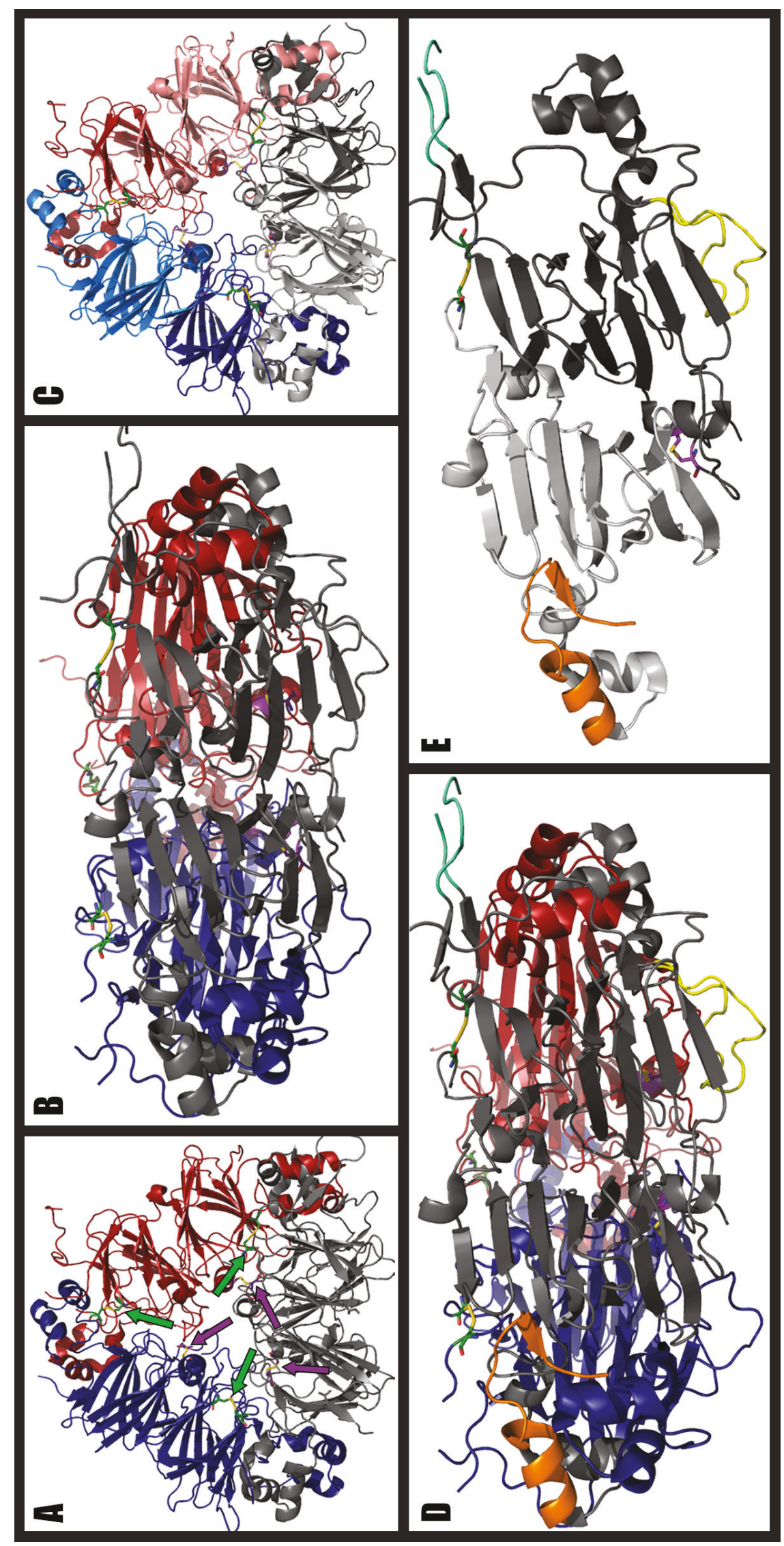


11S globulins from several plant species including soybean (PDB: 2D5H, 1OD5, 1FXZ), Brassica napus (proBcCRU, PDB: 3KGL), and Amaranthus hypochondriacus (PDB: 3QAC) have been successfully expressed in Escherichia coli and the structures of the resulting purified proglobulin trimers have been solved (Medina-Godoy et al, 2004; Tandang et al, 2004; Prak et al, 2005; CarrazcoPena et al, 2013). Although E. coli is devoid of the protease required to process the $11 \mathrm{~S}$ globulins to their mature hexameric state, the heterologously expressed $11 \mathrm{~S}$ proglobulins self-assemble into stable trimers with secondary structures similar to the mature $11 \mathrm{~S}$ globulins (Utsumi et al, 2002). These studies demonstrate the viability of $E$. coli as a heterologous expression system for plant $11 \mathrm{~S}$ proglobulins, providing valuable insight into the properties of these seed storage proteins, which sets the scene for the investigation of the effect of methionine insertions and substitutions on the stability of the resulting variant(s) described in this chapter.

Previous protein engineering studies on the 11 S globulins have generally focused on altering the emulsification properties of these seed protein for downstream food applications rather than increasing their nutritive value and have targeted the HVRs since investigations have shown that they influence the physicochemical and functional properties of the protein (Utsumi et al, 1993; Katsubi et al, 1994; Utsumi et al, 2002; Tandang-Silvas et al, 2011). Two variants of a soybean $11 \mathrm{~S}$ globulin with four sequential methionine residues inserted into either HVR IV or $\mathrm{V}$ can be purified from $E$. coli but undergo nonspecific proteolytic cleavage in Nicotina tabacum leaves and seeds when placed under the cauliflower mosaic virus $35 \mathrm{~S}$ promoter, suggesting that the resulting protein variants are less stable than the wild-type protein (Utsumi et al, 1993; Utsumi et al, 2002). This observation advocates for the effect that mutations have on protein stability to be ascertained prior to in vivo studies. In this manner, new strategies to introduce methionine residues into 11S globulins, which includes identifying locations within the structure 
that are more amenable to substitution or as insertion points, can be developed to more effectively alter the nutritional and physicochemical properties of native seed storage proteins. This study examined the tolerance of the different structural components of the model Arabidopsis thaliana 11S proglobulin (proAtCRU3) to the introduction of methionine residues into $11 \mathrm{~S}$ globulins.

\subsection{Methods and Materials.}

\subsubsection{Reagents.}

Isopropyl- $\beta$-D-thiogalactopyranoside (IPTG), tetracycline and ampicillin were purchased from BioShop; lysozyme from Sigma; and Ni-nitrilotriacetic acid (Ni-NTA) resin from Qiagen. Integrated DNA Technologies (IDT) synthesized the oligonucleotide primers, and BioBasic sequenced the coding sequences of all variants prior to purification. The Origami $E$. coli strain was obtained from Novagen.

\subsubsection{Designing and Constructing Methionine-Enriched proAtCRU3 Variants.}

To identify regions and/or types of mutations (e.g. substitutions or insertions) that can be used to introduce novel methionine residues into the $11 \mathrm{~S}$ globulin seed storage protein family, the model proAtCRU3 coding sequence was surveyed by making methionine-introducing mutations in the $\beta$-barrels and extended $\alpha$-helical regions of the cupin domains and in the hypervariable regions. The HVR I and IV regions were exempted from this study because they are involved in the proteolytic processing of $11 \mathrm{~S}$ globulins into their mature form in vivo. Variants with single,

double, triple and quadruple substitutions, and insertions of two or four methionine residues were designed for hypervariable regions II, III and V. HotSpot Wizard, a 
web-based bioinformatic tool was used to identify highly variable positions within the $11 \mathrm{~S}$ globulin protein sequence, on the premise that these regions may have a greater tolerance for methionine substitutions and/or insertions (Pavelka et al, 2009). The closely related $B$. napus $11 \mathrm{~S}$ proglobulin crystal structure, proBcCRU (PDB: 3KGL), was used as the input for the HotSpot Wizard analysis. Residues identified by HotSpot Wizard as being mutatable and/or where methionine holds that position in proteins related to $11 \mathrm{~S}$ globulins were chosen for substitution to methionine (Table 4.1).

Site-directed mutants of proAtCRU3 were constructed via the overlapextension polymerase chain reaction method using the wild-type proAtCRU3 coding sequence, reported by Jaworski and Aitken, 2014 (section 2.3.2. in Chapter 2 of this thesis), as the DNA template and the resulting amplicons were inserted in between the NdeI and BamHI restriction sites in the pTrc-99aAF expression plasmid, which contains an amino-terminal $\mathrm{His}_{6}$-tag and linker that enables affinity purification (Farsi et al, 2009).

\subsubsection{Expression and Purification of the Methionine-Enriched His- proAtCRU3 Variants.}

Each methionine-enriched His-proAtCRU3 variant was expressed in the Origami (Novagen) E. coli cell line, as described by Jaworski and Aitken (2014; section 2.3.3. in Chapter 2 of this thesis). Batch purifications from $1 \mathrm{~L}$ of culture per methionine-enriched variant were carried out at $4{ }^{\circ} \mathrm{C}$. Frozen cell pellets were resuspended in $\sim 20 \mathrm{~mL}$ buffer $\mathrm{B}$ (50 mM potassium phosphate, $\mathrm{pH} 8,400 \mathrm{mM}$ $\mathrm{NaCl}, 10 \mathrm{mM}$ imidazole) and disrupted by incubation with $1 \mathrm{mg} / \mathrm{mL}$ lysozyme (Sigma) at room temperature for $20 \mathrm{~min}$ followed by sonication (10 cycles of $30 \mathrm{~s}$ at $50 \%$ duty) on ice. The lysed cells were centrifuged at $17000 \mathrm{rpm}$ for $60 \mathrm{~min}$ and $100 \mu \mathrm{L}$ of a 50:50 slurry of Ni-NTA resin (Qiagen) was incubated with the cleared 
lysate for 3 hrs. The resin was collected via centrifugation at $5000 \mathrm{rpm}$ for $10 \mathrm{~min}$, and washed with $600 \mu \mathrm{L}$ of buffer B and then $600 \mu \mathrm{L}$ of buffer C. A series of elutions of increasing stringency was carried out, in buffer B, as follows: $500 \mu \mathrm{l}$ of $100 \mathrm{mM}$ imidazole, $300 \mu \mathrm{l}$ of $200 \mathrm{mM}$ imidazole, $300 \mu \mathrm{l}$ of $300 \mathrm{mM}$ imidazole and $2 \times 350$ $\mu \mathrm{l}$ of $400 \mathrm{mM}$ imidazole. Aliquots from each purification step were analyzed via SDS-PAGE and elutions identified as at least 90\% pure were pooled, and, prior to storage at $-80{ }^{\circ} \mathrm{C}$, were dialyzed against $250 \mathrm{~mL}$ of buffer $\mathrm{D}(50 \mathrm{mM}$ potassium phosphate, $\mathrm{pH} 8,400 \mathrm{mM} \mathrm{NaCl}, 1 \mathrm{mM}$ EDTA, 20\% glycerol, $150 \mathrm{mM}$ imidazole) followed by $500 \mathrm{~mL}(2 \times 250 \mathrm{~mL}$ ) of buffer $\mathrm{E}$ ( $50 \mathrm{mM}$ potassium phosphate, $\mathrm{pH} 8$, $400 \mathrm{mM} \mathrm{NaCl}, 1 \mathrm{mM}$ EDTA, 20\% glycerol). Protein concentrations were measured using the molar extinction coefficient, which was determined using the method described by Pace et al (1995).

\subsubsection{Guanidine Hydrochloride (GdnHCl) Denaturation of His- proAtCRU3 Methionine-Enriched Variants.}

Each procruciferin was incubated at $25^{\circ} \mathrm{C}$ with $\mathrm{o}-4 \mathrm{M} \mathrm{GdnHCl}$ for $18 \mathrm{hrs} \mathrm{in} 50$ $\mathrm{mM}$ potassium phosphate buffer, $\mathrm{pH}$ 8. Fluorescence spectra of the $1 \mu \mathrm{M}$ protein samples were recorded on a Varian spectrofluorimeter in a $1 \mathrm{~cm}$ path-length cuvette at $25{ }^{\circ} \mathrm{C}$ with settings of $\lambda_{\text {ex }}=295 \mathrm{~nm}$ and excitation and emission slit widths of $5 \mathrm{~nm}$. The effect of $\mathrm{GnHCl}$ concentration on the tryptophan fluorescence emission maxima $\left(\lambda_{\max }\right)$ was determined using equation 1, adapted from Aitken and colleagues (2003):

Equation 1:

$$
y=\frac{\mathrm{LL}-\mathrm{UL}}{1+\left([\mathrm{GnHCl}] / C_{\mathrm{m}}\right)^{\mathrm{n}}}+U L
$$

where LL and UL are the minimum and maximum values for $\lambda_{\max }$, the lower and upper plateaus, respectively, of the sigmoidal denaturation plots, $C_{m}$ is the 
chemical denaturation midpoint and $\mathrm{n}$ is the slope of the segment between the lower and upper plateau regions.

\subsection{Results.}

The work described in this chapter encompasses a survey of the various structural components of $11 \mathrm{~S}$ globulins to identify locations amenable to the introduction of methionine residues. This was undertaken to demonstrate both the feasibility of developing methionine-enriched $11 \mathrm{~S}$ globulin variants and the efficiency of the in vitro component of the 2-phase screen (developed in Chapter 2 of this thesis) by constructing 67 methionine-enriched variants and subjecting them to phase I of the screen. To follow the biochemical studies done on the $A$. thaliana $11 \mathrm{~S}$ proglobulin family in Chapter 2, differential scanning flourimetry (DSF) was also preformed on the variants constructed in this chapter. However, the results (data not shown) demonstrated that while DSF is an effective technique for distinguishing variants of the test protein (cystathionine $\beta$-lyase and the series of 17 tryptophan substitution variants constructed in Jaworski and Aitken, 2013, which have a range of thermostabilities that span $5{ }^{\circ} \mathrm{C}$ ), it was not able to differentiate the methionine-enriched proAtCRU3 variants from wild-type. This observation

precluded the use of DSF for screening in this chapter. Consequently, fluorescencemonitored guanidine hydrochloride denaturation was preformed on the variants constructed in this chapter to assess their relative in vitro thermodynamic stability, compared to the wild-type.

Previous protein engineering studies on $11 \mathrm{~S}$ globulins have primarily focused on the HVRs (Utsumi et al, 1993; Utsumi et al, 2002; Tandang-Silvas et al, 2011). A survey of three (II, III and V) of the five HVRs, focusing on those that are not involved in the processing of the $11 \mathrm{~S}$ globulins in vivo, and the cupin domains, was 
preformed in this study to determine sites within the $11 \mathrm{~S}$ globulin structure that are amenable to methionine substitution and/or insertion. Tolerant regions are those where the thermodynamic stability and unfolding profile of the variant is not altered from the wild-type protein, either by lowering 1$)$ the midpoint $\left(C_{m}\right.$ : Figure $\left.4.2 \mathrm{a}\right)$, or 2) the slope (cooperativity: Figure 4.2b) of the transition from the native state to unfolded state in the denaturing curve, compared to the wild-type protein. Variants that reduce the $C_{m}$ reduce stability as they cause the protein to denature at a lower concentration of denaturant than the wild-type whereas those that alter the slope of the transition region reflect a change in the cooperativity of protein unfolding. 
Figure 4.2: Schematic representations of the chemical denaturation of protein variants that alter $\mathrm{A}$ ) the $C_{m}$ and/or B) the cooperativity (slope) of the transition from the native to the unfolded state of the wild-type (black line) protein. Shifting the curve to the left (red line in A) reduces the $C_{m}$, while shifting it to the right (blue line in A) increases it, indicating decreased and increased thermodynamic stability, respectively. Increasing the cooperativity (represented by the green line in B) increases the slope of transition zone indicating that the individual components of the protein are interacting and reacting to the external environment/denaturant as a cohesive unit, which decreases the $\mathrm{x}$-axis span of transition zone. Decreasing the cooperativity (purple line in B), decreases the slope of the transition zone, which signifies a reduction in the synergistic unfolding of the components within the protein and increases the $\mathrm{x}$-axis span of the transition zone. 

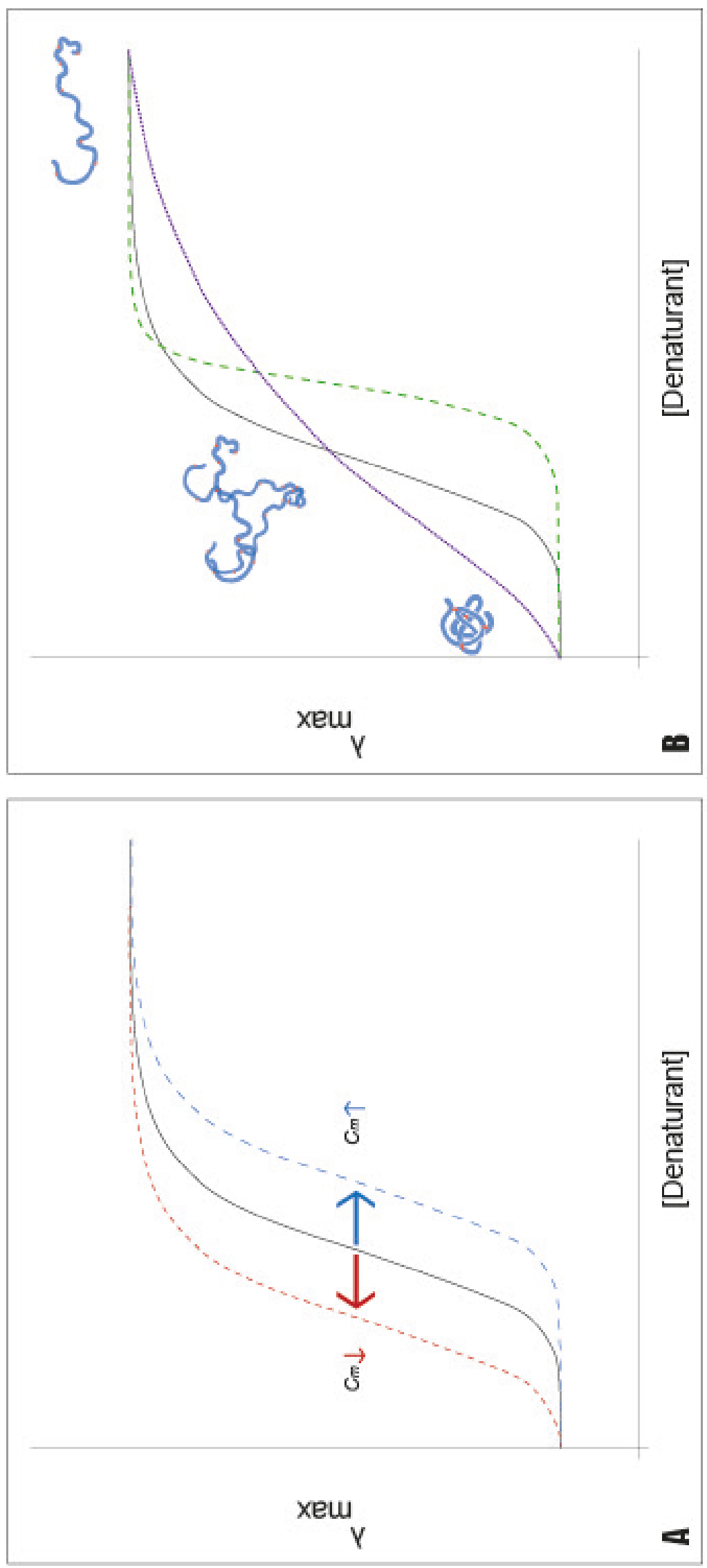
Generally, the effect on stability of single substitutions of mutatable residues, as determined by HotSpot Wizard, within the cupin domains, and double substitutions or insertions of two sequential methionine residues within the HVRs is more subtle than for the introduction of more than two sequential methionine residues (Table 4.1). Variants constructed to have three or more sequential methionine residues at a given location reduce the stability or alter the cooperativity of unfolding of the resulting $11 \mathrm{~S}$ globulin, compared to the wild-type. Four of the ten variants with extended methionine-substitution repeats, those located within the cupin domains (V181M:F182M:A183M:N184M, L200M:V201M:I202M:I203M, V253M:I254M:A255M and V459M:I460M:S461M:N462M), cannot be purified, indicating that the protein does not adopt a stable, folded structure. While the six variants introducing extended methionine repeats into the HVRs were sufficiently stable to purify from E. coli, they reduce the cooperativity of unfolding (Table 4.1).

HotSpot Wizard was used to identify residues in proAtCRU3, which correspond to substitution-tolerant, or mutatable, positions in the proBcCRU structure. The results of this study suggest that residues with higher mutability according to HotSpot Wizard are more accepting of substitution to methionine than those with lower mutability (Table 4.1). Additionally, residues assigned a lower mutability score by HotSpot Wizard but where methionine holds that position in other related proteins, such as L268 and F285 in proAtCRU3, were observed to be tolerant of methionine substitution. 


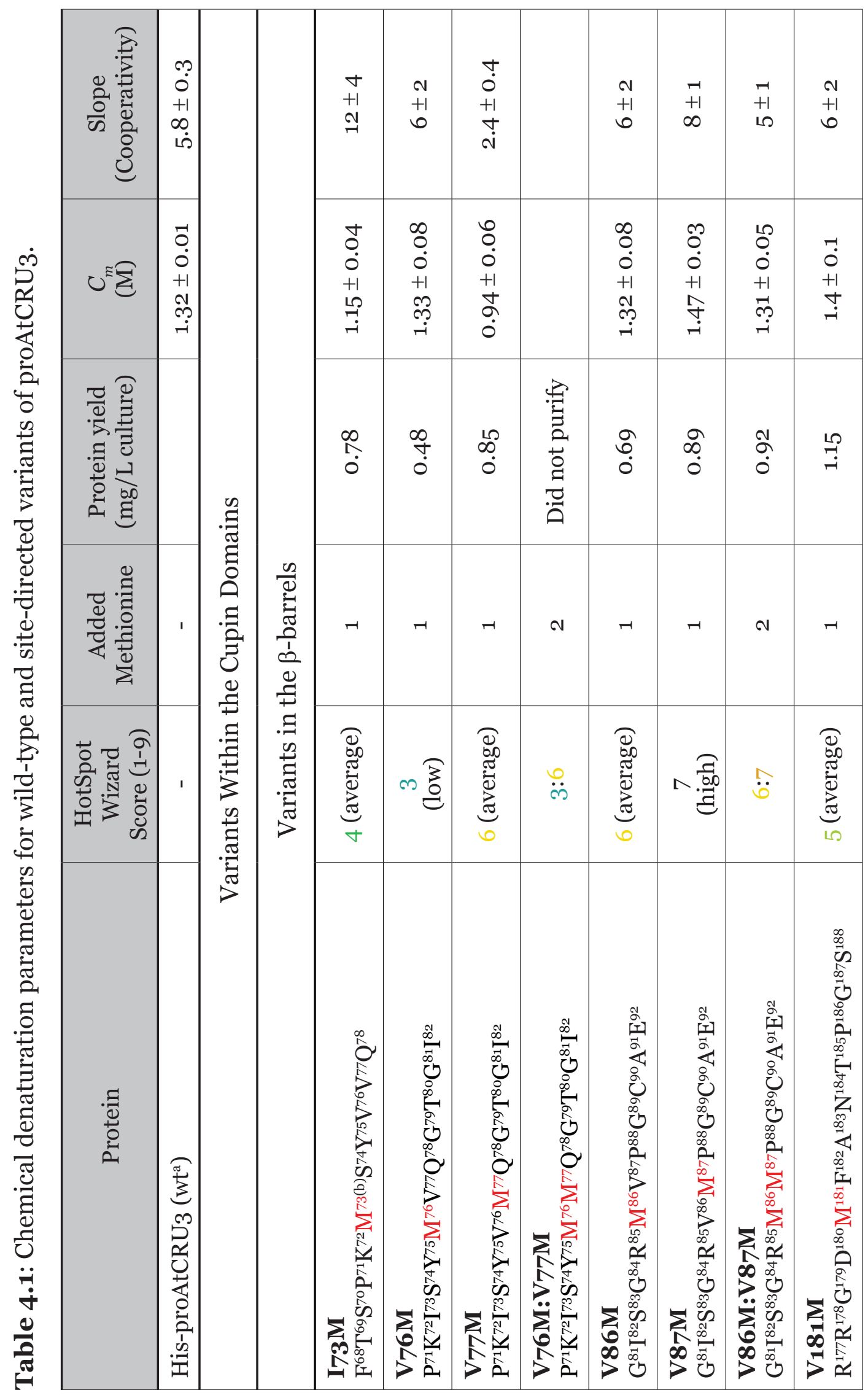




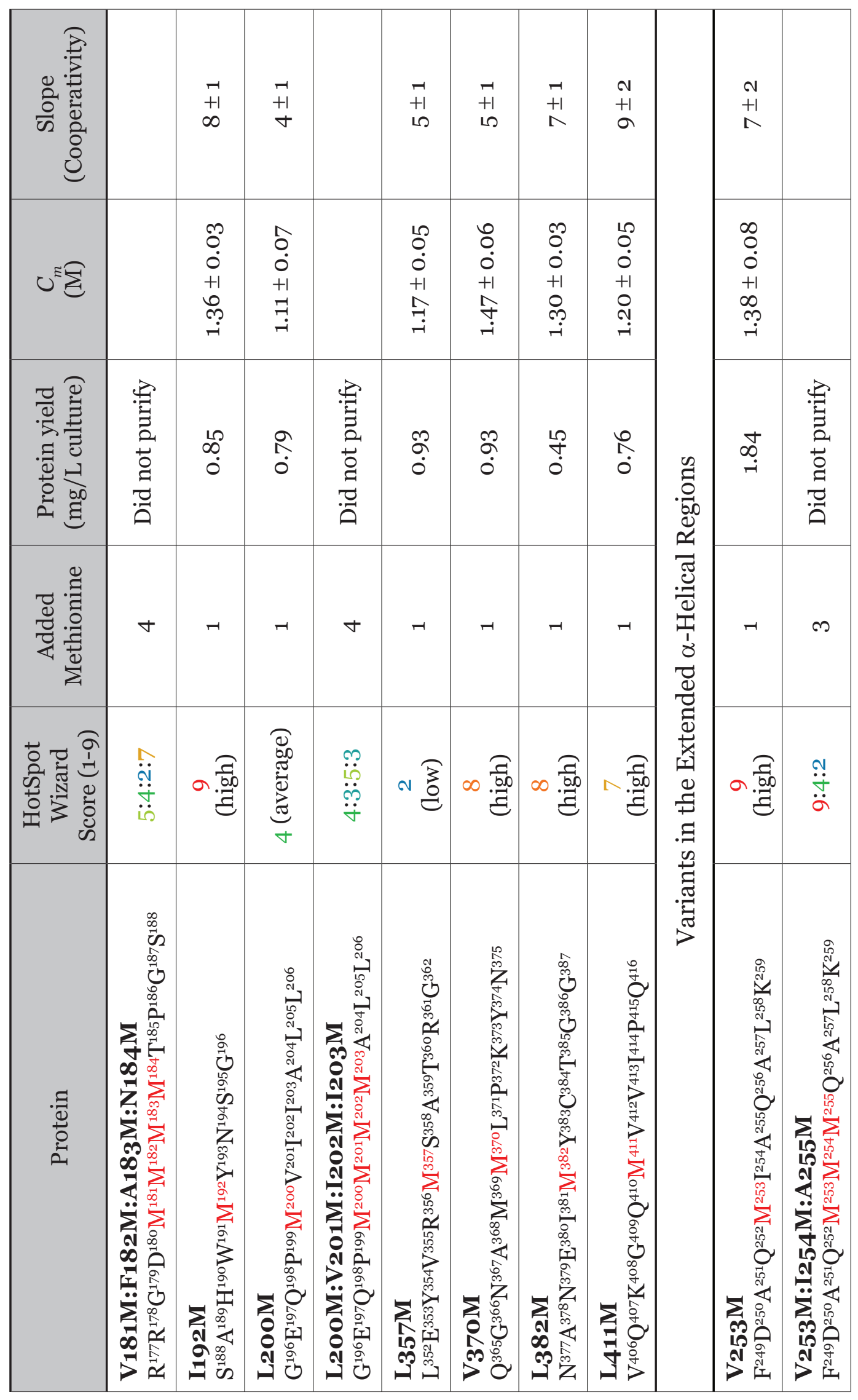




\begin{tabular}{|c|c|c|c|c|c|c|c|c|c|c|}
\hline 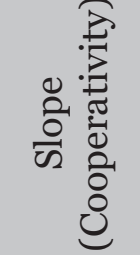 & \begin{tabular}{l}
$\infty$ \\
$\dot{0}$ \\
+1 \\
$m$ \\
\multirow{+}{*}{}
\end{tabular} & $\begin{array}{l}N \\
+1 \\
a\end{array}$ & $\begin{array}{l}\infty \\
+1 \\
\approx \\
\sim\end{array}$ & $\begin{array}{l}0 \\
\dot{0} \\
+1 \\
\infty \\
\dot{\infty}\end{array}$ & & & \multirow{6}{*}{ 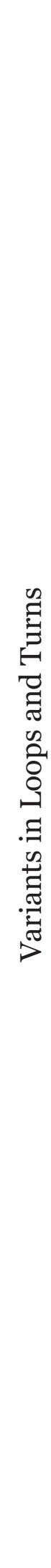 } & $\begin{array}{l}N \\
+1 \\
10\end{array}$ & $\begin{array}{l}7 \\
+1 \\
10\end{array}$ & $\begin{array}{l}\overrightarrow{1} \\
+1 \\
10\end{array}$ \\
\hline$u^{E} \equiv$ & $\begin{array}{l}\hat{0} \\
\dot{0} \\
+1 \\
10 \\
\stackrel{1}{+}\end{array}$ & $\begin{array}{l}0 \\
0 \\
0 \\
+1 \\
0 \\
\stackrel{-}{0}\end{array}$ & $\begin{array}{l}0 \\
0 \\
0 \\
+1 \\
10 \\
0 \\
-1\end{array}$ & $\begin{array}{l}\infty \\
0 \\
0 \\
+1 \\
+1 \\
\stackrel{0}{+} \\
-1\end{array}$ & & & & $\begin{array}{l}\infty \\
0 \\
0 \\
+1 \\
0 \\
\text { ?ి } \\
\text { - }\end{array}$ & $\begin{array}{l}0 \\
0 \\
0 \\
+1 \\
0 \\
\stackrel{1}{+} \\
-1\end{array}$ & 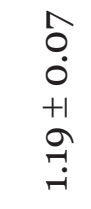 \\
\hline 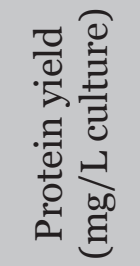 & $\begin{array}{l}\infty \\
\infty \\
0\end{array}$ & 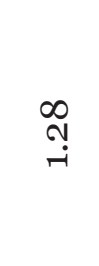 & ஜे & $\underset{0}{\hat{0}}$ & 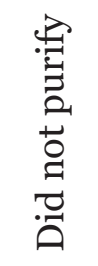 & 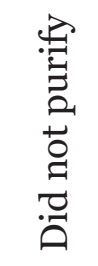 & & $\stackrel{1}{0}$ & $\begin{array}{c}\infty \\
\infty \\
0\end{array}$ & $\hat{\hat{0}}$ \\
\hline 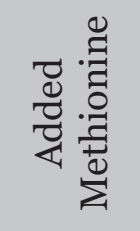 & -1 & -1 & N & -1 & $\tau$ & $\nabla$ & & -1 & $r$ & $-r$ \\
\hline 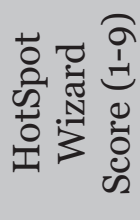 & a. & ๙ & & 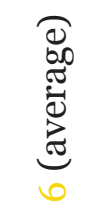 & - 胥 & 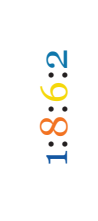 & & $\wedge \stackrel{\frac{\partial}{60}}{.00}$ & N & 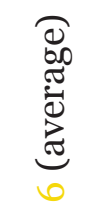 \\
\hline 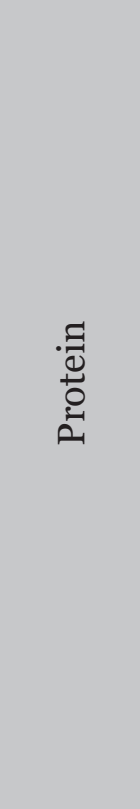 & 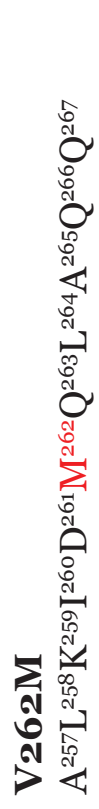 & 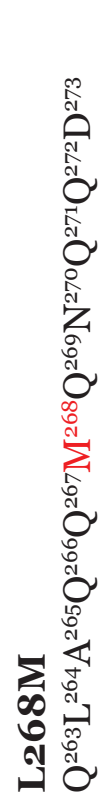 & 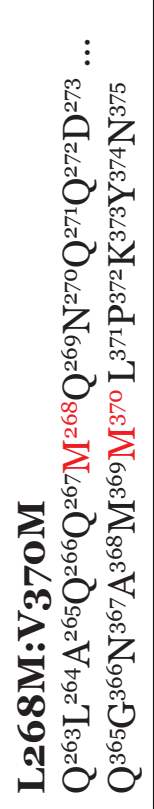 & 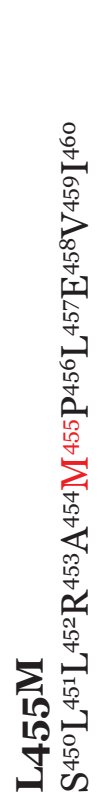 & 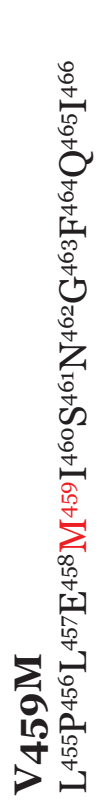 & 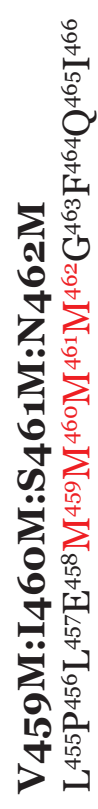 & & 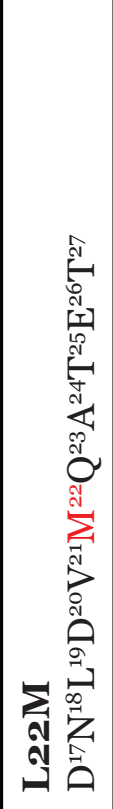 & 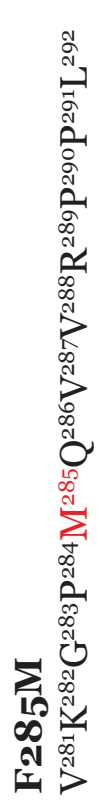 & 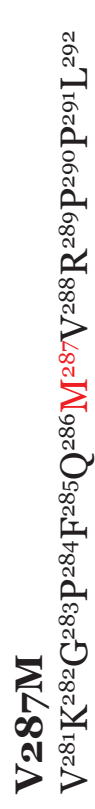 \\
\hline
\end{tabular}




\begin{tabular}{|c|c|c|c|c|c|c|c|c|c|c|}
\hline 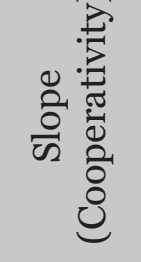 & 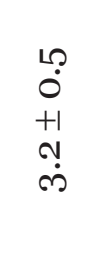 & $\stackrel{-1}{+1}$ & & $\begin{array}{l}N \\
+1 \\
0\end{array}$ & $\begin{array}{l}71 \\
+1 \\
10\end{array}$ & $\stackrel{\overrightarrow{+}}{\stackrel{+}{\Lambda}}$ & $\begin{array}{l}\infty \\
+1 \\
0 \\
-1\end{array}$ & $\begin{array}{l}\text { ? } \\
0 \\
+1 \\
0 \\
\text { i }\end{array}$ & $\begin{array}{l}N \\
+1 \\
a\end{array}$ & $\begin{array}{l}\infty \\
+1 \\
0 \\
-1\end{array}$ \\
\hline$u^{\approx} \sum$ & $\begin{array}{l}0 \\
0 \\
0 \\
+1 \\
ت \\
ت \\
-1\end{array}$ & \begin{tabular}{l}
$\stackrel{2}{0}$ \\
$\dot{0}$ \\
+1 \\
\multirow{2}{+}{} \\
$\stackrel{+}{+}$
\end{tabular} & & $\begin{array}{l}0 \\
0 \\
\dot{0} \\
+1 \\
\stackrel{+}{+} \\
\stackrel{-}{-}\end{array}$ & $\begin{array}{l}10 \\
0 \\
0 \\
+1 \\
-1 \\
\stackrel{-1}{-1}\end{array}$ & $\begin{array}{l}\infty \\
0 \\
0 \\
+1 \\
+1 \\
\stackrel{+}{+} \\
\stackrel{-}{1}\end{array}$ & $\begin{array}{l}\stackrel{0}{0} \\
\stackrel{0}{0} \\
+1 \\
\stackrel{0}{+} \\
\stackrel{-}{+}\end{array}$ & $\begin{array}{l}\infty \\
0 \\
0 \\
0 \\
+1 \\
N \\
0 \\
0 \\
-i\end{array}$ & $\begin{array}{l}0 \\
0 \\
0 \\
+1 \\
10 \\
\stackrel{-}{-}\end{array}$ & $\begin{array}{l}0 \\
0 \\
0 \\
+1 \\
+ \\
\stackrel{+}{-1}\end{array}$ \\
\hline 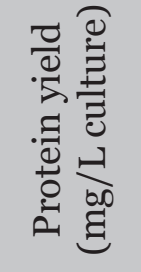 & $\stackrel{+}{\dot{0}}$ & $\stackrel{F}{-}$ & & $\stackrel{+}{\overleftarrow{0}}$ & $\begin{array}{l}+\infty \\
\dot{0} \\
\dot{0}\end{array}$ & $\begin{array}{l}10 \\
\stackrel{1}{\circ}\end{array}$ & $\begin{array}{l}\infty \\
\infty \\
0 \\
0\end{array}$ & $\begin{array}{l}9 \\
1 ? \\
0 \\
0\end{array}$ & $\begin{array}{l}\stackrel{N}{\hat{~}} \\
\dot{0}\end{array}$ & $\stackrel{⿱ 亠}{\stackrel{0}{0}}$ \\
\hline 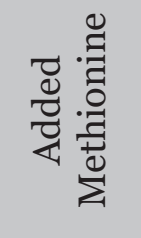 & N & - & 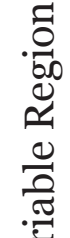 & -1 & - & -1 & N & $\nabla$ & N & N \\
\hline 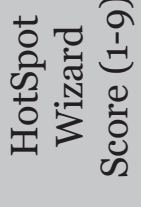 & $\begin{array}{l}\bullet \\
\ddot{ה}\end{array}$ & a & 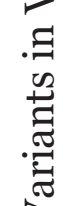 & ' & ๑. & ๑) & $\dddot{\sigma}$ & 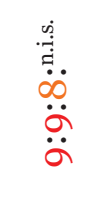 & نُ & \\
\hline 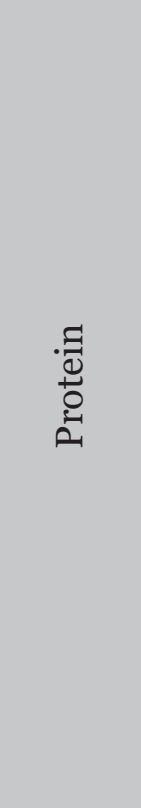 & 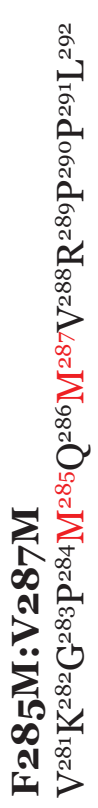 & 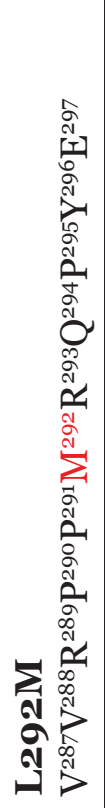 & & 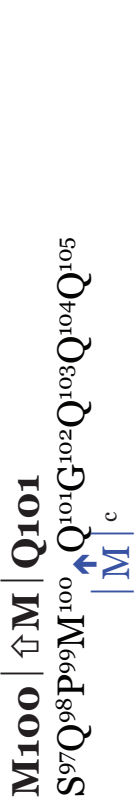 & 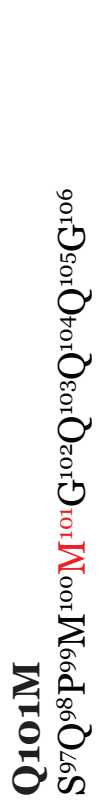 & 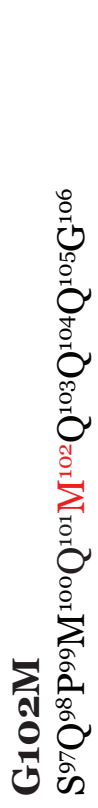 & 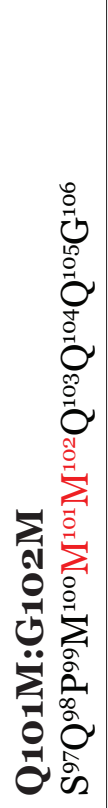 & 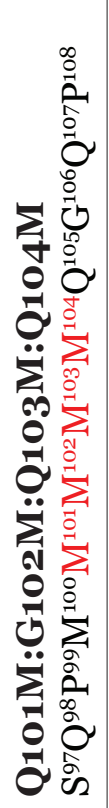 & 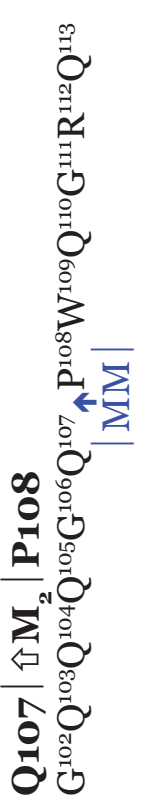 & 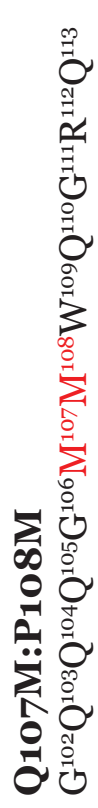 \\
\hline
\end{tabular}




\begin{tabular}{|c|c|c|c|c|c|c|c|c|c|}
\hline 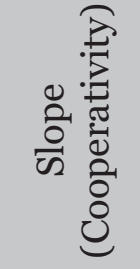 & $\begin{array}{l}7 \\
+1 \\
10\end{array}$ & $\begin{array}{l}N \\
+1 \\
a\end{array}$ & $\begin{array}{l}r \\
+1 \\
0\end{array}$ & & $\begin{array}{l}0 \\
+1 \\
a\end{array}$ & $\begin{array}{l}N \\
+1 \\
\forall\end{array}$ & $\begin{array}{l}-1 \\
+1 \\
0\end{array}$ & $\begin{array}{l}\infty \\
\dot{0} \\
+1 \\
n \\
\dot{1}\end{array}$ & $\begin{array}{l}\vec{T} \\
+1 \\
\text { N }\end{array}$ \\
\hline$u^{\approx} \Xi$ & $\begin{array}{l}0 \\
0 \\
0 \\
+1 \\
+1 \\
\stackrel{+}{+}\end{array}$ & \begin{tabular}{l}
$\dot{J}$ \\
$\dot{0}$ \\
$\dot{0}$ \\
+1 \\
\multirow{2}{*}{} \\
$\stackrel{+}{+}$
\end{tabular} & $\begin{array}{l}\hat{0} \\
0 \\
0 \\
+1 \\
+ \\
\stackrel{+}{-}\end{array}$ & & $\begin{array}{l}10 \\
0 \\
0 \\
+1 \\
0 \\
10 \\
-1\end{array}$ & $\begin{array}{l}-1 \\
0 \\
+1 \\
10 \\
-1\end{array}$ & \begin{tabular}{l}
\multirow{0}{0}{} \\
0 \\
+1 \\
10 \\
$\stackrel{0}{-1}$ \\
-1
\end{tabular} & 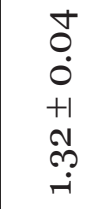 & $\begin{array}{l}\dddot{m} \\
0 \\
+1 \\
\dddot{r} \\
\ddot{r}\end{array}$ \\
\hline 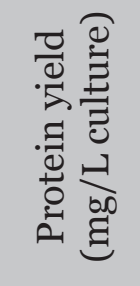 & $\begin{array}{l}0 \\
\stackrel{0}{0} \\
0\end{array}$ & $\stackrel{-1}{+}$ & $\stackrel{\leftrightarrow}{0}$ & & $\begin{array}{l}D^{-1} \\
\dot{0}\end{array}$ & $\stackrel{N}{N}$ & 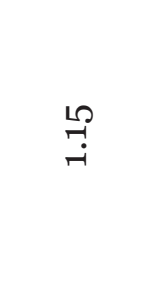 & $\underset{\text { ஜ }}{\mathscr{r}}$ & $\begin{array}{l}\stackrel{0}{+} \\
\dot{0}\end{array}$ \\
\hline 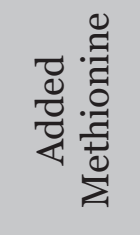 & $\nabla$ & N & N & 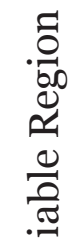 & N & $N$ & $N$ & $N$ & $\nabla$ \\
\hline 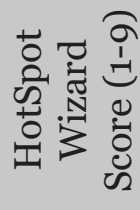 & تُ & \multicolumn{2}{|c|}{ 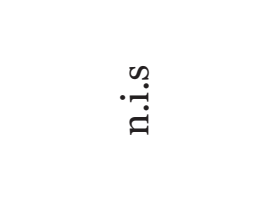 } & 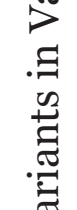 & \multicolumn{2}{|c|}{ 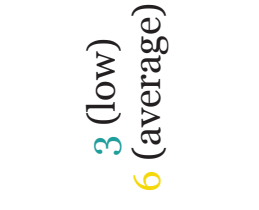 } & \multicolumn{2}{|c|}{ 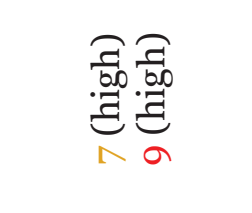 } & $\begin{array}{l}\ddot{\leftrightarrow} \\
\ddot{\ddot{n}} \\
\ddot{m}\end{array}$ \\
\hline 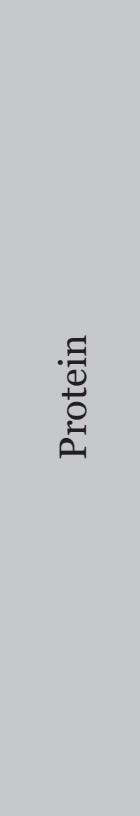 & 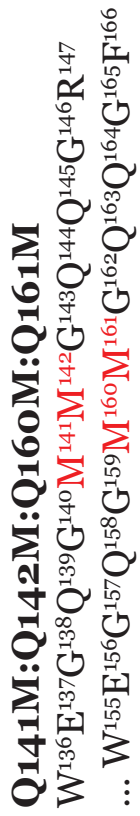 & 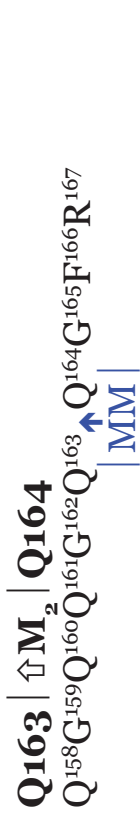 & 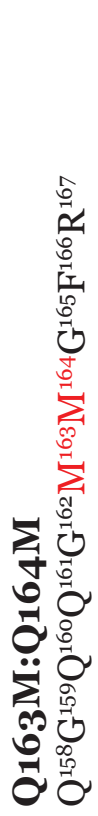 & & 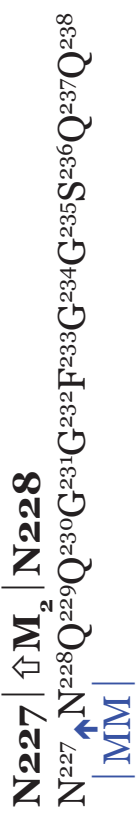 & 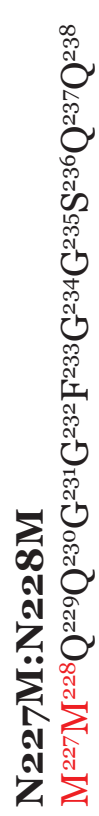 & 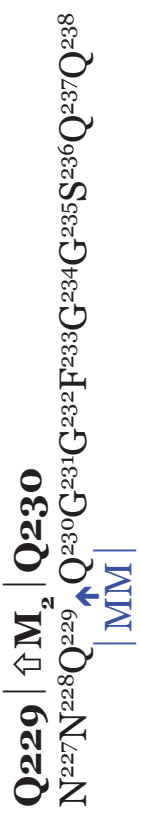 & 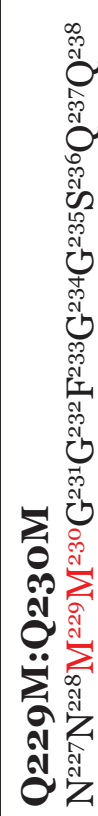 & 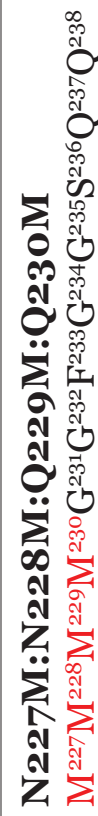 \\
\hline
\end{tabular}




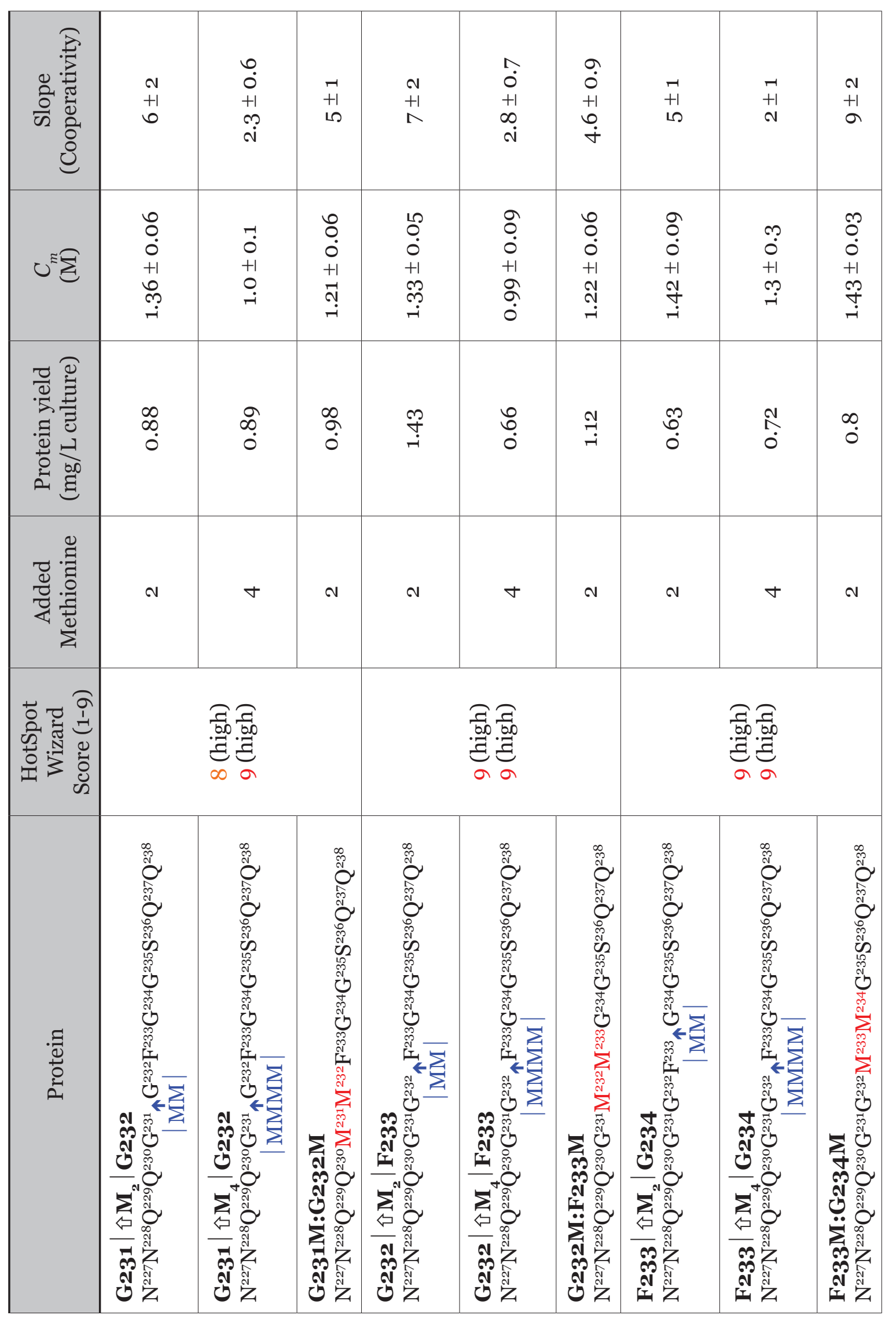




\begin{tabular}{|c|c|c|c|c|c|c|c|c|c|}
\hline 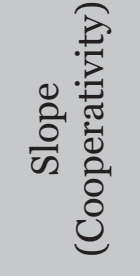 & $\begin{array}{l}10 \\
0 \\
+1 \\
10 \\
i \\
i\end{array}$ & $\begin{array}{l}+1 \\
+1 \\
n\end{array}$ & $\begin{array}{l}\tilde{H} \\
\mathrm{~N}\end{array}$ & $\begin{array}{l}0 \\
\dot{0} \\
+1 \\
0 \\
\dot{\sigma}\end{array}$ & $\begin{array}{l}+1 \\
+ \\
\forall\end{array}$ & $\begin{array}{c}N \\
+1 \\
0\end{array}$ & $\begin{array}{l}a \\
0 \\
+1 \\
0 \\
\dot{m}\end{array}$ & $\begin{array}{l}9 \\
\dot{0} \\
+1 \\
0 \\
\dot{\sigma}\end{array}$ & $\begin{array}{l}\infty \\
0 \\
+1 \\
\infty \\
\dot{N} \\
\dot{N}\end{array}$ \\
\hline$u^{\approx} \Xi$ & $\begin{array}{l}\stackrel{+}{0} \\
0 \\
+1 \\
\stackrel{-1}{-1}\end{array}$ & $\begin{array}{l}-1 \\
0 \\
+1 \\
\text { vִ } \\
\text { r. }\end{array}$ & 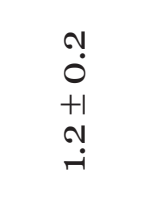 & $\begin{array}{l}0 \\
\circ \\
\dot{0} \\
+1 \\
\mathscr{0} \\
\stackrel{+}{+} \\
\stackrel{+}{1}\end{array}$ & 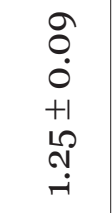 & 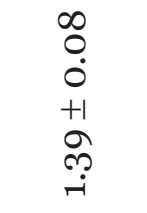 & $\begin{array}{c}\infty \\
0 \\
0 \\
+1 \\
+1 \\
-1 \\
\\
-1\end{array}$ & 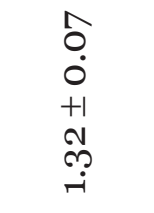 & $\begin{array}{l}-1 \\
0 \\
+1 \\
\stackrel{+}{+}\end{array}$ \\
\hline 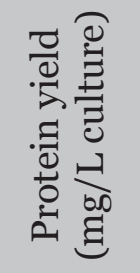 & $\begin{array}{l}\infty \\
10 \\
0 \\
0\end{array}$ & $\begin{array}{l}10 \\
1 ? \\
0\end{array}$ & $\stackrel{+1}{+}$ & $\begin{array}{l}\stackrel{0}{0} \\
\dot{0}\end{array}$ & $\begin{array}{l}0 \\
0 \\
\end{array}$ & $\begin{array}{c}\infty \\
\dot{0} \\
\dot{0}\end{array}$ & مُ & ঙे & $\hat{0}$ \\
\hline 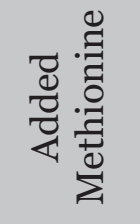 & $\nabla$ & $\nabla$ & 6 & $N$ & N & N & N & N & N \\
\hline 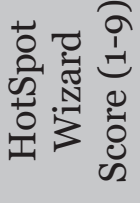 & $\begin{array}{l}a \\
a \\
\infty\end{array}$ & $\begin{array}{l}\stackrel{9}{\sigma} \\
\ddot{\sigma} \\
\ddot{\infty}\end{array}$ & $\begin{array}{l}a \\
a \\
a \\
\infty\end{array}$ & \multicolumn{2}{|c|}{ 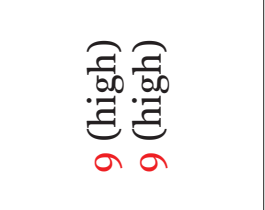 } & \multicolumn{2}{|c|}{ 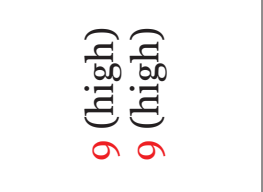 } & \multicolumn{2}{|c|}{ 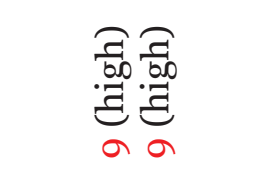 } \\
\hline . & 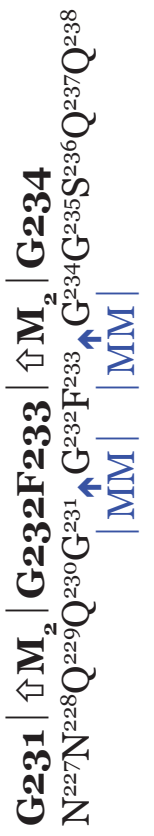 & 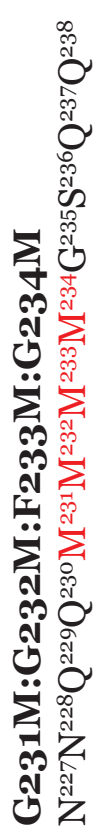 & 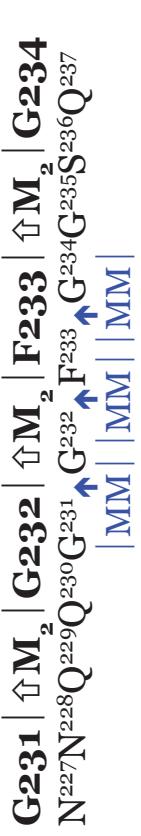 & 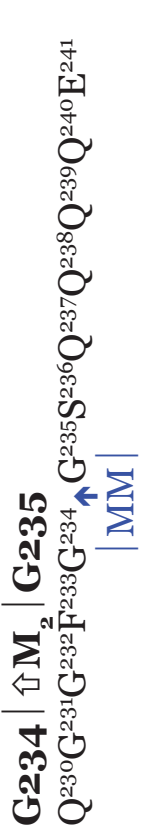 & 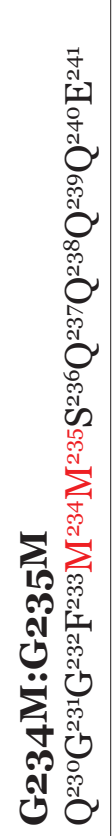 & 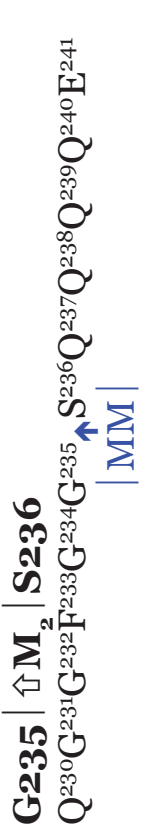 & 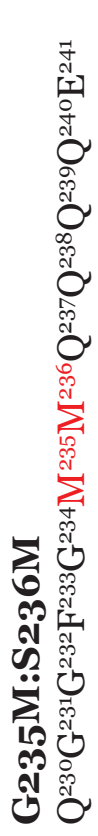 & 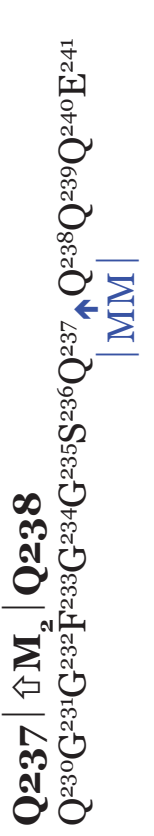 & 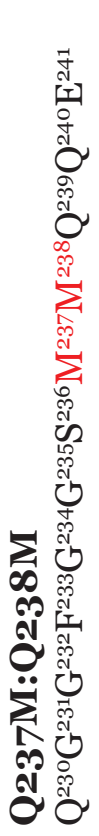 \\
\hline
\end{tabular}




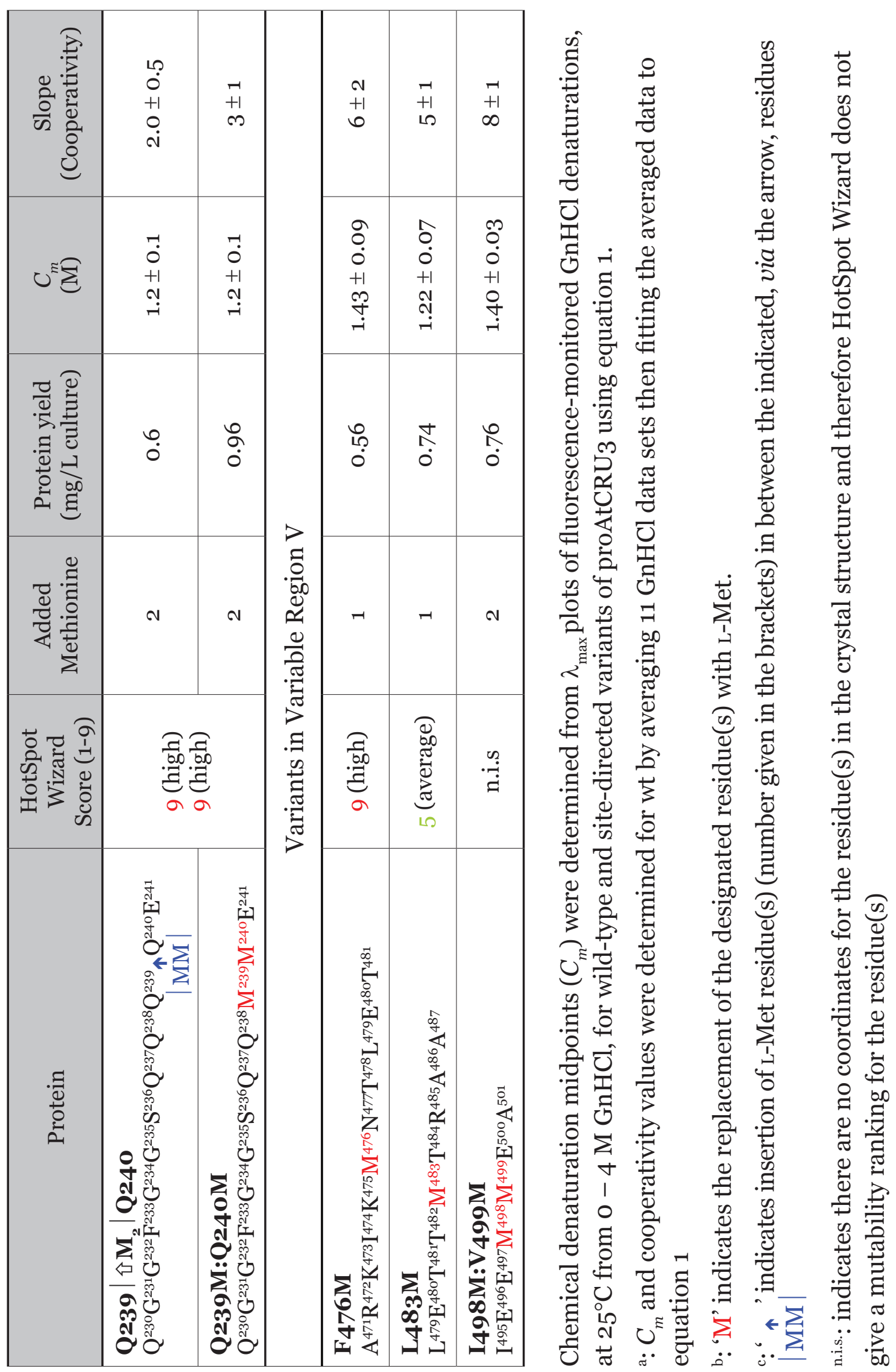




\subsubsection{Variants Within the Cupin Domains.}

Single substitution variants that were designed within the cupin domains of proAtCRU3 yield several stable methionine-enriched variants, assessed by the similarity of their unfolding parameters to the wild-type protein, including V86M, V87M, V181M, I192M, L268M, V370M, L292M and L382M (Table 4.1). Combining pairs of a selection of these variants also produce stable double substitution variants, V86M:V87M and L268M:V370M (Figure 4.3). Interestingly, the V87M, I192M, L268M, L268M:V370M and L292M substitution variants are more stable than wild-type proAtCRU3, having greater $C_{m}$ and cooperativity values (Table 4.1). In contrast, variants introducing extended sequential methionine residues within the $\beta$-barrel or $\alpha$-helical regions of the protein, including V181M:F182M:A183M:N184M and V253M:I245M:A255M, which extend the stable V181M and V253M single substitution variants, respectively, destabilize the native folded structure sufficiently to preclude purification (Table 4.1). 
Figure 4.3: The effect of $\mathrm{GnHCl}$ concentration on the tryptophan fluorescence emission maxima $\left(\lambda_{\max }\right)$ of wild-type proAtCRU3 and methionine substitution variants located in the cupin domains. Panels A-C: The relative locations of the residues in Brassica napus procruciferin (PDB: $3 \mathrm{KGL}$ ) corresponding to proAtCRU3 V370 (red in A and B) and L268 (light blue in B and C) are illustrated. The IA and IE disulfide bonds are purple and green, respectively, and HVR II, III and V are highlighted in green-cyan, yellow and orange, respectively (in panels A-C). Panel D: $\mathrm{GnHCl}$ denaturation of $1 \mu \mathrm{M}$ wild-type His-proAtCRU3 (black) and the L268M (blue), V370M (red) and L268M:V370M (purple) site-directed variants. 


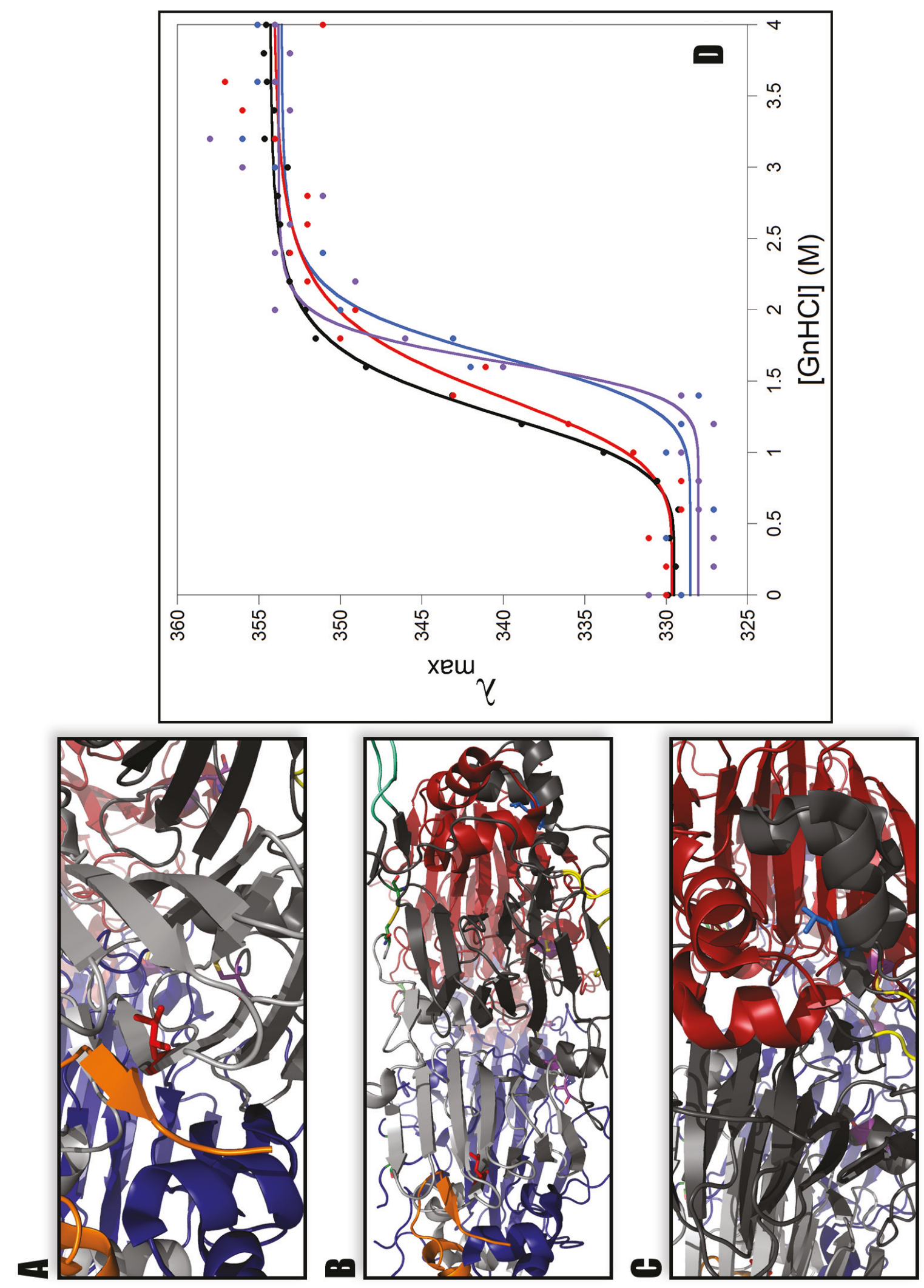


In general, the $\beta$-barrels within the cupin domains are more receptive to methionine substitution than the $\alpha$-helices (Table 4.1), although substituting L268, which is located in the third $\alpha$-helix of the $\mathrm{N}$-terminal cupin domain at the core of the hydrophobic interactions between the $\alpha$-helices of monomers a and b (Figure 4.3a), with methionine increases the $C_{m}$ and cooperativity by $30 \%$ and $55 \%$, respectively. The results suggest that, within the context of the $\beta$-barrels of the cupin domains, residues situated within the $\beta$-strands and positioned so their side chains face inside the $\beta$-barrel, such as V76, I192, V370 and L382, can be substituted to methionine without reducing the stability of the variant (Figure 4.4). In contrast, substitution of $\beta$-strand residues with side chains facing the solvent, such as I73 and V77, results in a reduction of the $C_{m}$ value by $13 \%$ and $30 \%$ respectively (Table 4.1 and Figure 4.4). 
Figure 4.4: The effect of $\mathrm{GnHCl}$ concentration on the tryptophan fluorescence emission maxima $\left(\lambda_{\max }\right)$ of wild-type proAtCRU3 and methionine substitution variants located within the $\beta$-strands of the $\beta$-barrels that comprise the cupin domains. Panel A: The relative locations of the residues in Brassica napus procruciferin (PDB: $3 \mathrm{KGL}$ ) that correspond to proAtCRU3 I73 (red), V76 (dark blue), V77 (orange), I192 (blue), V370 (purple-blue) and L382 (light blue) are illustrated. The IA and IE disulfide bonds are purple and green, respectively, and HVR II, III and V are highlighted in green-cyan, yellow and orange, respectively. Panels B and C: $\mathrm{GnHCl}$ denaturation of $1 \mu \mathrm{M}$ wild-type His-proAtCRU3 (black) with site-directed variants in Panel B: I192M (blue) and L382M (light blue); and Panel C: I73M (red) and V77M (orange). 

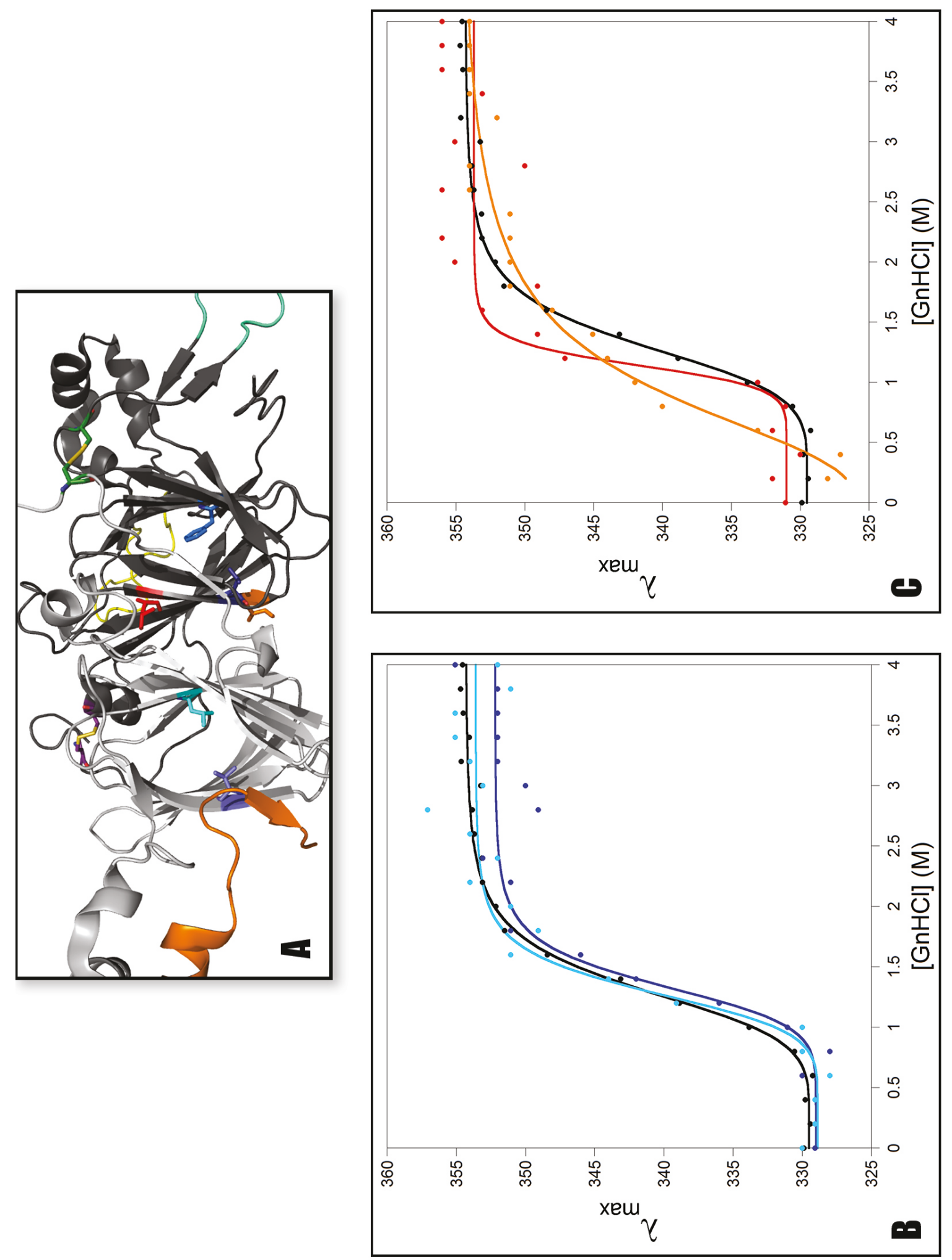


\subsubsection{Variants Within the Hypervariable Regions.}

The three HVRs investigated in this survey are amenable to the majority of the single and double substitution and insertion mutations tested, as demonstrated by the observation that 20 of the 29 variants exhibit near wild-type unfolding parameters. Generally, insertions of two methionine residues in HVR II and III were observed to impact stability to a lesser degree than double substitutions in the same locations (Table 4.1). For example, Q107 $\left|\uparrow M_{2}\right| \mathrm{P} 108$ in HVR II and G231 $\mid$ 仓 $\mathrm{M}_{2} \mid \mathrm{G} 232$ and G235 $\mid$ 仓 $\mathrm{M}_{2} \mid \mathrm{S} 236$ in HVR III have higher $C_{m}$ values, $\sim 10-$ 25\%, than their double substitution counterparts Q107M:P108M, G231M:G232M and G235M:S236M.

Although methionine residues can be introduced, via substitution or insertion, into HVRs II, III and V of the $11 \mathrm{~S}$ globulins, these regions should not be considered as methionine sinks, for the addition of strings of sequential methionine residues. The addition of more than two sequential methionine residues in the investigated HVRs cause the denaturation profile of the resulting proAtCRU3 variant to shift, compared to the wild-type, due to a reduction in the cooperativity for all six extended sequential methionine variants tested (Table 4.1). For example, while the single and double substitution variants Q101M, G102M and Q101M:G102M retain the wild-type denaturation profile, the quadruple substitution variant Q101M:G102M:Q103M:Q104M reduces $C_{m}$ by $23 \%$ and cooperativity by $55 \%$ (Figure 4.5). Separating the insertion of multiple methionine residues by one or two native residues, as in the $G 231\left|\imath \mathrm{M}_{2}\right| \mathrm{G} 232\left|\imath \mathrm{M}_{2}\right| \mathrm{F} 233\left|\imath \mathrm{M}_{2}\right| \mathrm{G} 234$ and G231 $\left|\uparrow \mathrm{M}_{2}\right| \mathrm{G} 232 \mathrm{~F} 233\left|\uparrow \mathrm{M}_{2}\right| \mathrm{G} 234$ variants, respectively, did not alleviate this issue, for the combinations tested. Although the $C_{m}$ values of the double insertion variants between residues G231 to G234 are similar to the wild-type

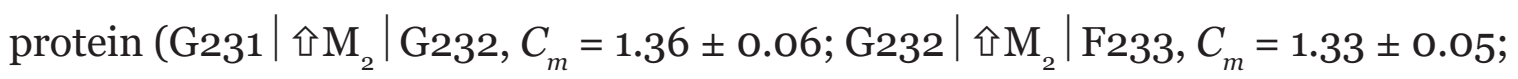
F233 $\mid$ 仓 $\mathrm{M}_{2} \mid \mathrm{G} 234, C_{m}=1.42 \pm 0.09$, Figure 4.6a), thoseofthequadrupleand hextuple 


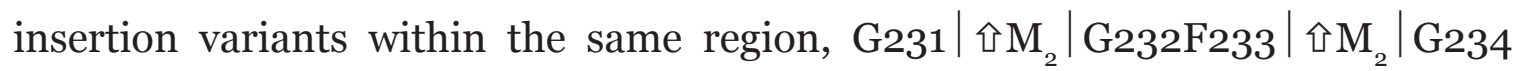
and $\mathrm{G} 231\left|\imath \mathrm{M}_{2}\right| \mathrm{G}_{232}\left|\imath \mathrm{M}_{2}\right| \mathrm{F} 233\left|\imath \mathrm{M}_{2}\right| \mathrm{G} 234$, are reduced by $17 \%$ and $10 \%$, respectively (Figure 4.6b). In contrast, four methionine residues were inserted into a single HVR, via the quadruple substitution variant Q141M:Q142M:Q16oM:Q161M, which is in essence a double two-methionine substitution variant, without reducing the stability or cooperativity of proAtCRU3 (Figure 4.7). This differs from the Q101M:G102M:Q103M:Q104M quadruple sequential substitution variant in the same HVR (HVR II), which reduces the stability and cooperativity of the protein, demonstrating that the HVRs can accept more than two novel methionine residues but suggests that methionine pairs should not be adjacent to one another. 
Figure 4.5: The effect of $\mathrm{GnHCl}$ concentration on the tryptophan fluorescence emission maxima $\left(\lambda_{\max }\right)$ of wild-type proAtCRU3 and a sequential series of methionine substitution variants (Q101M, G102M, Q101M:G102M and Q101M:G102M:Q103M:Q104M) located in HVR II. Panel A: The relative locations of HVR II (illustrated in green-cyan), the IA and IE disulfide bonds (in purple and green, respectively) and HVR III and V (in yellow and orange, respectively) in Brassica napus procruciferin (PDB: 3KGL) are illustrated. Panels B and C: $\mathrm{GnHCl}$ denaturation of $1 \mu \mathrm{M}$ wild-type His-proAtCRU3 (black) with site-directed variants in Panel B: Q101M (blue) and G102M (red); and Panel C: Q101M:G102M (purple) and Q101M:G102M:Q103M:Q104M (grey). 


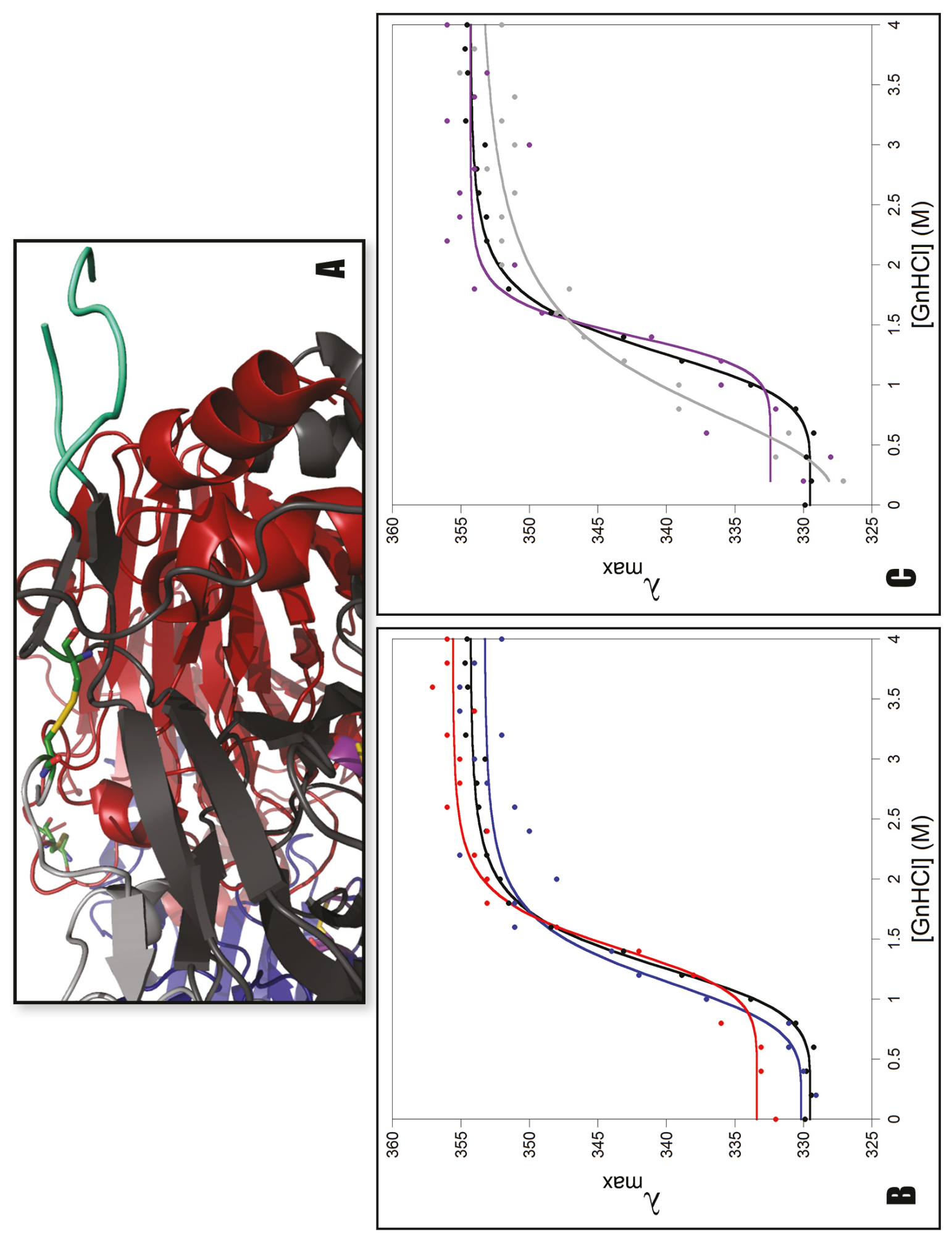


Figure 4.6: The effect of $\mathrm{GnHCl}$ concentration on the tryptophan fluorescence emission maxima $\left(\lambda_{\max }\right)$ of wild-type proAtCRU3 and double, quadruple and hextuple methionine insertion variants located in HVR III. Panel A: The relative locations of HVR III (illustrated in yellow), the IA and IE disulfide bonds (in purple and green, respectively) and HVR II and V (in green-cyan and orange, respectively) in Brassica napus procruciferin (PDB: $3 \mathrm{KGL}$ ) are illustrated. Panels $\mathrm{B}$ and $\mathrm{C}$ : $\mathrm{GnHCl}$ denaturation of $1 \mu \mathrm{M}$ wild-type His-proAtCRU3 (black) with sitedirected variants in Panel B: G231 $\left|\uparrow \mathrm{M}_{2}\right|$ G232 (red), G232 $\left|\uparrow \mathrm{M}_{2}\right|$ F233 (blue), and

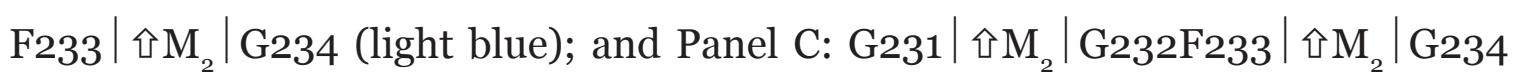
(purple) and G231 $\left|\uparrow M_{2}\right| G 232\left|\uparrow M_{2}\right| F 233\left|\uparrow M_{2}\right| G 234$ (orange). 

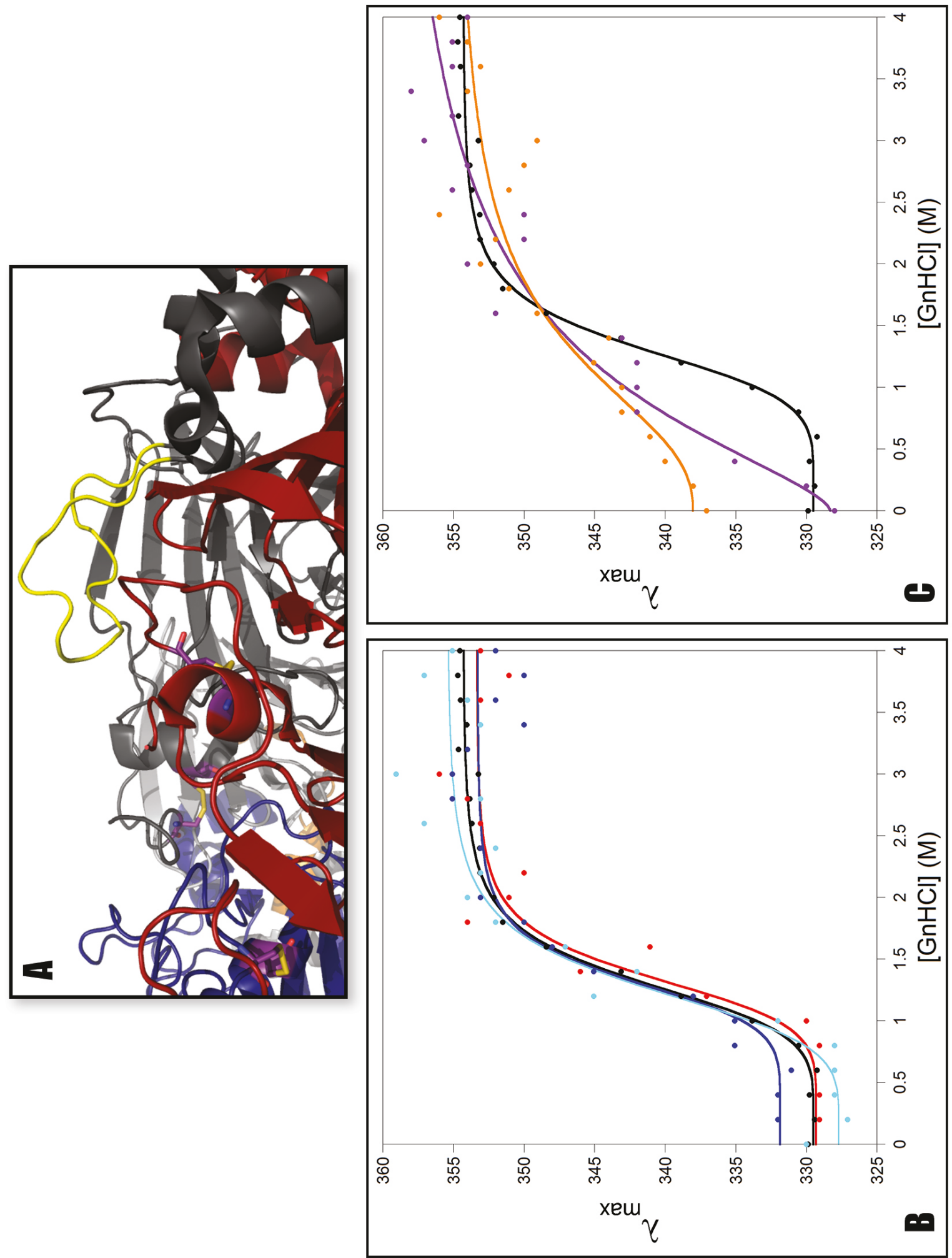

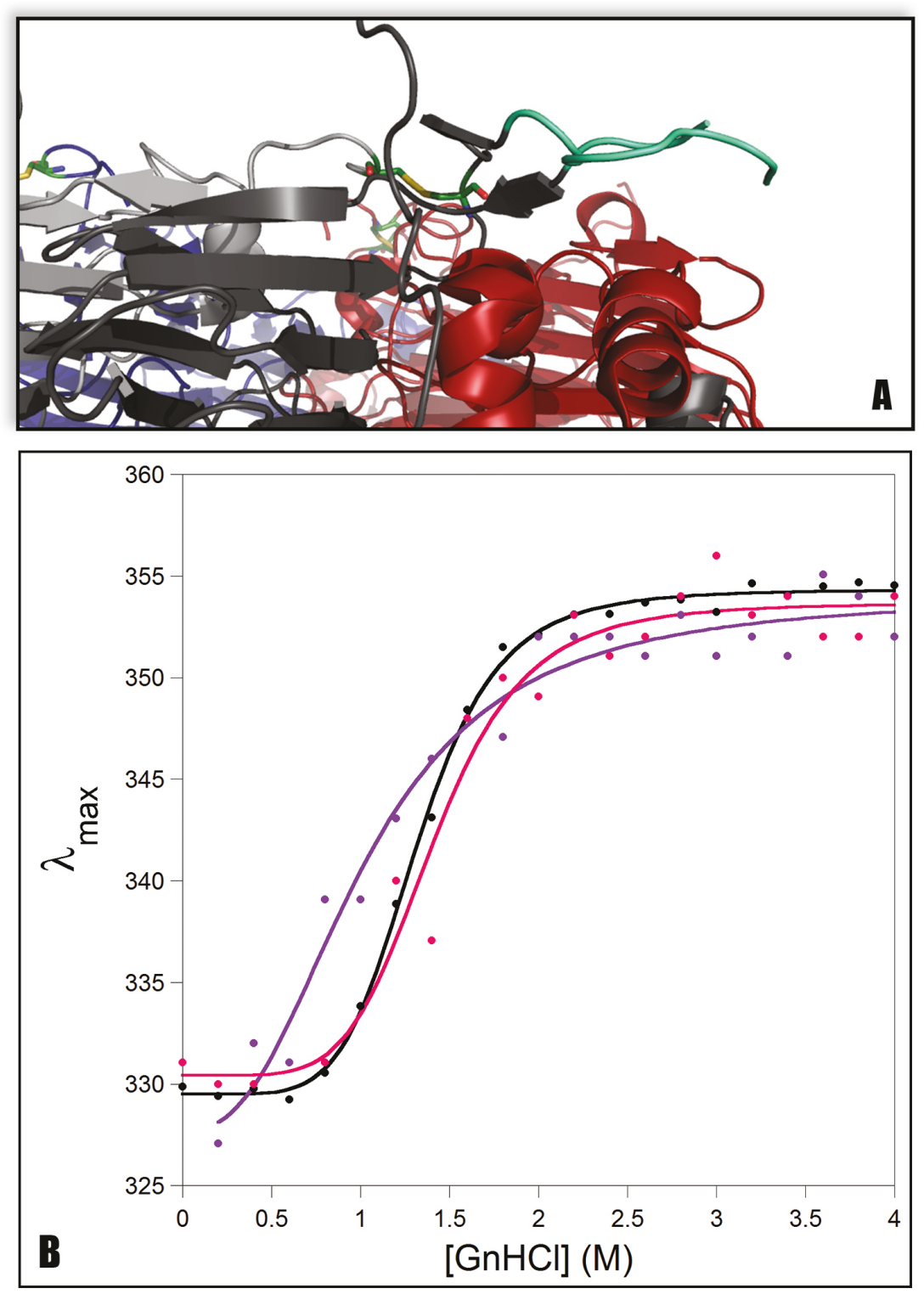

Figure 4.7: The effect of $\mathrm{GnHCl}$ concentration on the tryptophan fluorescence emission maxima $\left(\lambda_{\max }\right)$ of wild-type proAtCRU3 and the two quadruple methionine substitution variants constructed in HVR II. Panel A: The relative locations of HVR II (illustrated in green-cyan), the IA and IE disulfide bonds (in purple and green, respectively) and HVR III and V (in yellow and orange, respectively) in Brassica napus procruciferin (PDB: $3 \mathrm{KGL}$ ) are illustrated. Panel B: $\mathrm{GnHCl}$ denaturation of $1 \mu \mathrm{M}$ wild-type His-proAtCRU3 (black) and Q101M:G102M:Q103M:Q104M (purple) and Q141M:Q142M:Q16oM:Q161M (pink) site-directed variants. 


\subsection{Discussion.}

Seed storage proteins can account for up to $90 \%$ of the protein in a seed and as such the major seed storage protein(s) of a given crop dictate the physicochemical properties of their seed protein extracts and their nutritional value, with respect to amino acid content (Shewry et al, 1995; Tandang-Silvas et al, 2010). The $11 \mathrm{~S}$ globulins dominate the protein content of seeds from the agriculturally important legume and mustard families and therefore are regarded as key targets for improving the physicochemical properties, such as emulsification and gelling, and the nutritional value, with respect to amino acid content, of these crops (Muntz et al, 1998; Mandal and Mandal, 2000). Previous protein engineering studies have primarily focused on altering the physicochemical properties of the $11 \mathrm{~S}$ globulins for downstream food applications rather than increasing their nutritive value. Consequently, these studies have focused on engineering the HVRs, which are situated on the molecular surfaces of the $11 \mathrm{~S}$ proglobulin trimer, to optimize the surface hydrophobic:hydrophilic ratio in order to increase the emulsification and gelling properties (Kim et al, 1990; Utsumi et al, 1993; Katsube et al, 1994; Utsumi et al, 2002; Carrazco-Pena et al, 2013). Improvements in these physicochemical properties were achieved by inserting four sequential methionine residues into HVR IV and V. However, the resulting variants are destabilized and undergo nonspecific proteolytic cleavage when transiently expressed in tobacco leaves and seeds, suggesting they would not accumulate effectively in the seed (Kim et al, 1990; Utsumi et al, 1993; Tabe and Higgins, 1998). As this example illustrates, a key factor that has limited the success of protein engineering studies on $11 \mathrm{~S}$ globulins: insufficient accumulation of the engineered protein variants in vivo due to their improper folding and/or reduced stability, compared to the native protein (Galili and Amir, 2013). 
This investigation focused on surveying regions within the 11S globulin structure (three of the five HVRs (II, III and V), avoiding those involved in the proteolytic processing in vivo, and the cupin domains) in order to increase the knowledge base on these seed storage proteins to facilitate future protein engineering studies, with the goal of increasing their nutritive value and/or other value-added properties, such as emulsification. A heterologous $E$. coli expression system and in vitro fluorescence-monitored chemical denaturation studies were used to screen variants to identify sites that are amenable to methionine substitution and/or insertion. This in vitro screen permits the rapid assessment of the methionine-enriched $11 \mathrm{~S}$ globulin. It enables identification of variants with the desired properties, which ultimately reduces the number of variants for assessment of accumulation in the seeds of the model plant species A. thaliana in the more resource-intensive in vivo phase of the screen (described in chapter 3 of this thesis), prior to testing the optimized methionine-enriched variants in the plant species of interest. Demonstrating the feasibility and efficiency of the in vitro component of this twophase screen, by putting 67 variants through the screen, in combination with the results of the survey assessing the tolerance of the model proAtCRU $311 \mathrm{~S}$ globulin to a wide range of methionine substitution and insertion variants, forms a foundation for future protein engineering strategies with the goal of developing methionineenriched 11S globulins that are not diminished in stability and therefore able to accumulate appropriately in vivo.

The results of this investigation demonstrate that the introduction of point substitution(s) within the $11 \mathrm{~S}$ globulin cupin domains can be a successful strategy to introduce methionine residue(s) into the protein as several stable single substitution variants were identified, including V86M, V87M, V181M, I192M, L268M, V370M, L292M and L382M (Table 4.1). A pair of double substitution variants, created by combining successful single substitutions, that retain wild- 
type stability (e.g. V86M:V87M and L268M:V370M) were also identified. This indicates that the successive addition of successful substitutions can be viable and would provide the means for introducing multiple methionine residues into $11 \mathrm{~S}$ globulins, which is required to increase the methionine content of these proteins to a nutritionally significant level. The results of this survey also demonstrate that the location of the substitution(s) must be strategically selected as there are a number of single methionine substitution variants that destabilize the protein (e.g. I73M, V77M, L357M and V459M). Using HotSpot Wizard in conjunction with available structural data proved to be a successful strategy for short-listing residues as targets for substitution to methionine in 11S globulins (Table 4.1).

Residues indicated by HotSpot Wizard as having a high mutability index were demonstrated to be more amenable to substitution to methionine than those with lower mutability. For example, residues in proBcCRU corresponding to proAtCRU3 I192, L292, V370 and L382 were assigned higher mutability rankings than I73, L357 and V459, and their substitution to methionine maintains wild-type stability. In contrast, the substitution of I73 and L357 with methionine reduces $C_{m}$ by $\sim 10 \%$ and $\mathrm{V} 459 \mathrm{M}$ is destabilized to the point that it is not stable enough to be expressed in and purified from E. coli (Table 4.1). However, positions assigned a lower mutability rating by HotSpot Wizard but are occupied by methionine in the sequences of related proteins, such as residues L268 and F285 in proAtCRU3, retain wild-type stability as they are likely specifically tolerant of methionine substitution (Table 4.1). This observation underlines the value of the amino acid alignment component of the HotSpot Wizard analysis for the selecting residue(s) as targets for substitution by a specific amino acid, methionine in this case.

The methionine substitution and insertion survey described in this study also demonstrates that the location of the target residue within the cupin domains 
and the packing of its side chain are important considerations when selecting target regions and/or residue(s) for methionine introduction. This is due to the conservation of residues required for packing of the hydrophobic core, as observed for other model proteins (Godoy-Ruiz et al, 2005). For example, substitution of cupin-domain residues given the same mutability ranking by HotSpot Wizard (e.g.: V77 and V86, V87 and L411, and V253 and V262; Table 4.1) yielded variants with differing effects on stability. Although these residues were assigned a common mutability and are situated in the same relative position within the structure (in a $\beta$-strand that comprises a $\beta$-barrel or in the $\alpha$-helical region of the cupin domain), the location with respect to side chain packing differs. For example, both V77 and L411 are situated in the $\beta$-barrels so that their side chains face the solvent filled space in between the two $\beta$-barrels and their substitution to methionine reduces the stability of the protein. Alternatively, V86 and V87, are buried in a hydrophobic environment, packing against an $\alpha$-helix in the adjacent monomer and a loop, respectively, and retain wild-type stability (Table 4.1). Similarly, V262 is solvent exposed and its substitution to methionine reduces the cooperativity by $25 \%$ but V253, which packs against a $\beta$-barrel in the adjacent monomer, retains wild-type stability. Therefore, this study demonstrates that methioninesubstitution of residues with buried side chains, such as I192 (in the $\beta$-barrel of the a chain (Figure 4.4a)), L268 (in the hydrophobic cleft created by the $\alpha$-helices of neighboring monomers (Figure 4.3b,c)) and V370 (in the $\beta$-barrel of the $\beta$ chain (Figure $4.3 \mathrm{a}, \mathrm{b})$ ) retains or improves stability by, 10-30\%, compared to the wildtype (Table 4.1). Conversely, substitution of solvent-exposed residues, such as I73 and $\mathrm{V} 77$, to methionine decreases the cooperativity and $C_{m}$ of unfolding of the resulting variants by 13 and $28 \%$, respectively (Figure 4.4 ).

The five HVRs of the 11S globulins are hydrophilic and generally coincide with the disordered regions in available $11 \mathrm{~S}$ proglobulin structures (Tandang-Silvas et 
al, 2010; Tandang-Silvas et al, 2012). The limited structural data available for the HVRs suggests that they are extended mobile loops situated at the IA (HVR I and III) and IE (HVR II and IV) faces, and the side (HVR V) of the trimer (Figure 4.1) (Adachi et al, 2001; Adachi et al, 2003; Tandang-Silvas et al, 2010). Since HVR I contains the signal peptide cleavage site and HVR IV includes the proteolytic cleavage site for the vacuolar-processing asparaginyl endopeptidase and spans the IE face of the proglobulin trimer to prevent hexamer formation prior to proteolytic cleavage to form the $\alpha$ and $\beta$ chains, these regions were not investigated in this study in order to avoid interfering with $11 \mathrm{~S}$ globulin processing when moving forward into the in vivo phase of screening in future studies. The introduction of methionine residues into the three remaining HVRs, II, III and V, via single and double substitutions and double insertions was demonstrated to be a successful strategy for engineering $11 \mathrm{~S}$ globulins. In this study, 29 such variants were constructed, of which 20 exhibit near wild-type stability and unfolding profiles (Table 4.1). The results of this study suggest that the HVRs are more accepting of insertions of two methionine residues, meaning they do not impact the stability or unfolding profiles of the variant to the same extent as double substitutions do in the same locations. For example, the Q107 $\left|\uparrow \mathrm{M}_{2}\right| \mathrm{P} 108$ in HVR II, and G231 $\left|\uparrow \mathrm{M}_{2}\right| \mathrm{G}_{232}$ and G235 $\left|\uparrow \mathrm{M}_{2}\right|$ S236 double-methionine insertion variants targeting HVR III have higher $C_{m}$ values than their double substitution counterparts, Q107M:P108M, G231M:G232M and G235M:S236M (Table 4.1). This may be because insertions of two methionine residues does not alter the hydrophobic:hydrophilic ratio of these surface exposed regions to the same extent as double substitution variants, which replace hydrophilic residues. Utsumi and colleagues noted that increasing the hydrophobicity of the $11 \mathrm{~S}$ globulin surface within localized regions tends to destabilize the protein, likely by inducing aggregation (Utsumi et al, 2002). The understanding of the substitution tolerance of the HVRs provided by this detailed 
survey will be useful for future engineering studies endeavoring to increase the nutritional value and/or to alter the hydrophobic:hydrophilic ratio of the molecular surfaces of $11 \mathrm{~S}$ globulins to increase the emulsification of protein extracts (Kim et al, 1990).

In addition to surveying sites in $11 \mathrm{~S}$ globulins that are amenable to methionine substitution and/or insertion, this work investigated the number of methionine residues that can be sequentially introduced at a given location. Insertions and/ or substitutions of multiple sequential methionine residues easily permit rapid addition of multiple methionine residues into the protein. However, the results of this study support previous engineering studies on $11 \mathrm{~S}$ globulins indicating that the introduction of strings of multiple, sequential methionine residues are generally not tolerated as they destabilize the resulting variant (Table 4.1, Utsumi et al, 1993; Utsumi et al, 2002; Carrazco-Pena et al, 2013). Ten variants with three or four sequential methionine residues introduced into HVR II, HVR III, the $\alpha$-helical regions or $\beta$-strands that compose the $\beta$-barrels of the cupin domains were characterized in this study and all reduce the stability or change unfolding profile of the resulting variant, compared to the wild-type protein (Table 4.1). The four variants in which multiple adjacent methionine residues were introduced into the cupin domains are destabilized to the point of precluding purification, suggesting that they may have impacted the efficient packing of the hydrophobic core. The six variants introducing strings of methionine residues into the HVRs reduce the cooperativity of unfolding by $50-60 \%$ (Table 4.1). The observed reductions in their cooperativity and stability are likely due to the creation of a hydrophobic patch on the molecular surface of the trimer that may result in increased aggregation, compared to the wild-type protein (Utsumi et al, 2002). In contrast, the Q141M:Q142M:Q160M:Q161M double twomethionine substitution variant in HVR II demonstrates that HVRs can accept the introduction of more than two methionine residues. This suggests that the spacing 
of introductions within the HRV is a factor to consider as separating the addition of two methionine residues by 19 amino acids yields a variant that retains wild-type stability (Table 4.1, Figure 4.7) but separating the insertions by only one or two residues does not, as exemplified by the G231 $\left|\imath \mathrm{M}_{2}\right| \mathrm{G}_{232}\left|\imath \mathrm{M}_{2}\right| \mathrm{F} 233\left|\imath \mathrm{M}_{2}\right| \mathrm{G} 234$ and $\mathrm{G} 231\left|\imath \mathrm{M}_{2}\right| \mathrm{G} 232 \mathrm{~F} 233\left|\imath \mathrm{M}_{2}\right| \mathrm{G} 234$ variants (Table 4.1, Figure 4.6). The differences in stability between these three variants suggest that the introduction of a series of double methionine insertions and/or substitutions, spanning the HVRs may be a viable strategy for increasing the methionine content of $11 \mathrm{~S}$ globulins. This strategy could be used to address both the physicochemical properties and nutritive values inadequacies of the $11 \mathrm{~S}$ globulins. Multiple methionine residues need to be introduced to increase their content to a nutritional significant level, which this strategy provides. Also, to increase the emulsification properties of $11 \mathrm{~S}$ globulins, the hydrophilic:hydrophobic ratio on the molecular surfaces must be altered to increase the amount of hydrophobic residues therein, which, this study suggests, can be addressed by introducing a series of double methionine insertions and/or substitutions that span the HVRs (Kim et al, 1990; Tandang-Silvas et al, 2011).

\subsection{Concluding Remarks.}

Previous protein engineering studies on $11 \mathrm{~S}$ globulins have focused on inserting strings of sequential methionine residues into HVR IV and V with the goal of increasing the molecular surface hydrophobicity in order to improve the emulsification and gelling properties of these proteins for downstream food applications (Kim et al, 1990; Tandang-Silvas et al, 2011; Utsumi et al, 1993; Utsumi et al, 2002; Carrazco-Pena et $a l$, 2013). In contrast, the comprehensive survey of the cupin domains and HVRs (II, III and V) of the model A. thaliana 11S globulin described in this chapter, including the assessment of the thermodynamic stability of 67 methionine-enriched variants, enables a comparative assessment of their tolerance (e.g. number of sequential methionine 
residues) of methionine introduction. This creates an information platform to facilitate subsequent protein engineering studies focusing on increasing the nutritive value and/ or altering the physicochemical properties of $11 \mathrm{~S}$ globulins. The understanding of the suitability and tolerance of the cupin domains and HVRs towards the introduction of methionine residues provided by this detailed survey is vital to focus future protein engineering studies on identifying combinations of successfully methionine-enriched variants, described in this chapter, that do not disrupt wild-type stability prior to testing them in native $11 \mathrm{~S}$ globulins of more agriculturally relevant species.

While the use of HotSpot Wizard facilitated the selection assessment of target sites for methionine substitution or insertion, the results of the fluorescence-monitored unfolding study demonstrate the importance of assessing the thermodynamic stability of the methionine-enriched $11 \mathrm{~S}$ globulin variants in vitro. The in vitro screen enables identification of variants with near wild-type properties in order to avoid selecting variants that are likely to be degraded and not accumulate in vivo. The results of this survey indicate that although methionine residues can be introduced, via substitution or insertion, into the HVRs, single locations cannot be treated as methionine sinks for the introduction of multiple, sequential methionine residues. As reported in previous protein engineering studies, the addition of more than two sequential methionine residues results in protein variants with reduced stability (Utsumi et al, 1993; Utsumi et al, 2002; Carrazco-Pena et al, 2013). Also, while methionine residues can be introduced into the cupin domains of proAtCRU3, the selection of target sites must be strategic (e.g. guided by HotSpot Wizard) and their effective combination, to introduce the multiple methionine residues required to alter their food values, will rely on the in vitro screen described herein. The results of this survey demonstrate that, for residues in the cupin domains, those designated as mutatable by HotSpot Wizard and positioned with their side chains shielded from solvent are more tolerant of methionine substitution than those exposed to solvent and/or with a low mutability index. 


\section{General Conclusions.}

Grain legumes, members of the Fabaceae (legume) plant family, provide approximately $10 \%$ of the world's supply of dietary protein (Saskatchewan Pulse Growers, 2009). Legumes are rich in protein ( 20-40\%), carbohydrates, fiber and essential minerals (e.g. calcium and iron) and therefore are considered among the most nutritional sources of plant protein (Singh, 1985; Dixon and Hosking, 1992). However, proteins from plant sources are generally deficient, from the perspective of human nutrition, in at least one of the ten essential proteogenic amino acids (Mandal and Mandal, 2000). Grain legumes are deficient in the essential amino acid methionine and therefore agriculturally important crops within the legume family, including Glycine max (soybean), Cicer arietinum (chickpea), Lens culinaris (lentil) and Pisum sativum (pea), are not complete protein sources.

Nutritional deficiency of any of the ten essential proteogenic amino acids, including methionine, in humans may lead to Protein-Energy Malnutrition (PEM), a syndrome with symptoms that include diminished resistance to disease, lowered blood protein levels, and potentially irreversible retardation of both mental and physical development in young children, particularly those under the age of four (Amir and Hacham, 2008; Muntz et al, 1998). An estimated 30\% of the developing world population suffers from PEM and this syndrome is associated with the deaths of approximately 6 million children each year (Galili and Amir, 2013; Institute of Medicine, 2005).

Approaches to create crops with increased nutritional value, with respect to amino acid content, can be classified as either 'push' or 'pull' strategies. Push approaches focus on altering the flux of metabolites within the biosynthetic pathway of the deficient amino acid, or that of a competing metabolite, to increase the soluble reservoir of the target amino acid(s) (Hesse et al, 2004; Muntz et al, 1998). Alternatively, pull strategies focus on the amino acid profile of the seed, 
attempting to increase the demand for the deficient amino acid(s) therein, resulting in an increase in their content within the edible portion of the plant (Hesse et al, 2004; Muntz et al, 1998). Seed storage proteins account for 50-90\% of the protein within a seed, and therefore are generally the targets for studies attempting to alter the seed amino acid profile (Shewry et al, 1995; Tandang-Silvas et al, 2010). Pull strategies include the introduction of foreign seed storage proteins that are rich in the deficient amino acid and the engineering of native seed storage proteins to increase their content of the target amino acid (Hesse et al, 2004; Mandal and Mandal, 2000; Muntz et al, 1998). Engineering the native seed proteins of a given plant species to increase their methionine content, has the potential to address the methionine deficiencies found in the agriculturally important legume crops without the adverse side effects of cross-allergenicity and the creation of new allergens that introducing foreign methionine-rich proteins into the seed has caused (Nordlee et al, 1996; Muntz et al, 1998).

The 11S globulins are salt-soluble, seed storage proteins that are deficient in the essential amino acid methionine (Mandal and Mandal, 2000). They are characterized by a pair of cupin domains, a protein domain comprised of a jellyroll $\beta$-barrel of antiparallel $\beta$-strands followed by a cluster of three $\alpha$-helices, and five hypervariable regions (HVR) (Adachi et al, 2001; Shutov et al, 2012). The $11 \mathrm{~S}$ globulins dominate the protein content of dicot seeds and as such dictate the physicochemical properties of their seed protein extracts as well as their nutritional value, with respect to amino acid content. Therefore, the $11 \mathrm{~S}$ globulins are important targets for protein engineering studies aimed at improving the food value, which includes increasing the nutritive value and altering physicochemical properties (e.g. emulsification and gelling qualities), of agriculturally important crops, such as soybean, chickpea and lentil. In their comprehensive 2013 review, Galili and Amir conclude that the success of reported protein engineering studies 
on seed storage proteins, including $11 \mathrm{~S}$ globulins, has been limited because of the resulting protein variants' generally diminished ability to accumulate in vivo, due to reduced stability and/or improper folding (Galili and Amir, 2013).

Reported attempts to engineer native $11 \mathrm{~S}$ globulins to increase their food value have been limited to insertions of strings of four or more sequential methionine residues into HVR IV and V, which ultimately destabilizes the protein, causing it to undergo non-specific proteolysis, thereby preventing it from accumulating in vivo (Kim et al, 1990; Utsumi et al, 1993; Katsube et al, 1994; Utsumi et al, 2002; Carrazco-Pena et al, 2013). The limited scope and success of reported studies attempting to introduce novel methionine residues into $11 \mathrm{~S}$ globulin reflects a limitation of the approach to date rather than the potential of this pull engineering strategy. It demonstrates the need for a screening process that can efficiently identify variants with stability similar to the wild-type protein and assess their ability to accumulate in vivo in seed tissue prior to introduction into the plant species of interest.

A pair of complementary expression systems has been developed in this thesis to create a 2-phase screening system to facilitate protein engineering studies on native seed storage proteins by enabling the selection of stable variants that accumulate appropriately in vivo for testing in the target plant species. The heterologous expression of three 11S proglobulins, from the model plant species A. thaliana, in the Origami E. coli cell line and the use of biophysical techniques to probe their in vitro stability, described in Chapter 2, forms the basis for phase I of the proposed 2-stage screening system. The first phase of the screen allows for the rapid assessment of variant stability, relative to the wild-type 11S protein. This enables the identification of protein region(s) tolerant to the introduction of methionine, the efficient screening of an array of insertion and substitution 
variants, and assessment of the effect of combining several of the successful mutations on the stability of the resulting methionine-enriched 11S globulin. With the first phase of the 2-stage process developed in this thesis, more individual substitution and/or insertion variants may be assessed and combinations of those that do not impact stability may be created and reassessed in the time that it takes to assess a smaller subset of the original individual methionine-enriched variants in vivo in the target species. To complement this in vitro system for variant screening, we employed the Phaseolus vulgaris $7 \mathrm{~S}$ globulin promoter in A. thaliana as a seed-specific expression system, coupled with immunoblot detection of HA-tagged 11S globulins, to develop phase II, the in vivo component, of the 2-phase screening system (Chapter 3). Phase II of the screen allows for the assessment of the ability of methionine-enriched variants, identified in phase I as having in vitro stability comparable to the wild-type protein, to accumulate in vivo.

The 2-phase system established in this thesis allows for the identification of protein regions tolerant of methionine introduction and screening of the very large pool of possible methionine-enriched variants by using $E$. coli and biochemical assessments of in vitro stability as a high throughput system that rapidly eliminates unstable variants. The variants that pass through this first phase can be then be assessed in the easily-transformed model plant species $A$. thaliana. This evaluates the in vivo stability and accumulation in seeds prior to testing in the species of interest where the transformation process is more time and resource intensive, generally involving tissue culture. This 2-phase screening process enables elimination of the variants that will not accumulate appropriately in vivo, thereby enhancing the success and encouraging the use of protein engineering for modification of the nutritive and physicochemical properties of native seed storage proteins. It is an example of knowledge mobilization between the disciplines biochemistry and plant science and can help make protein engineering a more readily accessible tool in plant biotechnology. 
Following the development of the 2-phase screening system to assess the in vitro and in vivo stability of $11 \mathrm{~S}$ globulin variants, a comprehensive survey of 67 methionine-enriched $11 \mathrm{~S}$ globulin variants was performed to identify regions within the model $A$. thaliana $11 \mathrm{~S}$ globulin that are tolerant of methionine enrichment (Chapter 4). The effect of each of these insertions and/or substitutions was assessed in vitro via fluorescence-monitored $\mathrm{GnHCl}$ denaturation. Single, double, triple and quadruple methionine substitution, and double and quadruple methionine insertion variants were constructed throughout the two cupin domains and HVRs II, III and V of the model $A$. thaliana $11 \mathrm{~S}$ proglobulin 3 (proAtCRU3). The results of this survey demonstrate that constructing substitution variants located in the cupin domains of proAtCRU3, such as V86M, V87M, I192M, L268M and V370M, is a viable strategy for adding methionine residue(s) to $11 \mathrm{~S}$ globulins since they retain a wild-type unfolding profile. They also demonstrate the feasibility of combining pairs of methionine substitutions, as demonstrated by the wild-type stability and unfolding profiles of the V86M:V87M and L268M:V370M variants. Generally, residues situated in the cupin domains and occupying sequence positions with a low degree of conservation in related $11 \mathrm{~S}$ globulins, as determined by in silico tools such as HotSpot wizard, were observed to be tolerant of methionine substitution if their side chains are situated in a hydrophobic environment rather than solvent exposed. The thorough survey of HVRs II and III reveals that although methionine residues can be introduced, via substitution or insertion, into the HVRs, single locations therein cannot be treated as methionine sinks for the introduction of multiple, sequential methionine residues. Variants constructed to have three or more sequential methionine residues at a given location reduced the stability and/ or altered the cooperativity of unfolding of the resulting $11 \mathrm{~S}$ globulin, compared to the wild-type. For example, four of the ten variants with extended methionine repeats, those located within the cupin domains, destabilize the native folded 
structure sufficiently to preclude purification. The denaturation profile of the remaining six variants, located in the HVRs, is shifted compared to the wild-type, suggesting that the cooperativity of unfolding is changed. These findings shed light on the results of previous protein engineering studies, which have also reported that the addition of more than two sequential methionine residues results in protein variants with reduced accumulation in vivo (Carrazco-Pena et al, 2013; Utsumi et al, 1993; Utsumi et al, 2002).

\subsection{Future Directions.}

The current genetic engineering strategies to address the amino acid deficiencies, classified as push and pull, are complementary to one another. Engineering native seed storage proteins to require more methionine necessitates an enlarged pool of soluble methionine in the seed since expression of the methionine-enriched engineered protein diminishes the free methionine pool, causing native methionine-deficient seed storage proteins to accumulate preferentially, at the expense of endogenous methionine-containing proteins, which ultimately limits the change in the overall methionine content in the seed (Galili and Hofgen, 2002). An increase in flux through the methionine biosynthetic pathway created by a push strategy, as illustrated by the A. thaliana methionine overacumulating (mto) lines, could alleviate this issue. The application of this complementary hybrid 'push-pull' strategy requires development of a thorough understanding of the regulation of the methionine biosynthetic pathway and the metabolic flux through it in the target species to prevent disturbing physiological processes. It also relies upon the development of the reliable method for engineering seed storage proteins, enabled by the 2-phase screen described in this thesis, to increase their methionine content while maintaining wild-type stability and permitting appropriate accumulation in vivo. 
The work described in this thesis contributes to the 'pull' component of the hybrid 'push-pull' strategy by creating a 2-phase screen that enables the comparative assessment of the effect of methionine enrichment of native $11 \mathrm{~S}$ globulins on the in vitro and in vivo stability of the resulting variants. It also demonstrated both the feasibility of developing methionine-enriched $11 \mathrm{~S}$ globulin variants and the efficiency of the in vitro component of the 2-phase screen (developed in Chapter 2 and used in Chapter 4 of this thesis). The use of this 2-phase screen in future protein engineering studies will relieve the stability issues that have plagued earlier attempts and should enable:

1. the continued combination of successful methionine-enriched variants from Chapter 4 to determine how many methionine residues the $11 \mathrm{~S}$ globulin structure can tolerate;

2. assessment of the ability of stable, according to phase I, methionineenriched variants (those from Chapter 4 and created by objective 1 above) to accumulate in vivo by subjecting them to phase II of the screen;

3. investigations of the viability of the hybrid 'push-pull' strategy, and how many methionine residues may be required to increase the methionine content to a nutritionally significant level. This can be assessed in the model plant species by expressing stable methionineenriched variants in one of the commercially available $m$ to $A$. thaliana transgenic lines and assessing the relative increase in methionine content in the seed, as compared the wild-type.

4. engineering native $11 \mathrm{~S}$ globulins from agriculturally relevant species (e.g. chickpea or soybean) by introducing the corresponding successful variants identified in Chapter 4. 


\section{Appendix A: List of Publications.}

Jaworski, A.F. and Aitken, S.M. 2014. Expression and characterization of the Arabidopsis thaliana 11S globulin family. Biochim. Biophys. Acta. 1844: 730-5.

Hughes, P.W., Jaworski, A.F., Davis, C.S., Aitken, S.M., and Simons, A.M. 2014. Development of polymorphic microsatellite markers for Indian Tobacco, Lobelia inflata (Campanulaceae). Applictions in Plant Sciences 2: 1300096

Jaworski, A.F. and Aitken, S.M. 2013. Exploration of the six tryptophan residues of Escherichia coli cystathionine $\beta$-lyase as probes of enzyme conformational change. Arch. Biochem. Biophys. 538: 138-144.

Manders, A. L., Jaworski, A. F., Ahmed, M., and Aitken, S. M. 2013. Chimerics constricts for the exploration of structure-function relationships in Escherichia coli Cystathionine $\gamma$-synthase and Cystathionine $\beta$-lyase. Biochim. Biophys. Acta. 1834: 1044-1053.

Morneau*, D. J. K., Jaworski*, A. F., and Aitken S. M. 2013. Identification of Cystathionine $\gamma$-Synthase and Threonine Synthase from Cicer arientinum and Lens culinaris. Biochem. Cell Biol. 91: 1-7. *These authors contributed equally to this work and share first authorship.

Jaworski*, A. F., Lodha*, P. H., Manders, A. L., and Aitken, S. M. 2012. Exploration of the Active Site of Escherichia coli Cystathionine $\gamma$-Synthase. Protein Science 21: 1662-1671. *These authors contributed equally to this work and share first authorship.

Lodha, P. H., Jaworski, A. F., and Aitken, S. M. 2010. Characterization of sitedirected mutants of residues R58, R59, D116, W340 and R372 in the active site of E. coli cystathionine $\beta$-lyase. Protein Science 19: 383-391. 


\section{References}

Adachi, M., Takenaka, Y., Gidamis, A.B., Mikami, B., and Utsumi, S. 2001. Crystal structure of soybean proglycinin AlaB1b homotrimer. J. Mol. Biol. 305: 291-305.

Adachi, M., Kanamori, J., Masuda, T., Yagasaki, K., Kitamuran, K., Mikami, B., and Utsumi, S. 2003. Crystal structure of soybean 11S globulin: Glycine A3B4 homohexamer. PNAS 100: 7395-7400.

Aitken, S.M., Ouellet, M., Percival, M.D., and English, A.M. 2003. Mechanism of horseradish peroxidase inactivation by benzhydrazide: a critical evaluation of arylhydrazides as peroxidase inhibitors. Biochem. J. 375: 613-621.

Amir, R, and Hacham, Y. 2008. Methionine Metabolism in Plants In: Jez, J. Sulfur: A Missing Link Between Soils, Crops and Nutrition p264-272.

Amir, R., Hacham, Y., Galili, G. 2002. Cystathionine $\gamma$-synthase and threonine synthase operate in concert to regulate carbon flow towards methionine in plants. Trends Plant Sci. 7:153-156.

Autran, J. C., Halford, N. G., and Shewry, P.R. 2001. The Biochemistry and Molecular Biology of Seed Storage Proteins. In: Lea, P. L., and Morot-Gaudry, J. F. (eds.) Plant Nitrogen. Springer p295 - 342.

Azevedo, R, A., Arruda, P., Turner, W.L., and Lea, P.J. 1997. The Biosynthesis and Metabolism of the Aspartate Derived Amino Acids in Higher Plants. Phytochemistry 46: 395-419.

Barba de la Rosa, A.P., Gueguen, J., Paredes-Lopez, O., and Viroben, G. 1992a. Fractionation procedures, electrophoretic characterizatin, and amino acid composition of amaranth seed proteins. J. Agric. Food Chem. 40: 931-936. 
Barba de la Rosa, A.P., Paredes-Lopez, O., and Viroben, G. 1992b. Characterization of amaranth globulins by ultracentrifugation and chromatographic techniques. $J$. Agric. Food Chem. 40: 937-940.

Bartlem, D., Lambein, I., Okamoto, T., Itaya, A., Uda, Y., Kijima, F., Tamaki, Y., Nambara, E., and Naito, S. 2000. Mutation in the threonine synthase gene results in overaccumulation of soluble methionine in Arabidopsis. Plant Phys. 123: 101110.

Beauregard, M., M. Hefford. 2006. Enhancement of essential amino acid contents in crops by genetic engineering and protein design. Plant Biotech. J. 4:561-574.

Benfey, P.N. and Chua, N.H. 1990. The Cauliflower Mosaic Virus 35S Promoter: Combinatorial Regulation of Transcription in Plants. Science. 250: 959-66.

Breitender, H., and Radauer, C. 2004. A classification of plant food allergens. $J$. Allergy Clin. Immunol. 113: 821 - 830 .

Carrazco-Pena, L., Osuna-Castro, J.A., De Leon-Rodriguez, A., Maruyama, N., Toro-Vazquez, J.F., Morales-Rueda, J.A., and Barba de la Rosa, A.P. 2013. Modification of solubility and heat-induced gelation of amaranth 11S globulin by protein engineering. J. Ag. Food Chem. 61: 3509-3516.

Chandrasekharan, M.B., Bishop, K.J. and Hall, T.C. 2003. Module-specific regulation of the b-phaseolin promoter during embryogenesis. Plant J. 33: 853866.

Chen, S. and Paredes-Lopez, O. 1997. Isolation and characterization of the 11S globulin from amaranth seeds. J. Food Biochem. 21: 53-65. 
Chiaiese, P., Ohkama-Ohtsu, N., Molvig, L., Godfree, R., Dove, H., Hocart, C., Fujiwara, T., Higgins, T.J.V., and Tabe, L.M. 2004. Sulphur and nitrogen nutrition influence the response of chickpea seeds to an added, transgenic sink for organic sulphur. J. Exp. Botany 55: 1889-1901.

Croy, R.R.D., Derbyshire, E., Krishna, T.G., Boulter, D. 1979.Legumin of Pisum sativum and Vicia faba. New Phytol. 83: 29-35.

Day, L. 2013. Proteins from land plants - Potential resources for human nutrition and food security. Trends in Food Sci. \& Technol. 32: 25-42.

Derbyshire, E., Wright, D.J., and Boulter, D. 1976. Legumin and Vicilin, Storage Proteins of Legume Seeds. Phytochem. 15: 3-24.

Dixon, R.M. and Hosking, B.J. 1992. Nutritional value of grain legumes for ruminants. Nutritional Research Reviews 5: 19-43.

Farsi, A., Lodha, P.H., Skanes, J.E., Los, H., Kalidindi, N., and Aitken, S.M. 2009. Interconversion of a pair of active-site residues in Escherichia coli cystathionine g-synthase, E. coli cystathionine b-lyase and Saccharomyces cerevisiae cystathionine g-lyase and development of tools for the investigation of their mechanisms and reaction specificity. Biochem. Cell Biol. 87: 445-457.

Galili, G. and Amir, R. 2013. Fortifying plants with the essential amino acids lysine and methionine to improve nutritional quality. Plant Biotech. J. 11: 211-222.

Galili, G., and Hofgen, R., 2002. Metabolic Engineering of Amino Acids and Storage Proteins in Plants. Metabolic Engineering 4: 3-11.

Galili, G., Altschuler, Y., and Levanony, H. 1993. Assembly and transport of seed storage proteins. Trends in Cell Biol. 3: 437-442. 
Gallardo, K., Job, C., Groot, S.P.C., Puype, M., Demol, H., Vandekerchkhove, J. and Job, D. 2002. Proteomics of Arabidopsis seed germination. A comparative study of wild-type and gibberellin-deficient seeds. Plant Physiol. 129: 823-837.

Gatehouse, J.A., Croy, R.R.D., Morton, H., Tyler, M., and Boulter, D. 1981. Characterization and Subunit Structure of the Vicilin Storage Proteins of Pea (Pisum sativum L.). Eur. J. Biochem. 118: 627-633.

Godoy-Ruiz, R., Perez-Jimenez, R., Ibarra-Molero, B. and Sanchez-Ruiz J.M. 2005. A stability patter of protein hydrophobic mutations that reflects evolutionary structural optimization. Biophys. J. 89: 3320-3331.

Goto, D., M. Ogi, F. Kijima, T. Kumagai, F. van Werven, H. Onouchi, S. Naito. 2002. A single-nucleotide mutation on a gene encoding S-adenosylmethionine synthase is associated with methionine over-accumulation phenotype in Arabidopsis thaliana. Genes and Genetic Systems 77: 89-95.

Hajduch, M., Casteel, J.E., Hurrelmeyer, K.E., Song, Z., Agrawal, G.K., and Thelen, J.J. 2006. Proteomic Analysis of Seed Filling in Brassica napus. Developmental Characterization of Metabolic Isozymes Using High-Resolution Two-Dimensional Gel Electrophoresis. Plant Phys. 141: 32-46.

Hara-Nishumura, I., Takeuchi, Y., Inoue, K., and Nishimura, M. 1993. Vesicle transport and processing of the precursor to $2 \mathrm{~S}$ albumin in pumkin. Plant J. 4: 793-800.

Hara-Nishimra, I., Shimada, T., Hiraiwa, N., and Nishimura, M. 1995. Vacuolar processing enzyme responsible for maturation of seed proteins. J. Plant Phys. 145: 632-640. 
Harder A, Wildgruber R, Nawrocki A, Fey SJ, Larsen PM, and Gorg A. 1999. Comparison of yeast cell protein solubi- lization procedures for two-dimensional electrophoresis. Electrophoresis 20: 826-829.

Haughn, G.W. and Somerville, C. 1981. Sulfonylurea-resistant mutants of Arabidopsis thaliana. Mole. Gen. Genetics 204:430-434.

Herman, E.M., and Larkins, B.A. 1999. Protein Storage Bodies and Vacuoles. Plant Cell 11: 601-613.

Hesse, H., Kreft, O., Maimann, S., Zeh, M., and Hoefgen, R. 2004. Current understanding of the regulation of methionine biosynthesis in plants. J. Exp. Botany 55: 1799-1808.

Hoffman, L.M., Donaldson, D.D., and Herman, E.M. 1988. A modified storage protein is synthesized, processed and degraded in the seeds of transgenic plants. Plant Mol. Biol. 11: 717-729.

Inaba, K., T. Fujiwara, H. Hatashi, M. Chino, Y. Komeda, S. Naito. 1994. Isolation of an Arabidopsis thaliana Mutant, mto1, That Overaccumulates Soluble Methionine. Plant Phys. 104: 881-887

Institute of Medicine. 2005. Protein and Amino Acids In: Dietary Reference Intakes: Energy, Carbohydrate, Fibre, Fat, Fatty Acids, Cholesterol, Protein, and Amino Acids. National Academy Press. p6o8-611.

Jackson, P., Boulter, D., and Thurman, D.A. 1969. A Comparison of some Properties of Vicilin and Legumin Isolated from Seeds of Pisum sativum, Vicia faba, and Cicer arietinum. New Phytol. 68:25-33. 
Jaworski, A.F. and Aitken, S.M. 2013. Exploration of the six tryptophan residues of Escherichia coli cystathionine $\beta$-lyase as probes of enzyme conformational change. Arch. Biochem. Biophys. 538: 138-144.

Jaworski, A.F. and Aitken, S.M. 2014. Expression and characterization of the Arabidopsis thaliana 11S globulin family. Biochim. Biophys. Acta. 1844: 730-5.

Jhee, K.H., McPhie, P., and Miles, E.W. 2000. Yeast cystathionine b-synthase is a pyridoxal phosphate enzyme but unlike the human enzyme it is not a heme protein. J. Biol. Chem. 275: 11541-11544.

Jung, R., Nam, Y.W., Saalbach, I., Muntz, K., and Nielsen N.C. 1997. Role of Sulfhydryl Redox State and Disulfide Bonds in Processing and Assembly of $11 \mathrm{~S}$ Seed Globulins. Plant Cell 9: 2037-2050.

Jung, R., Scott, M.P., Nam, Y.W., Beaman, T.W., Bassuner, R., Saalbach, I., Muntz, K., and Nielsen, N.C. 1998. The Role of Proteolysis in the Processing and Assembly of 11S Seed Globulins. Plant Cell 10: 343-357.

Kadlec, P., Bjergegaard, C., Gulewicz, K., Horbowicz, M., Jones, A., Kintia, P., Kratchanov, C., Kratchanova, M., Lewandowicz, G., Soral-Smietnan, M., Sorensen, H., and Urban, J. 2001. Carbohydrate Chemistry. In: Hedley, C.L. Carbohydrates in Grain Legume Seeds: Improving Nutritional Quality and Agronomic Characteristics. CABI Publishing p15-56.

Katsube, T., Gidamis, A. B., Kanamori, J., Kang, J., I., Utsumi, S., and Kito, M. 1994. Modification tolerability of the hypervariable region of soybean proglycinin. J. Agric. Food Chem. 42: 2639-2645. 
Kim, C.S., Kamiya, S., Sato, T. Utsumi, S. and Kito, M. 1990. Improvement of nutritional value and functional properties of soybean glycinin by protein engineering. Protein Engineering 3: 725-731.

Krebbers, E., Herdies, L., De Clercq, A., Seurinck, J., Leeman, J., Van Damme, J., Segura, M., Gheysen, G., Van Montagi, M., and Vandekerckhove, J. 1988. Determination of the Processing Sites of an Arabidopsis 2S Albumin and Characterization of the Complete Gene Family. Plant Phys. 87: 859-866.

Krishnan, H.B. 2005. Engineering Soybean for Enhanced Sulfur Amino Acid Content. Crop Science 45: 454-461.

Kusano, M., Fukushima, A., Redestig, H., Kobayashi, M., Otsuki, H., Onouchi, H., Naito, S., Hirai, M.Y., and Kazuki, K. 2010. Comparative metabolomics charts the impact of genotype-dependent methionine accumulation in Arabidopsis thaliana. Amino Acids 39: 1013-1021.

Lawrence, M.C., Izard, T., Beuchat, M., Blagrove, R.J., and Colman, P.M. 1994. Structure of Pahseolin at 2.2 $\AA$ Resolution. Implications for a Common Vicilin/ Legumin Structure and the Genetic Engineering of Seed Storage Proteins. J. Mol. Biol. 238: 748-776.

Mandal, S., and Mandal, R.K. 2000. Seed storage proteins and approaches for improvement of their nutritional quality by genetic engineering. Current Science 79: $576-589$.

Marcone, M.F. 1999. Biochemical and biophysical properties of plant storage proteins: a current understanding with emphasis on 11S seed globulins. Food Research International 32: 79-92. 
Maruyama, N., Mun, L.C., Tatsuhara, M., Sawada, M., Ishimoto, M., and Utsumi, S. 2006. Multiple vacuolar sorting determinants exist in soybean $11 \mathrm{~S}$ globulin. Plant Cell 18: 1253-1273.

Medina-Godoy, S., Nielsen, N.C., and Paredes-Lopez, O. 2004. Expression and characterization of a His-tagged $11 \mathrm{~S}$ seed globulin from Amaranthus hypochondriacus in Escherichia coli. Biotechnol. Prog. 20:1749-1756.

Mills, E.N.C., Jenkins, J., Marigheto, N., Belton, P.S., Gunning, A.P., and Morris, V.J. 2002. Allergens of the cupin superfamily. Biochem. Soc. Trans. 30: 925-929.

Monsalve, R.I., Vilalba, M., Rico, M., Shewry, P.R., and Rodriguez, R. 2003. The 2S Albumins. In: Mills, E.N.C., and Shewry, P.R. Plant Food Allergens. Blackwell Publishing p42-56.

Moreno, F.J., and Clemente, A. 2008. 2S Albumin Storage Proteins: What Makes them Food Allergens? The Open Biochemistry Journal 2: 16-28.

Moreno, F.J., Jenkins, J.A., Mellon, F.A., Rigby, N.M., Roberston, J.A., Wellner, N., and Mills, C.E.N. 2004. Mass spectrometry and structural characterization of 2S albumin isoforms from Brazil nuts (Bertholletia excelsa). Biochim. Biophys. Acta 1698: 175-186.

Muntz, K. 1996. Proteases and proteolytic cleavage of storage proteins in developing and germinating dicotyledonous seeds. J. Exp. Botany 47: 605-622.

Muntz, K. 1998. Deposition of storage proteins. Plant Mol. Biol. 38: 77-99. 
Muntz, K., Christov, V., Saalbach, G., Saalbach, I., Waddell, D., Pickard, T., Schieder, O., and Wustenhagen, T. 1998. Modification by Genetic Engineering: Genetic engineering for high methionine grain legumes. Nahrung 42: 125-127.

Muramatsu, M., and Fukazawa, C. 1993. A high-order structure of plant storage proprotein allows its second conversion by an asparagines-specific cysteine protease, a novel proteolytic enzyme. Eur. J. Biochem. 215: 123-132.

Niesen, F.H., Berglund, H., and Vedadi, M. 2007. The use of differential scanning fluorimetry to detect ligand interactions that promote stability. Nature Protocols 2: 2212-2221.

Nordlee, J., S. Taylor, J. Townsend, L. Thomas, R. Bush. 1996. Identification of a Brazil-Nut Allergen in Transgenic Soybeans. New England Journal of Medicine 334:688-692

Osborne, T.B., The vegetable proteins, Longmans Green, London, 1924.

Pace, C.N., Vajdos, F., Fee, L., Grimsley, G., and Gray, T. 1995. How to measure and predict the molar absorption coefficient of a protein. Protein Science 4: 24112423 .

Pavelka, A., Chovancova, E. and Damborsky, J. 2009. HotSpot Wizard: a a web server for identification of hot spots in protein engineering. Nucleic Acids Research 37: W376-W383.

Prak, K., Nakatani, K., Katsube-Tanaka, T., Adachi, M., Maruyama, N., and Utsumi, S. 2005. Structure-function relationships of soybean proglycinins at subunit levels. J. Ag. Food Chem. 53: 3650-3657.

Pulse Canada, 2010. Pulse Industry. http://www.pulsecanada.com/pulse-industry 
Ravanel, S., Gakiere, B., Job, D., Douce, R. 1998b. The specific features of methioninebiosynthesis and metabolism in plants. Proc. Nat. Acad. Sci. 95: 78057812.

Sales, M.P., Rodrigues Gerhardt, I., Grossi-de-Sa, M.F., Xavier-Filho, J. 200o. Do Legume Storage Proteins Play a Role in Defending Seeds against Bruchids? Plant Phys. 124: 515-522.

Saskatchewan Pulse Growers, 2009. Pulse Industry Report. http://www.saskpulse.com

Shen, B., Li, C., Tarczynski, M. 2002. High free-methionine and decreased lignin content result from a mutation in the Arabidopsis $S$-adenosyl-L-methionine synthetase 3 gene. Plant J. 29: 371-380.

Shewry, P. R. and Halford, N. G. 2002. Cereal seed storage proteins: structures, properties and role in grain utilization. J. Exp. Botany 53: 947-958.

Shewry, P. R., and Tatham, A.S. 1990. The prolamine storage proteins of cereal seeds: structure and evolution. Biochem. J. 267: 1-12.

Shewry, P. R., Napier, J.A., and Tatham, A.S. 1995. Seed Storage Proteins: Structures and Biosynthesis. Plant Cell 7: 945-956.

Shewry, P.R., Jenkins, J.A., Beaudoin, F., and Mills, C.E.N. 2003. The Classification, Functions and Evolutionary Relationships of Plant Proteins in Relation to Food Allergies. In: Mills, E.N.C., and Shewry, P.R. (eds). Plant Food Allergens. Blackwell Publishing p24-41.

Shutov, A.D., Braun, H., Chesnokov, Y.V., and Baumlein, H. 1998. A gene encoding a vicilin-like protein is specifically expressed in fern spores: Evolutionary pathway of seed storage globulins. Eur. J. Biochem. 252: 79-89. 
Shutov, A.D., Baumlein, H., Blattner, F.R., and Muntz, K. 2003. Storage and mobilization as antagonistic functional constraints on seed storage globulin evolution. J. Exp.Botany 54: 1645-1654.

Shutov, A., Rudakova, A., Rudakov, S., Kakhovskaya, I., Schallau, A., Maruyama, N. and Wilson, K. 2012. Limited proteolysis regulates massive degradation of glycinin, storage 11 S globulin from soybean seeds: An in vitro model. J. Plant Phys. 169: $1227-1233$.

Singh, U. 1985. Nutritional quality of chickpea (Cicer arietinum L.): current status and future research needs. Qual. Plant Foods Hum. Nutr. 35: 339-351.

Stoger, E., Parker, M., Christou, and P., Casey, R. 2001. Pea legumin overexpressed in wheat endosperm assembles into an ordered paracrystalline matrix. Plant Phys. 125: 1732-1742.

Tabe, L., and Higgins, T.J.V. 1998. Engineering plant protein composition for improved nutrition. Trends in Plant Science 3: 282-286.

Tandang-Silvas, M.R.G., Adachi, M., and Utsumi, S. 2004. Cloning and expression of rapeseed procruciferin in Escherichia coli and crystallization of the purified recombinant protein. Biotech. Letters 26: 385-391.

Tandang-Silvas, M.R.G., Fukuda, T., Fukuda, C., Prak, K., Cabanos, C., Kimura, A., Itoh, T., Mikami, B., Utsumi, S., and Maruyama, N. 2010. Conservation and divergence on plant seed $11 \mathrm{~S}$ globulins based on crystal structures. Biochim. Biophys. Acta 1804: 1432-1442.

Tandang, M.R.G., Tecson-Mendoza, E.M., Mikami, B., Utsumi, S., and Maruyama, N. 2011. Molecular design of seed storage proteins for enhanced food physiochemical properties. Annu. Rev. Food Sci. Technol. 2: 59-73. 
Tandang-Silvas, M.R., Cabanos, C.S. Carrazco Peña, L.D., Barba De La Rosa, A.P., Osuna-Castro, J.A., Utsumi, S., Mikami, B., and Maruyama, N. 2012. Crystal structure of a major seed storage protein, 11S proglobulin, from Amaranthus hypochondriacus: Insight into its physico-chemical properties. Food Chemistry 135: 819-826.

Utsumi, S., Kitagawa, S., Katsube, T., Kang, I.J., Gidamis, A.B., Takaiwa, F., and Kito, M. 1993. Synthesis, processing and accumulation of modified glycinins of soybeanin the seeds, leaves and stems of transgenic tobacco. Plant Science 92: 191-202.

Utsumi, S. Maruyama, N., Satoh, R., and Adachi, M. 2002. Structure-function relationships of soybean proteins revealed by using recombinant systems. Enzyme and Micro. Tech. 30: 284-288.

Valdez-Ortiz, A., Rascon-Cruz, Q., Medina-Godoy, S., Sinagawa-Garcia, S.R., Valverde-Gonzalez, M.E., and Paredes-Lopez, O. 2005. One-step purification and structural characterization of a recombinant His-tag $11 \mathrm{~S}$ globulin expressed in transgenic tobacco. J. Biotech. 115: 413-423.

Vogel, H.J., and Bonner, D.M. Acetylornithinase of Escherichia coli: Partial purification and some properties. J. Biol. Chem. 218: 97-106.

Wan, L., Ross, A.R.S., Yang, J., Hegedus, and D.D., Kermode, A.R. 2007. Phosphorylation of the $12 \mathrm{~S}$ globulin cruciferin in wild-type and abi1-1 mutant Arabidopsis thaliana (thale cress) seeds. Biochem. J. 404: 247-256.

Wang, T.L., Domoney, C., Hedley, C.L., Casey, R., and Grusak, M.A. 2003. Can we Improve the Nutritional Quality of Legume Seeds?. Plant Phys. 131: 886-891. 
Washida, H., Sugino, A., Messing, J., Esen, A., and Okita, T.W. 2004. Asymmetric Localization of Seed Storage Protein RNAs to Distinct Subdomains of the Endoplasmic Reticulum in Developing Maize Endosperm Cells. Plant Cell Physiol. 45: $1830-1837$.

Withana-Gamage, T.S., Hegedus, D.D., Qiu, X., Yu, P., May, T., Lydiate, D., and Wanasundara, J.P.D. 2013. Characterization of Arabidopsis thaliana lines with altered seed storage protein profiles using synchrotron-powered FT-IF spectromicroscop. J. Ag. Food Chem. 61: 901-912.

Yamada, K., Shimada, T., Kondo, M., Nishimura, M., and Hara-Nishumira, I. 1999. Multiple Functional Proteins are Produced by Cleaving Asn-Gln Bonds of a Single Precursor by Vacuolar Processing Enzyme. J. Biol. Chem. 274: 2563-2570.

Zhang, Y., and Cremer, P.S. 2006. Interactions between macromolecules and ions: The Hofmeister series. Current Opinion in Chemical Biology 10: 658-663.

Zhang, X., R. Henriques, R., Lin, S.S., Niu, Q.W., and Chua, N.H. 2006b. Agrobacterium-mediated transformation of Arabidopsis thaliana using the floral dip method. Nature Protocols 1: 1-6. 
(C) 2015, Allison F. Jaworski 